This publication has been superseded by ODP Technical Note 31:

http://www-odp.tamu.edu/publications/tnotes/tn31/INDEX.HTM

\title{
Design and Operation of a Drill-In-Casing System (DIC)
}

\section{OCEAN DRILLING PROGRAM TEXAS A\&M UNIVERSITY}

Technical Note 21

\author{
T.L. Pettigrew \\ Ocean Drilling Program \\ Texas A\&M University \\ 1000 Discovery Drive
}

College Station, Texas 77845-9547

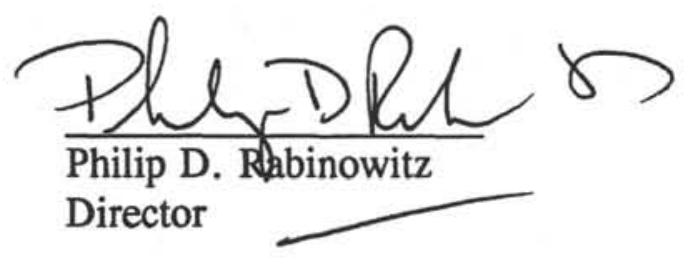

The Trancis

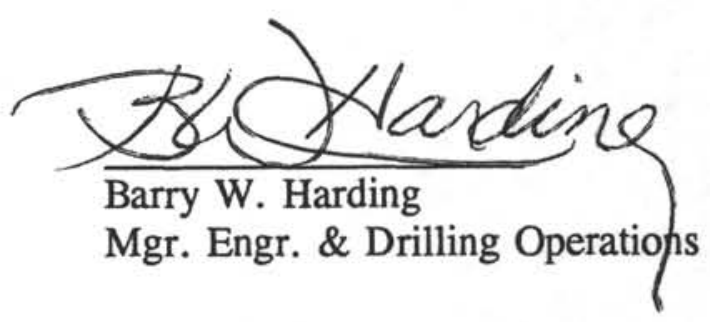

Timothy J.G. Francis

Deputy Director 


\section{COPY RESTRICTIONS}

Material in this publication may be copied without restraint for library, abstract service, educational, or personal research purposes. However, republication of any portion requires the written consent of the Director, Ocean Drilling Program, Texas A\&M University Research Park, 1000 Discovery Drive, College Station, Texas 77845-9547, as well as appropriate acknowledgment of this source.

Technical Note 21

First Printing 1993

Copies of this publication may be obtained from the Director, Ocean Drilling Program, Texas A\&M University Research Park, 1000 Discovery Drive, College Station, Texas 77845-9547. In some cases, copies may require a payment for postage and handling.

\section{DISCLAIMER}

This publication was prepared by the Ocean Drilling Program, Texas A\&M University, as an account of work performed under the international Ocean Drilling Program, which is managed by Joint Oceanographic Institutions, Inc., under contract with the National Science Foundation. Funding for the program is provided by the following agencies:

Academy of Sciences (Russia)

Canada/Australia Consortium for the Ocean Drilling Program

Deutsche Forschungsgemeinschaft (Federal Republic of Germany)

European Science Foundation Consortium for the Ocean Drilling Program

(Belgium, Denmark, Finland, Iceland, Italy, Greece, the Netherlands, Norway, Spain, Sweden, Switzerland, and Turkey)

Institut Francais de Recherche pour l'Exploitation de la Mer (France)

Ocean Research Institute of the University of Tokyo (Japan)

National Science Foundation (United States)

Natural Environment Research Council (United Kingdom)

Any opinions, findings, conclusions, or recommendations expressed in this publication are those of the author(s) and do not necessarily reflect the views of the National Science Foundation, the participating agencies, Joint Oceanographic Institutions, Inc., Texas A\&M University, or the Texas A\&M Research Foundation. 


\section{FOREWORD}

\section{Ocean Drilling Program}

The Ocean Drilling Program (ODP) is an international scientific venture to explore the ocean basins, with Texas A\&M University designated as scientific operator. The ODP began coring in January 1985. Largely funded by the U.S. National Science Foundation (NSF), the ODP includes the United States, Canada/Australia, Germany, France, Japan, Russia, the United Kingdom, and the European Science Foundation, a consortium representing 12 European countries. This partnership is called Joint Oceanographic Institutions for Deep Earth Sampling (JOIDES). The ODP is based on the deliberations of the first International Conference on Scientific Ocean Drilling, convened in 1981 by JOIDES to determine how best to build on the successful work of the Deep Sea Drilling Project (DSDP). DSDP began in 1968 when the National Science Foundation funded an 18-month scientific mission to recover marine geology core samples by drilling a series of holes across (transect) the MidAtlantic Ridge.

\section{JOIDES Resolution}

The JOIDES Resolution (registered as SEDCO/BP 471) is the seagoing base for the ODP operations. The 143-meter former offshore oil exploration vessel is outfitted with the most modern laboratory, drilling, and navigation equipment available. It utilizes an on-board, computerized, positioning system controlling 12 thrusters which dynamically position the ship over a drill hole located in water as deep as 8,235 meters. The derrick rises 61.5 meters above the water line, and with a 400-ton heave compensator, the drilling system can handle 9,150 meters of drill pipe. The JOIDES Resolution recently completed a circumnavigation of the earth in the service of science.

\section{Coring Operations}

Most coring operations are conducted in very deep water (3,500 to 5,000 meters). All sites are carefully reviewed by a Safety Panel prior to drilling to ensure that the potential of encountering a hydrocarbon reservoir is minimal. The cores are constantly monitored for hydrocarbons, and if a potential hydrocarbon source is encountered, the borehole is plugged with cement and abandoned. For these reasons, no riser system or blowout equipment is used. The core barrels are retrieved on wireline using one of two winches with up to 9,450 meters of $3 \times 19$ wire rope. State-of-the-art shipboard laboratories are used to conduct comprehensive preliminary analysis immediately upon recovery of the cores. 


\section{ACKNOWLEDGMENTS}

The initial concept for the Drill-In-Casing System was proposed by G. Foss, Operations Superintendent with the Deep Sea Drilling Project who also participated in the initial deployment of the system.

The initial Drill-In-Casing System design work was performed by M. Storms, Development Engineer with the Deep Sea Drilling Project.

System analysis and redesign input was provided by L. Russell, Larry Russell \& Associates, Houston, Texas.

Later redesign work and modifications were carried out by T. Pettigrew, Sr. Development Engineer with the Ocean Drilling Program.

Additional engineering input was provided by D. Huey, Sr. Development Engineer with the Ocean Drilling Program.

Additional operational input was provided by P. Thompson, Staff Superintendent with the Ocean Drilling Program. 


\section{TABLE OF CONTENTS}

I. Design and Operation of a Drill-In-Casing System

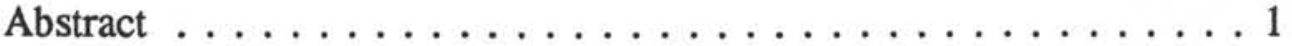

Introduction $\ldots \ldots \ldots \ldots \ldots \ldots \ldots \ldots \ldots \ldots \ldots \ldots \ldots \ldots \ldots$

General Description and Developmental History . . . . . . . . 3

Why Drill-In-Casing? . . . . . . . . . . . . . . 3

Function of the Drill-In-Casing System . . . . . . . . 3

Limitations of the Drill-In-Casing System . . . . . . . 3

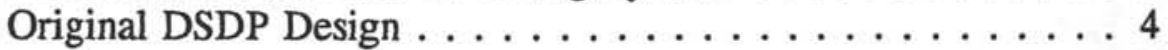

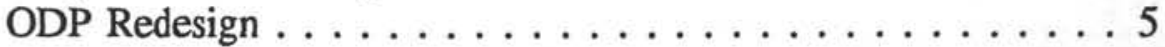

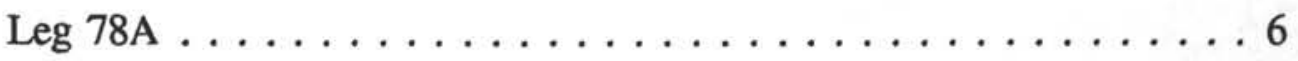

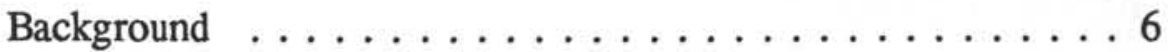

Release Mechanism . . . . . . . . . 6

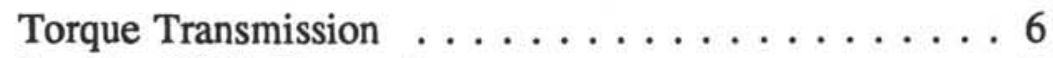

Locking BHA Connections . . . . . . . . . 7

General Conclusions Based on Leg 78A . . . . . . 7

$\operatorname{Leg} 110 \ldots \ldots \ldots \ldots \ldots \ldots \ldots \ldots$

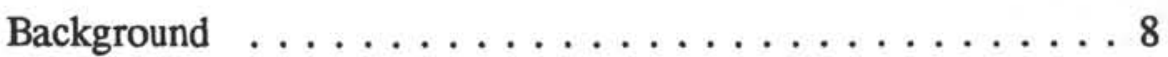

Suggested Revisions to DSDP Design $\ldots \ldots \ldots \ldots \ldots$

Actions Taken in Response to Recommendations ....... . 9

Results of Leg $110 \ldots \ldots \ldots \ldots \ldots$

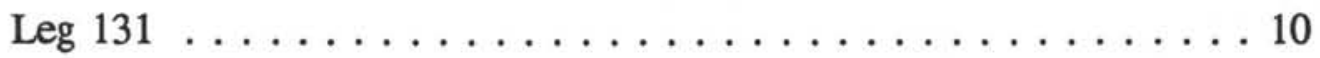

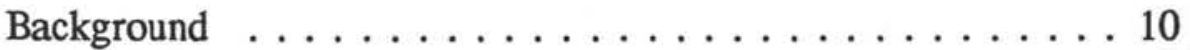

Initial ODP Deployment . . . . . . . . . . 10 


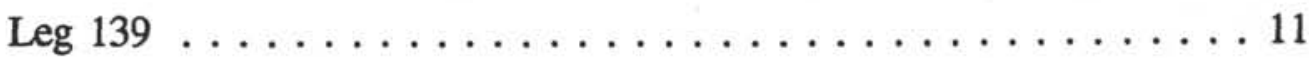

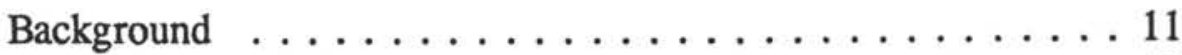

Deployment with Reentry Funnel $\ldots \ldots \ldots \ldots \ldots \ldots$

Leg 141 and Further Redesign $\ldots \ldots \ldots \ldots \ldots \ldots \ldots$

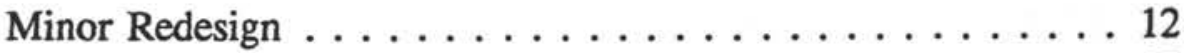

Further Redesign $\ldots \ldots \ldots \ldots \ldots \ldots \ldots \ldots \ldots \ldots \ldots \ldots \ldots$

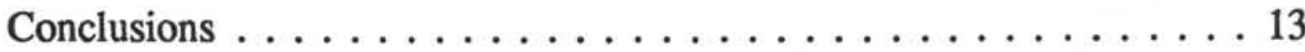

II. Figures

1. Drill-In-Casing System (DIC)

2. DIC Supporting Unconsolidated Sediments Below the Sea Floor .

3. DIC with Optional Re-Entry Funnel Supporting Unconsolidated Sediments at the Sea Floor

4. DIC with Optional Re-Entry Funnel

5. DIC Deployment, Step \#1

6. DIC Deployment, Step \#2

7. DIC Deployment, Step \#3

8. DIC Deployment, Step \#4

9. DIC Deployment, Step \#5

10. DIC Deployment, Step \#6

11. DIC with BHA/Casing Assembly Spaced Out 
III. Appendices
A. Present Status of Programs to Overcome Unstable Hole Problems
B. DIC Operating Procedures
C. ODP Proposal - Ultra Deep Water DIC System
D. Review of DIC System
E. DIC Computer Stress and Fatigue Analyses
F. Leg 131 Engineering Report
G. Recommended DIC Modifications
H. Drill-In Data for Leg 131, Hole 808C and Suggestions
I. Excerpt from Leg 139 Operations Report
J. DIC System Technical Manual
K. DIC System Parts List
L. DIC Assembly Drawings
M. DIC Machine Drawings 


\begin{abstract}
This Ocean Drilling Program (ODP) Technical Note No. 21 documents the design and operation of the Drill-In-Casing (DIC) System and its developmental history beginning in 1978 with the Deep Sea Drilling Project (DSDP). The DIC project continues the development of a system which allows the "drilling-in" of an 11-3/4" casing string to isolate unstable/unconsolidated zones in single bit holes without needing to round trip the drill string. Once the casing is at the desired location and it isolates the unstable/unconsolidated zone, it can be released from the bottom hole assembly (BHA) to allow continued drilling operations. The DIC System was first designed by DSDP in 1978. In 1985, ODP continued the DIC development by making several modifications to the original DSDP design.

Eventually, the DIC System was equipped with an optional reentry funnel to allow multiple entries. Thereafter, ODP incorporated several changes to the original design.

The DIC System was first deployed by DSDP Leg 78A, Hole 542B, in the Barbados Ridge complex. ODP redesigned the system for Leg 110 , but did not deploy it until Leg 131 (3/90 - 6/90), Hole 808C, in the Nankai accretionary complex. On Leg 139 (7/91 - 9/91), Hole $856 \mathrm{H}$, at the Bent Hill site in the Middle Valley area near the northern end of the Juan de Fuca Ridge, ODP deployed the system with an optional reentry funnel. The system was modified slightly for Leg 141. Further modifications were made for Leg 144 and subsequent legs.
\end{abstract}




\section{INTRODUCTION}

In 1968, the National Science Foundation funded the Deep Sea Drilling Project (DSDP) to embark on an eighteen-month scientific mission to recover marine geology core samples by drilling a series of holes across (transect) the Mid Atlantic Ridge. The intent of this research program was to support or disprove the theory of seafloor spreading. The DSDP research program recovered the deepest cores ever retrieved by an offshore drill ship and found evidence to support the theory of seafloor spreading. Due to the dramatic success of this pilot program and the immense scientific potential of continued scientific coring, the project was extended, recovering literally miles of deep-sea core samples. Over the next 15 years, the results of this program supported or disproved many marine geological theories and ideas.

The follow-up project to DSDP began in 1983 and was christened the "Ocean Drilling Program" (ODP). The ODP is managed by Texas A\&M University and operates the state-ofthe-art drill ship, JOIDES Resolution (SEDCO/BP 471). The principal funding agency for the ODP remains the National Science Foundation. However, the program receives significant financial, scientific, and technical support from its international partners in Germany, France, Japan, the United Kingdom, Canada, Australia, and the European Science Consortium.

The remarkable success of the Ocean Drilling Program is illustrated by the voluminous samples and information acquired over the 8 years of its operation to date. The program's success is also illustrated by its technological advancements. These advancements include refinement of drilling and coring equipment first developed during the Deep Sea Drilling Project (DSDP), and include a myriad of new tools and equipment required to meet the needs of scientists worldwide.

This Technical Note documents the developmental history, design, operation, and field testing results of the Drill-In-Casing (DIC) System. The DIC is the result of technological advancements which originated with the DSDP and are continued by the Ocean Drilling Program. 


\section{GENERAL DESCRIPTION AND DEVELOPMENTAL HISTORY}

The Drill-In-Casing (DIC) System is designed to allow deployment of an 11-3/4" casing string to support unstable zones in single bit holes without needing to round trip the drill string. The DIC System allows a casing string, along with its own expendable bit and the bottom hole assembly, to be "drilled in" as a unit (Figure 1). The DIC System utilizes a complex series of latches that enable the drilling torque, applied from the rig floor by the top drive, to be transmitted from the bottom hole assembly (BHA) to the casing string. Once the casing string has been drilled into place, the DIC System is released from the BHA, and drilling or coring operations continue (Figure 2). The casing string remains "up-hole" to support the unstable zone, prevent the drill pipe from sticking, and prevent premature loss of the hole.

\section{Why Drill-In-Casing?}

The need to develop a reliable Drill-In-Casing (DIC) System for use in ultra-deep water $(3,000+\mathrm{m}$.) scientific research coring has been apparent for many years. DSDP, managed by Scripps Institution of Oceanography, first recognized this need while attempting to conduct single bit coring operations in faulted and/or unstable formations throughout the world's oceans. They found that many highly desirable scientific drill sites were impenetrable with conventional "single bit" coring systems. Attempts to set reentry cones and emplace conventional casing systems to isolate the unstable zones were also unsuccessful. In most areas, hole integrity could not be maintained long enough to land and cement conventional casing strings. The need to isolate (i.e., case off) unstable formations with the first penetration through the problem zone was obvious.

\section{Function of the Drill-In-Casing System}

The DIC System was designed to meet the following two main objectives. First, the DIC System can be drilled in and left at the seafloor to support unconsolidated upper sediments (Figure 3). With the addition of an optional reentry funnel, multiple reentries may also be possible (Figure 4). Second, the DIC System can be drilled in below the seafloor without a reentry funnel and left straddling an unstable zone such as a fault (Figure 2).

\section{Limitations of the Drill-In-Casing System}

Coring operations cannot be carried out while the casing string is drilled into place. The DIC is compatible only with the Rotary Core Barrel (RCB) system. In addition, the deployment of the DIC System with an optional reentry funnel is not a substitute for a full reentry cone installation because it is not capable of drilling in a casing string from the seafloor to the basement, and the casing string cannot be cemented into place. 


\section{Original DSDP Design}

During its research, DSDP recognized the need for a system to control unstable hole conditions which might terminate scientific experiments. DSDP identified the problem of unstable holes as being twofold. The first problem associated with unstable holes is the possibility of large pieces of fractured rock becoming wedged between the wall of the hole and the BHA, thus preventing reciprocation or rotation. The second problem associated with unstable holes is the potential for restricted circulation caused by unconsolidated material "packing-off" between the hole and the drill string or the plugging of the drill string itself. When circulation is stopped or reestablished, the drill string could also become stuck.

Before the development of the DIC System, several techniques were used to deal with the problems presented by unstable holes. One technique used was mud flushing which consisted of flushing out accumulated cuttings with high viscosity mud "pills." A second technique was the use of low circulation rates which caused a greater amount of cuttings to regrind. A third technique was used when terrigenous shales were present. With this technique, the upper intervals were penetrated quickly by eliminating the coring process, and a second hole was drilled to investigate the upper sections. A final technique for dealing with unstable holes was to pull $30 \pm$ meters off bottom to recover the cores and allow the cuttings a sump in which to fall when seawater circulation stopped.

In 1976, an industry panel met at DSDP to consider alternatives to the techniques mentioned above. Several alternative methods were discussed. The first alternative was the use of reverse circulation. However, this technique was eventually considered too expensive to pursue, and its development was given low priority. A second proposed alternative was the use of high viscosity flushes. An attempt to employ this technique was made aboard the Glomar Challenger in 1977 using fluid that was developed to carry fracturing sand in oil wells . This attempt produced no favorable results, and various other proposed methods were directed at immobilizing the unstable zones. Among these methods was the concept of drilling-in short strings ( $60 \pm$ meters) through unstable zones. This concept resulted in the Drill-In-Casing (DIC) System.

The DIC System was originally designed in 1978 by Michael A. Storms and G.N. Foss of the DSDP with the assistance of engineers at Global Marine Drilling, Inc. Two assemblies were fabricated based on this original design, and one of these assemblies was successfully deployed on Leg 78A. However, during this initial deployment, the release mechanism on the assembly failed to operate, making it necessary to sever the drill string above the BHA. DSDP identified several flaws in this original design including (1) the possible failure of the release mechanism due to excessive and prolonged torque, (2) the possibility that the application of torque at the top of the casing string might cause a "spring" effect, and (3) the inadequacy of the locking sleeve. 


\section{ODP Redesign}

The DSDP-designed DIC assembly was subsequently redesigned for Leg 110 by the Ocean Drilling Program with the assistance of the engineering firm of Larry Russell and Associates. Various changes were made to the CSG Drive HD, the drive bushing, the combination lowering and drive sub, the drive adapter, the lower dog segment, the shifting sleeve, and the lower dog segment springs. ODP did not deploy this redesigned DIC System until Leg 131.

After successful deployment on Leg 131, ODP again modified the DIC System by adding an optional reentry funnel (a modified free fall funnel) (Figure 4). The modifications following Leg 131 also included increasing the DIC drive bushing inside diameter from 8-1/2" to 8$3 / 4$ " which allowed the 8-1/2" drilling jars and drill collars to pass through it.

After successfully deploying the DIC with the optional reentry funnel on Leg 139, ODP further redesigned the DIC by changing the expendable casing bit to a "slip-on-weld" configuration for Leg 141. Additional redesigns to the drive sub/shifting sleeve assembly and the drive head were made for future legs. 


\section{LEG 78A}

\section{Background}

The Drill-In-Casing System was first deployed by DSDP from its research drilling vessel, Glomar Challenger, during Leg 78A in the Barbados Ridge Complex on Leg 78A, Hole 542B (Figures 5-10). This attempt was a qualified success. A 57 meter string of 11-3/4" casing was drilled in to put the shoe (bit) at the desired depth of 323.5 meters below seafloor with the casing extending through a fault zone. However, the release mechanism failed to operate, and it was eventually necessary to sever the drill string above the BHA. The following weaknesses were identified:

\section{Release Mechanism}

As demonstrated by the failure of the shifting tool to disengage down hole, the release operation apparently failed due to the inability to move the release sleeve to the fully shifted position. Two of the dog hinge pins sheared and the tool was recovered on the first attempt, but the overshot pin sheared on the subsequent two attempts, leaving the shifting tool in place.

Since no failed components were recovered, primary failure analysis could not be performed. A design review and further testing of the release mechanism were required. It was theorized that the vertical and torsional loading attendant to the 11hour drilling operation may have caused distortion or failure of the drive/lowering system components which, in turn, prevented proper actuation of the release mechanism.

\section{Torque Transmission}

Exceptionally high and irregular drill string torque was recorded throughout the drilling operation. This was attributed at the time to a "torsional spring" effect in the casing string. Since the casing bit was driven from the top of the casing, it was felt that energy was alternately stored and released by the casing, causing the drill string to "torque up" and then spin free. A spline or similar arrangement was proposed to key the casing and BHA together torsionally near the bit. It was also theorized that the effect may have been simply the result of the high torque produced by the 17-1/2" bit arrangement acting through the long drill string. It was proposed that the "spring" properties of the casing be analyzed to determine if a problem existed.

It was felt that if the casing were driven from the bottom, rotating friction against the wall of the hole might tend to loosen and "back off" the casing collar connections. 
A related problem was the requirement of 60 RPM rotation due to the low torque output from the low speeds of the Glomar Challenger power sub.

\section{Locking BHA Connections}

DSDP predicted a tendency for rotary-shouldered connections below the lowering sub to loosen and back off due to vibration and irregular torque. A locking sleeve system was provided so that DSDP might avoid using epoxy glue (Bakerlok) on the connections or tack welding the 4140 drill collars. The sleeves could not be installed on Leg 78A because their diameter was too small, and steel straps were tack welded across the drill collar connections. Observers agreed that the locking sleeve concept was unsatisfactory because (1) it was too time consuming and difficult to predrill recesses in the drill collar, (2) sleeves would never fit properly due to differences in collar diameter from wear and fabrication specifications, and (3) the device was not strong enough to "break" a shouldered connection.

\section{General Conclusions Based on Leg 78A}

It was felt that the Drill-In-Casing System would have been completely successful at Site 542 , both in deployment and in isolating the unstable zone for further drilling, had the release failure not occurred. However, the high torque and low rate of penetration in the soft sediments left serious doubts as to the feasibility of penetrating igneous or even indurated sedimentary rock with the system. 


\section{LEG 110}

\section{Background}

In 1985, ODP continued the development of the DIC System which was begun by DSDP. In preparation for Leg 110, ODP analyzed the original DSDP design in hopes of improving upon it.

\section{Suggested Revisions to DSDP Design}

Several weaknesses were recognized in the DSDP design, and the following design changes were recommended to remedy these problems:

1. To remedy the apparent weakness of the lower dogs, make the string in the lowering assembly slightly more hard and centralized.

2. To aid in shifting and release, open up sleeve clearance to provide small reliefs for burrs.

3. Eliminate vertical play on the dogs, windows, and latch releases.

4. Design a simpler, more direct system of hanging only the lower dogs.

5. To ensure balanced retraction, make the lower dog retraction springs independent.

6. To alleviate burring due to excessive bearing loads, use multiple dog bearing faces.

7. Paint "RETRACT UPPER DOG SCREWS" on the tool, and ensure that retracting screws are included on the check-off list.

8. In order to reduce shifting sleeve drag, eliminate the metal scraper ring. To protect the O-Rings on the sleeve, possibly use a wider inside face on the Snap Ring.

9. To allow the existing sleeve to overtravel and relatch the lower dogs, omit the toggling nose in the first joint above the tool.

10. To avoid burring problems, double the area of the inner drive flats on the drive bushing. 


\section{Actions Taken in Response to Recommendations}

1. Casing Head Drive (SK 4801/OJ 4801) - Holes were tapped in the casing head drive for the flush pipe plug. The casing head drive was made up with the drive adapter (SK 4804)/drive adapter insert (SK 4810) assembly. A warning, "BACK OUT DOG SCREWS," was painted on the casing head drive assembly.

2. Drive Bushing (SK 4802/OJ 4802) - The drive flats in the drive bushing were enlarged. The existing flats were supplemented with add-in pieces to achieve approximately twice the bearing area to avoid severe burring.

3. Combination Lowering and Drive Sub (SK 4803/OJ 4803) - The junk (wiper) ring (OJ 4815 ) of the combination lowering/driving sub was replaced with an appropriate oring.

4. Drive Adapter with Holes (SK 4804/OJ 4804) - The drive adapter was sleeved to closely centralize the lower dogs and give a double bearing surface. A drive adapter insert (SK 4810/OJ 4810) was also added.

5. Lower Dog Segment (SK 4805/OJ 4805) - The lower dog segment was remade to better fit the windows, obtain retractive effort on both sides, be harder, and have more contact area. The lower dog segment pin was redesigned (SK 4808/OJ 4808).

6. Shifting Sleeve (SK 4806/OJ 4806) - The O.D. of the shifting sleeve was surface coated with Impreglon 218 Fluoropolymer to reduce friction.

7. Lower Dog Segment Spring (SK 4809/OJ 4809) - The springs were reduced from 4" of free length to $2 "$.

\section{$\underline{\text { Results of Leg } 110}$}

The ODP-redesigned DSDP DIC System was placed on board the JOIDES Resolution as a back-up system for Leg 110. However, ODP did not deploy this system until Leg 131. 


\section{LEG 131}

\section{Background}

The ODP redesign of the DSDP DIC System was first deployed during Leg 131 (3/90 $6 / 90$ ), on Hole 808C, in the Nankai accretionary complex. This site was identified as appropriate for initial deployment of the DIC on board the JOIDES Resolution because of the unconsolidated sands in the upper sedimentary section that had caused the loss of a previous hole. ODP decided to deploy a seven-joint string of 11-3/4" casing and drill it into place before proceeding with the drilling and coring of the planned deep Rotary Core Barrel (RCB) penetration.

\section{Initial ODP Deployment}

Assembly was difficult due to the Kuroshio Current and because this was the first deployment of the DIC on board the JOIDES Resolution, but the pipe trip to the seafloor was routine.

Hole $880 \mathrm{C}$ was spudded at 0030 hours, 17 April. The bit and casing were jetted-in without rotation to $14 \mathrm{mbsf}$ where progress slowed. Rotation was then initiated and drilling-in went smoothly to $105 \mathrm{mbsf}$ where the casing was to be released. None of the excessive torque conditions encountered on the previous DIC deployment on Leg 78A were noted. A wireline trip was then made with a "rotary" shifting tool to actuate the mechanism to release the casing. Initially, the sleeve could not be shifted, but normal function was achieved when weight approximately 3,000 pounds in excess of the casing string was set down.

Upon recovery of the shifting tool, drilling proceeded to $298.5 \mathrm{mbsf}$. 


\section{LEG 139}

\section{Background}

The DIC System was deployed with an optional reentry funnel during Leg 139 (7/91 - 9/91), in Hole $856 \mathrm{H}$, at the Bent Hill site in the Middle Valley area, near the northern end of the Juan de Fuca Ridge.

\section{Deployment with Reentry Funnel}

A $65+$ meter thickness of massive sulfides encountered in Hole $856 \mathrm{G}$ constituted a major scientific find and deeper penetration at or near the $856 \mathrm{G}$ location gained more importance. However, flowing sand and sulfide debris from the uppermost layers posed a serious threat to further deepening of Hole 856G. It was determined that the deployment of the Drill-InCasing with an optional reentry funnel was appropriate.

A new BHA was assembled including the DIC. A single 12-meter joint of 11-3/4" casing was equipped with a special 20" drilling shoe and attached to the DIC. The 9-7/8" bit was spaced out 1.25 meters beyond the casing shoe. When the DIC/BHA had been assembled, the reentry funnel was attached in the moon pool area as the last step before the drill string was lowered.

The BHA was jetted-in approximately $2.5 \mathrm{~m}$. The drilling-in operation then proceeded with a good ROP, alleviating concerns over the ability of the 20" casing bit to penetrate the hard sulfides. High ROP continued until the casing shoe reached the release point of $12 \mathrm{mbsf}$. The RST was run, and the casing was released without incident. Coring operations then began and the DIC was reentered for subsequent logging operations. 


\section{LEG 141 AND FURTHER REDESIGN}

\section{Minor Redesign}

Following Leg 139, the expendable casing bit was modified to a "slip-on-weld" configuration for Leg 141.

\section{Further Redesign}

For Leg 144, a new drive sub/shifting sleeve assembly was developed. The new design for the drive sub/shifting sleeve assembly eliminates the need to "jump" the snap ring and wiper ring with a seal while installing the shifting sleeve. This is accomplished by relocating the seal and seal groove on the bottom of the shifting sleeve to the drive sub. All drive sub/shifting sleeve assemblies following Leg 141 are made to this new design.

Also for Leg 144, a newly configured drive head assembly was developed with the drive head and drive adapter combined into one part. The outer configuration of the new drive head consists of a 16" O.D. circular cross section to replace the 17-1/2" O.D. quasi triangular cross section of the old design. 


\section{CONCLUSIONS}

\section{General}

The ODP drill-in-casing system (DIC) is the culmination of a long development program spanning both the Deep Sea Drilling Project and the Ocean Drilling Program. The DIC enables placement of short casing strings practically anywhere in a borehole. The DIC allows the casing strings to be deployed and coring operations to be carried out in a single trip of the drill pipe. The DIC can be used to place a section of casing across an unstable fault zone well below the sea floor. The formation below the fault zone then can safely be cored. The DIC can also be used to place a section of casing across layers of unstable sediments at or near the sea floor. When deployed at the sea floor, reentry capability is made possible with the addition of an optional reentry funnel. The current DIC configuration is considered to be an operational tool and thus supported aboard the JOIDES Resolution.

\section{Compatibility}

The DIC is only compatible with the rotary core barrel (RCB). Coring operations can not be carried out while drilling-in the casing string. Therefore, coring operations are limited to the formations below emplaced casing strings.

\section{$\underline{\text { Problems }}$}

Although all but the initial deployment of the DIC System have been successful, the DIC is susceptible to infiltration of detritus. Should detritus prevent complete shifting of the shifting sleeve, the casing string can not be released from the BHA.

Currently the DIC is only compatible with the RCB and 11-3/4" casing.

The current DIC design requires that the casing string transmit torque from the BHA to the casing bit. This can cause torsional whipping of the casing string when drilling through indurated material.

The DIC drive sub remains an integral part of the BHA as it is "drilled ahead". Although the drive sub has flats milled on it for fluid by-pass, the major OD is the same as the RCB bit. The drive sub could cause problems for hole cleaning. 
Figures 


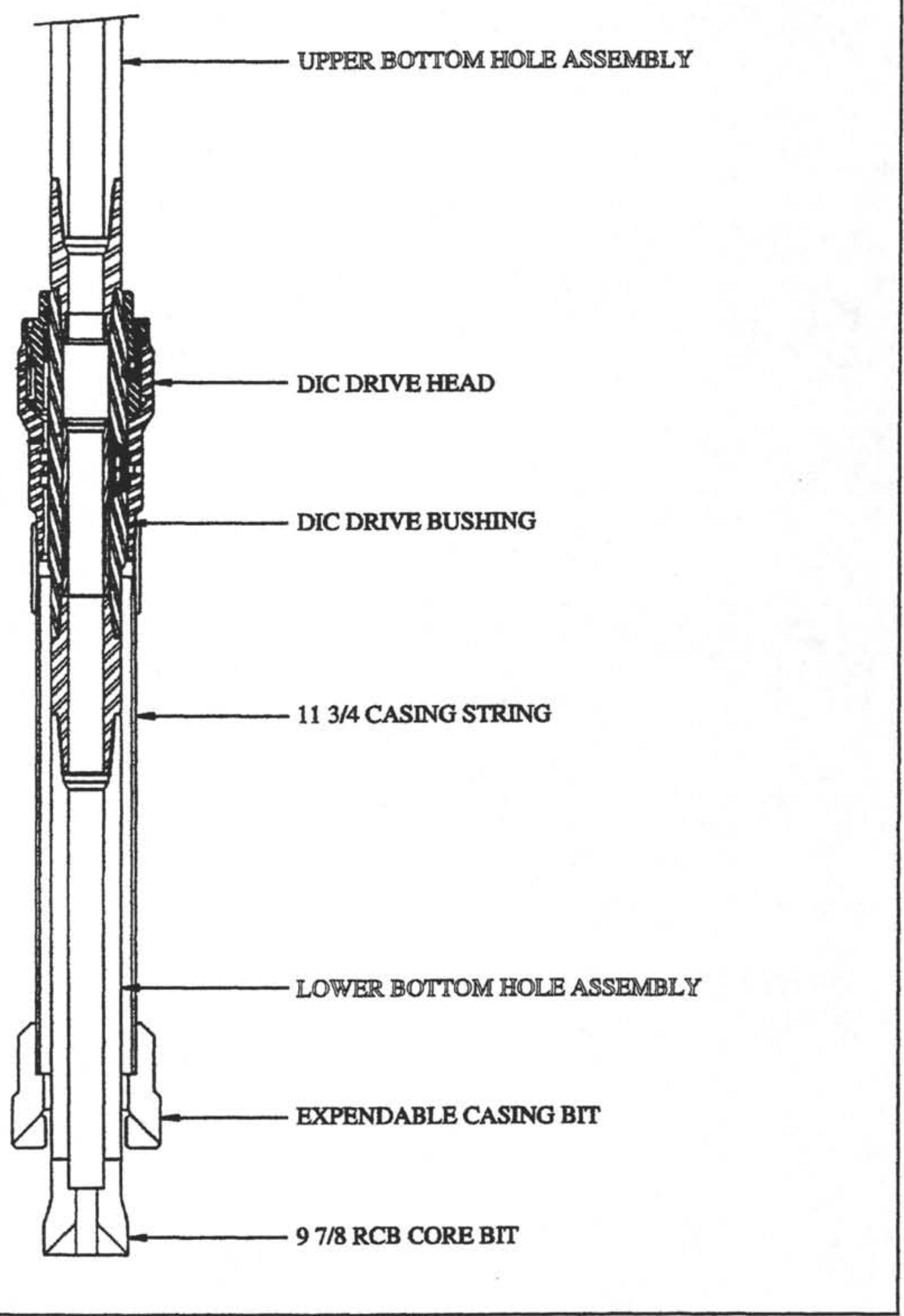

Figure 1: Drill-In Casing System (DIC) 


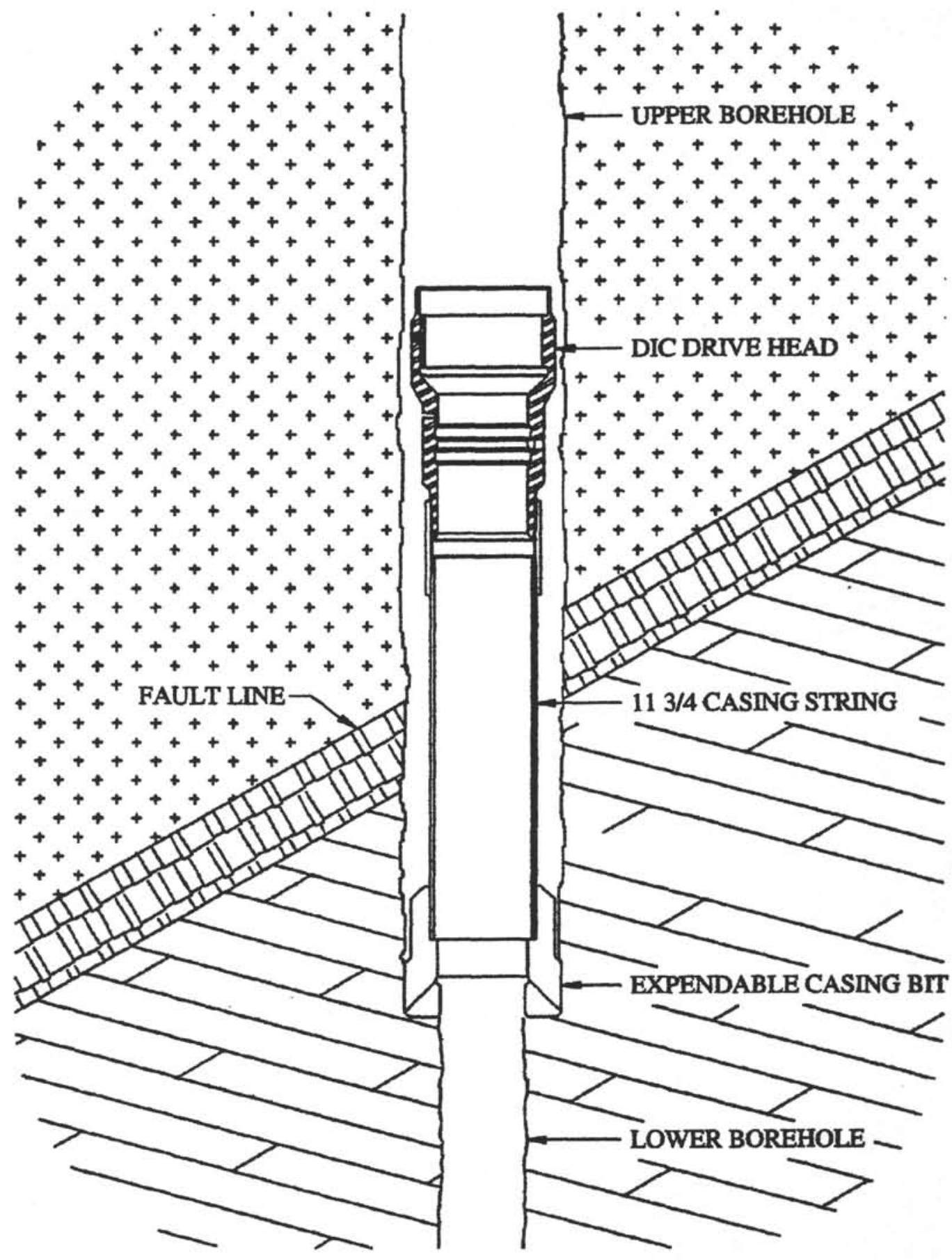

Figure 2: Drill-In Casing System Supporting Unconsolidated Sediments 


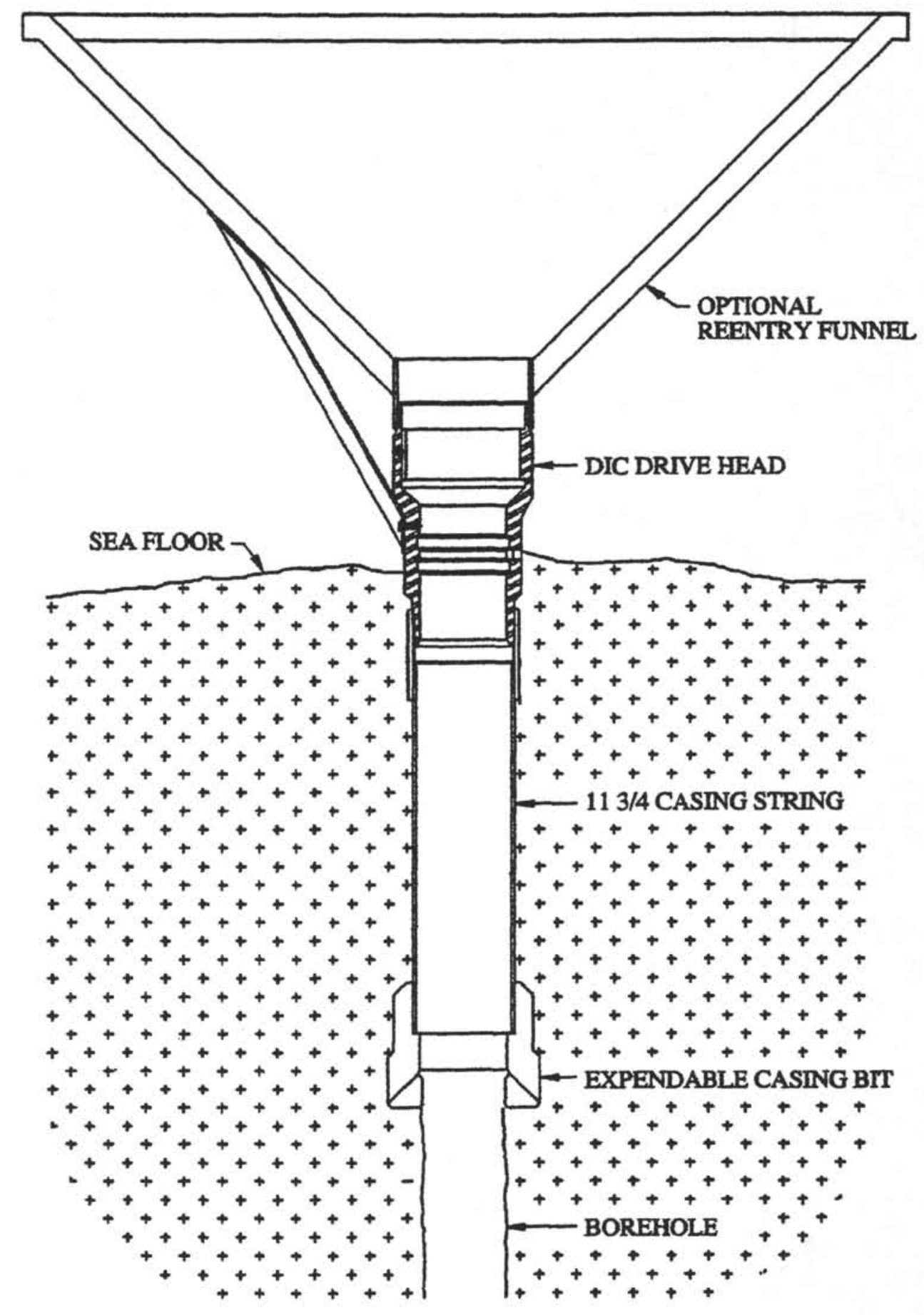

Figure 3: DIC with Optional Reentry Funnel

Supporting Unconsolidated Sediments

at the Sea Floor 


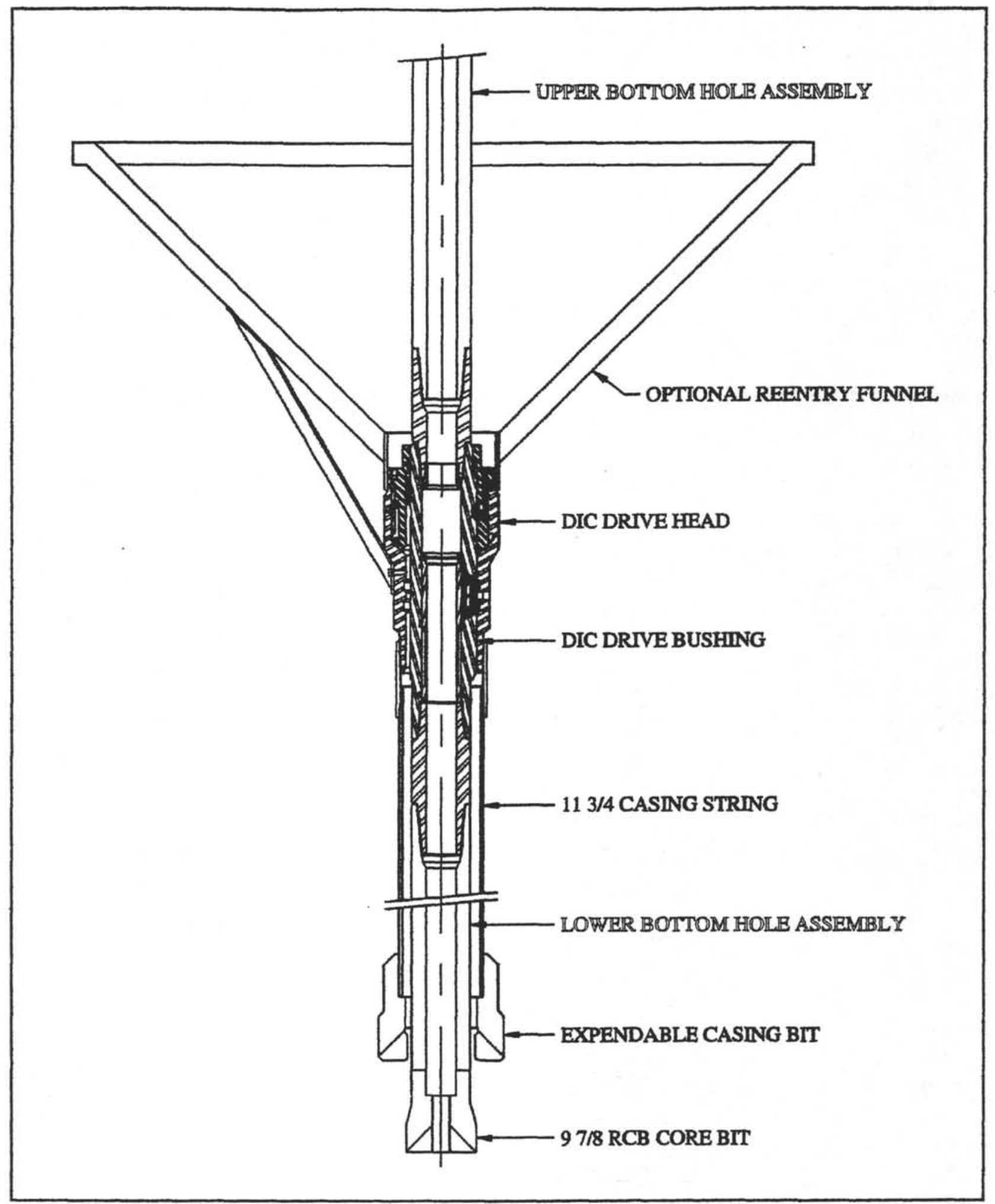

Figure 4: Drill-In Casing System (DIC) with Optional Reentry Funnel 


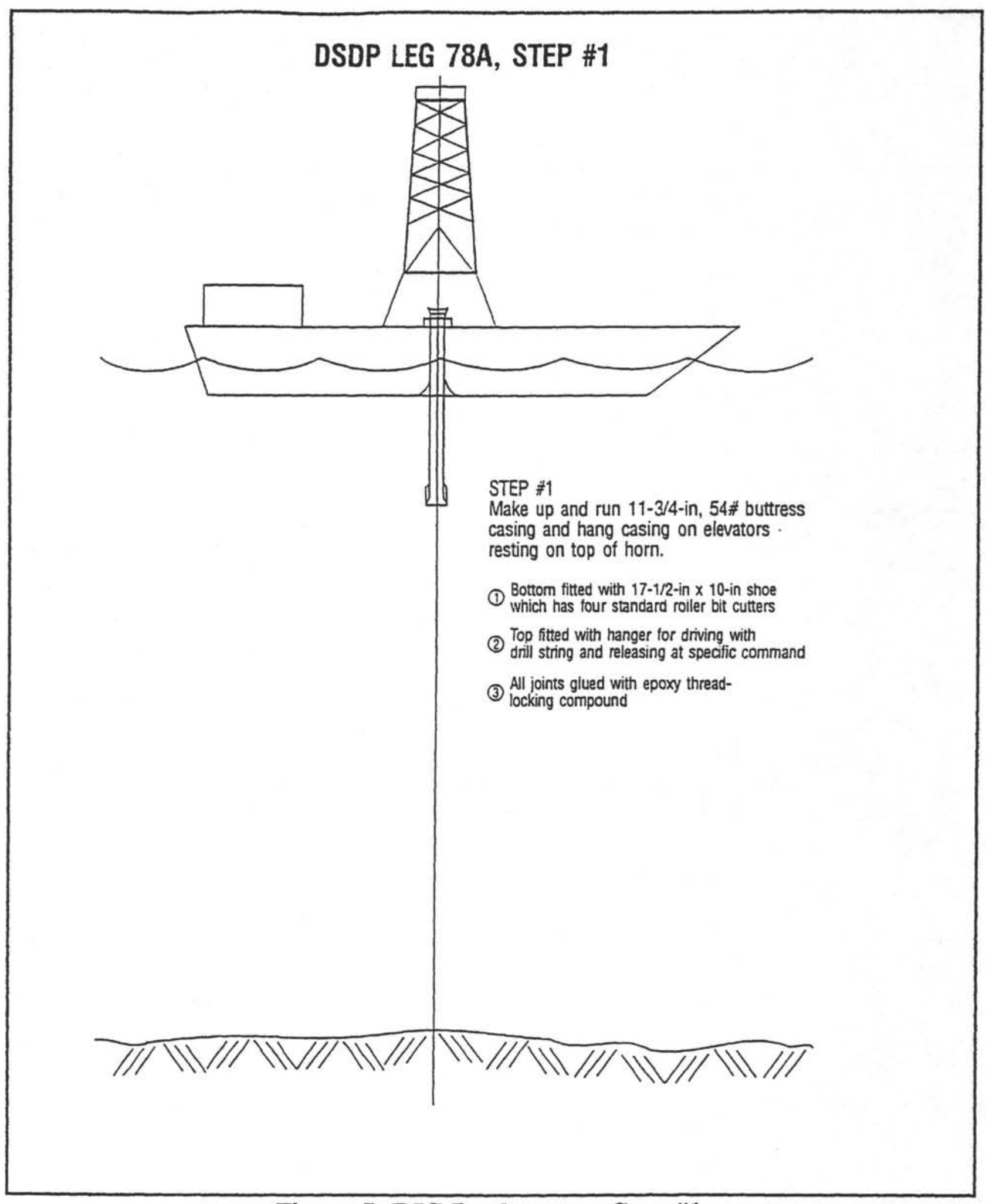

Figure 5: DIC Deployment, Step \#1 


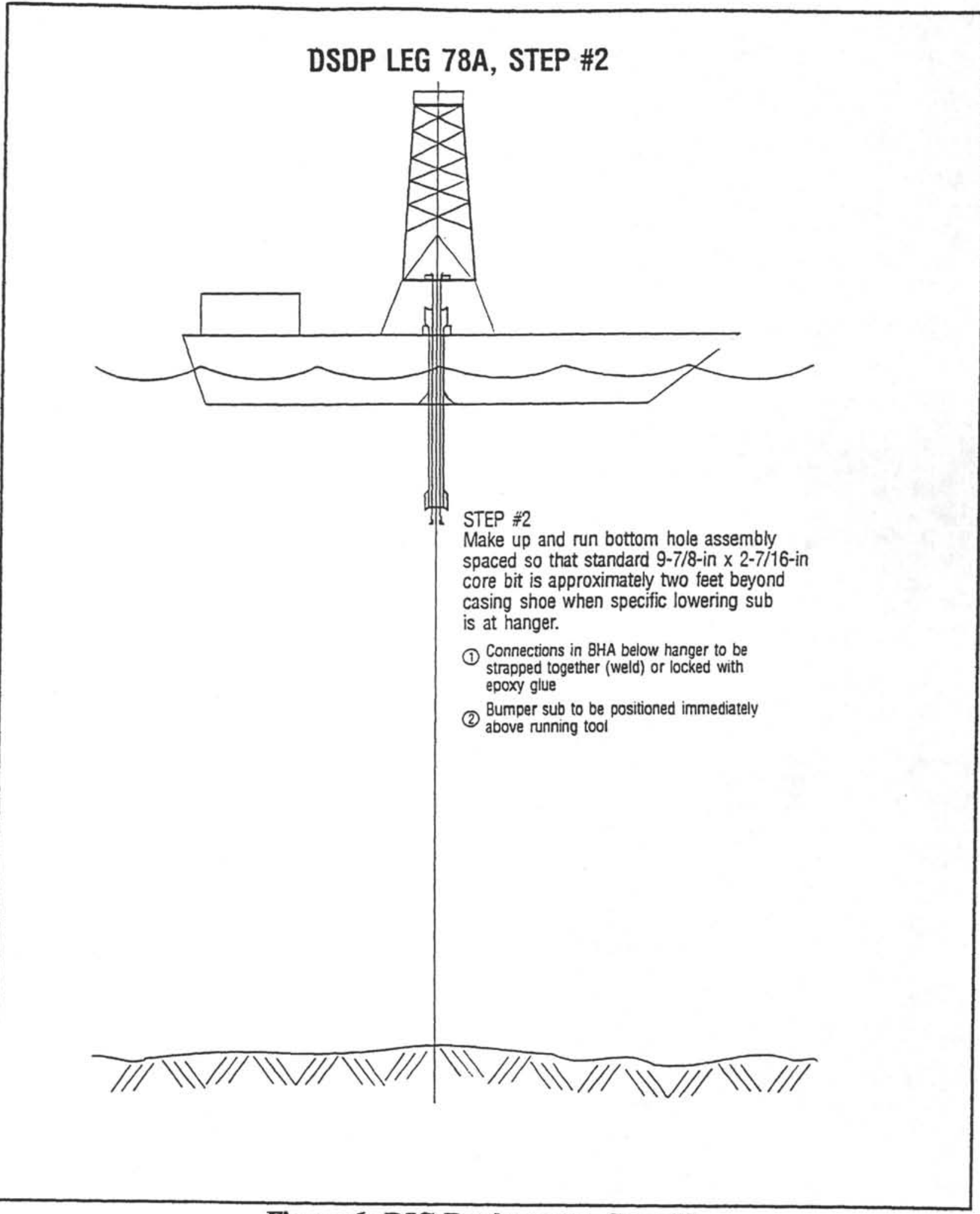

Figure 6: DIC Deployment, Step \#2 


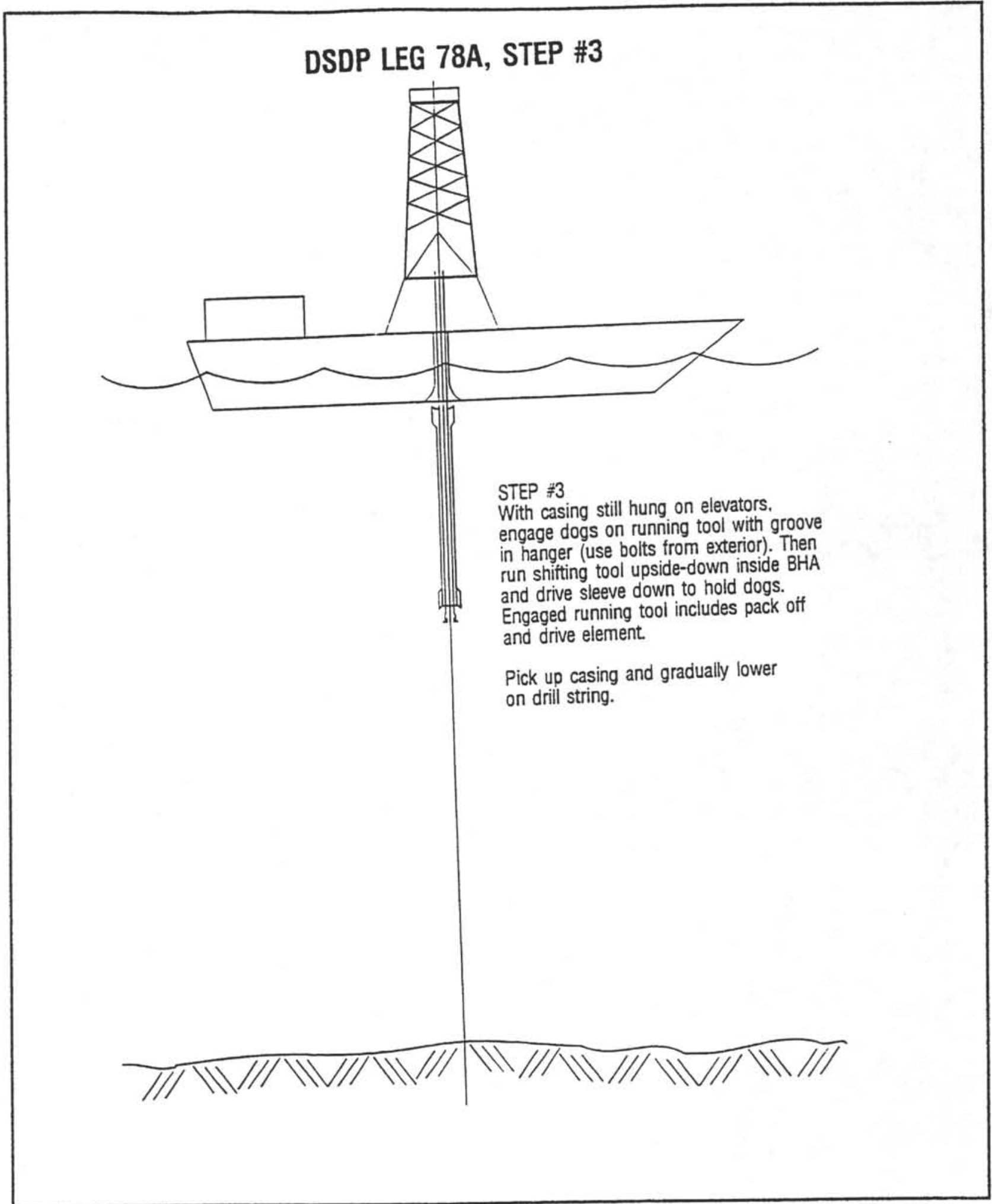

Figure 7: DIC Deployment, Step \#3 


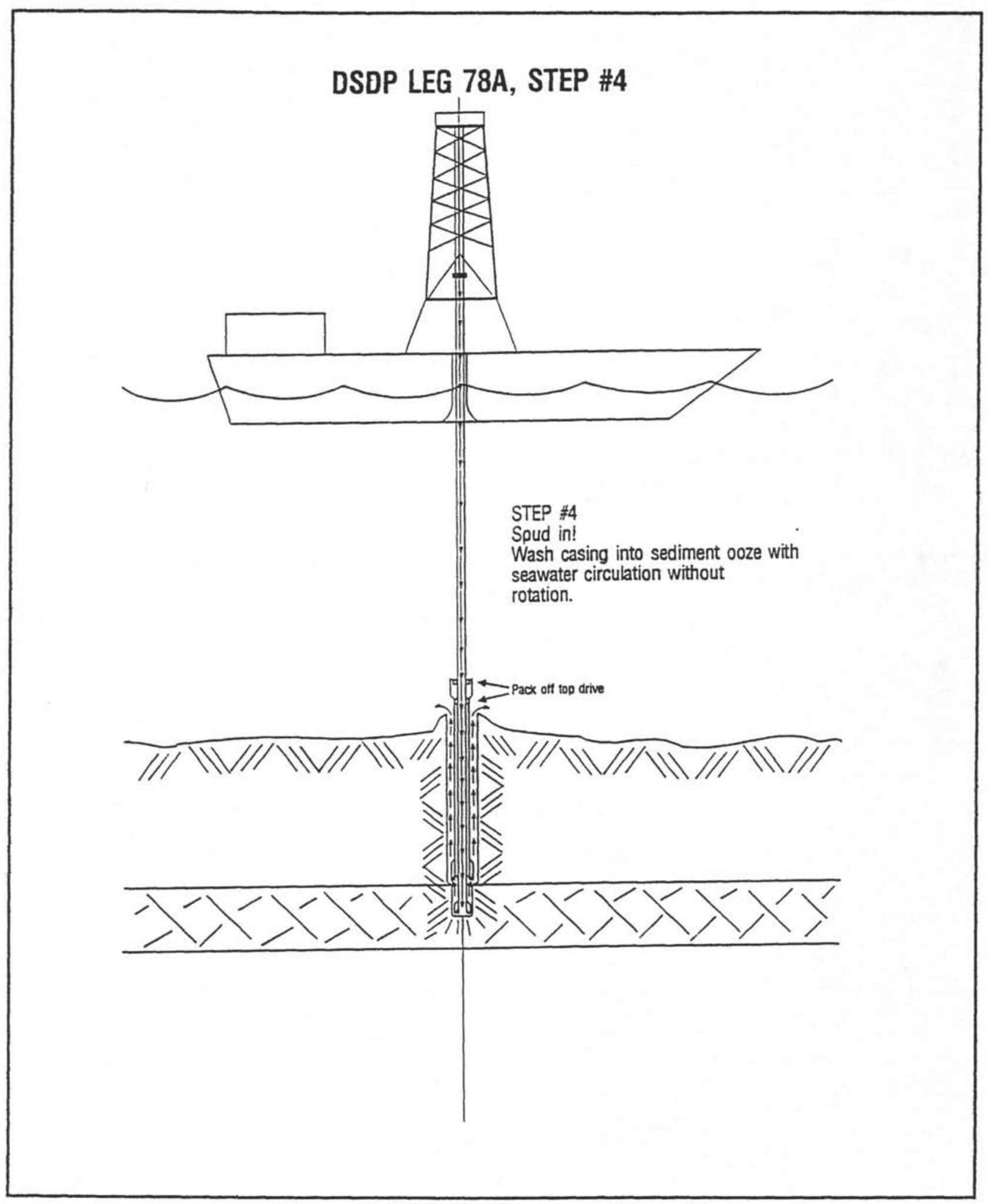

Figure 8: DIC Deployment, Step \#4 


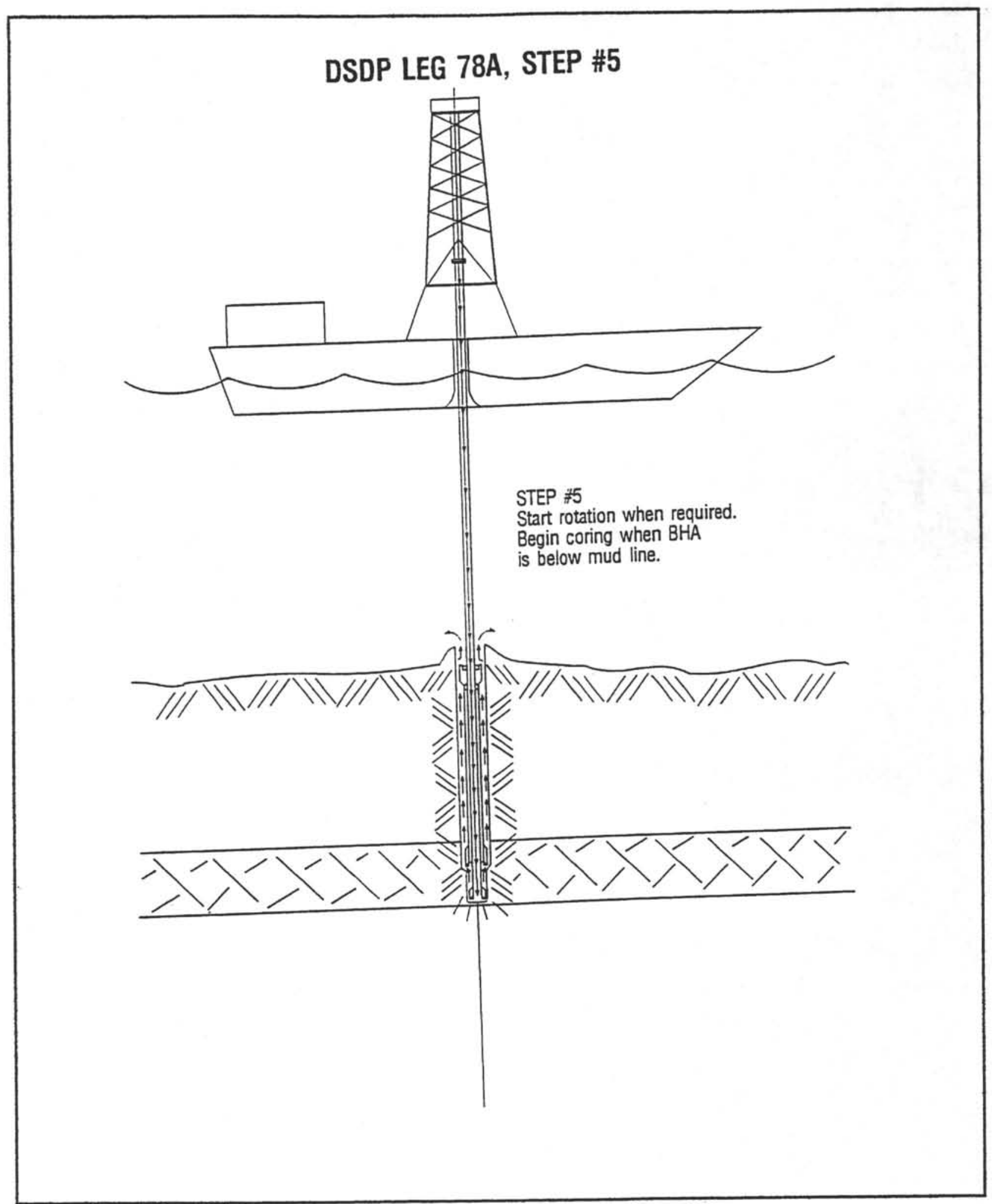

Figure 9: DIC Deployment, Step \#5 


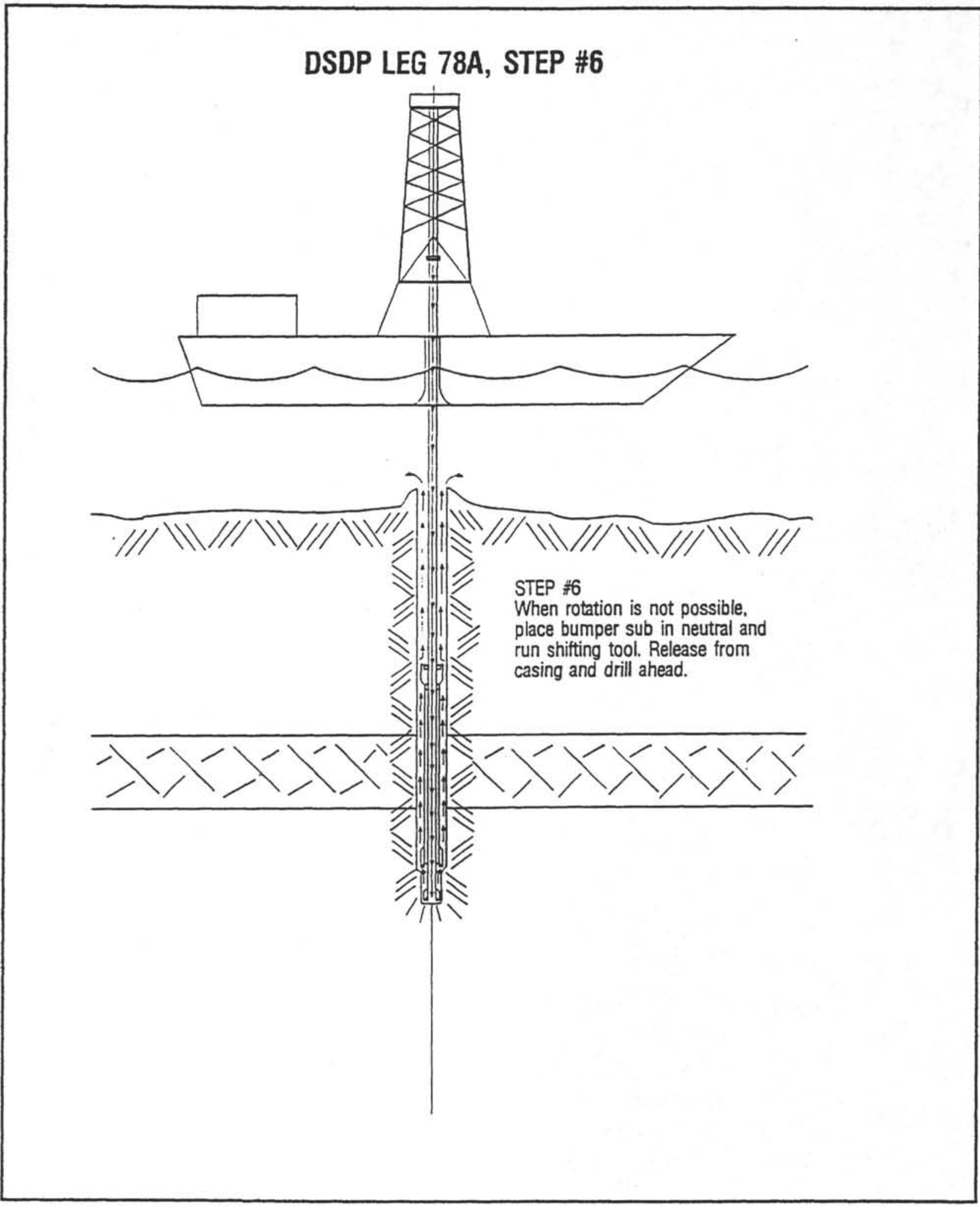

Figure 10: DIC Deployment, Step \#6 


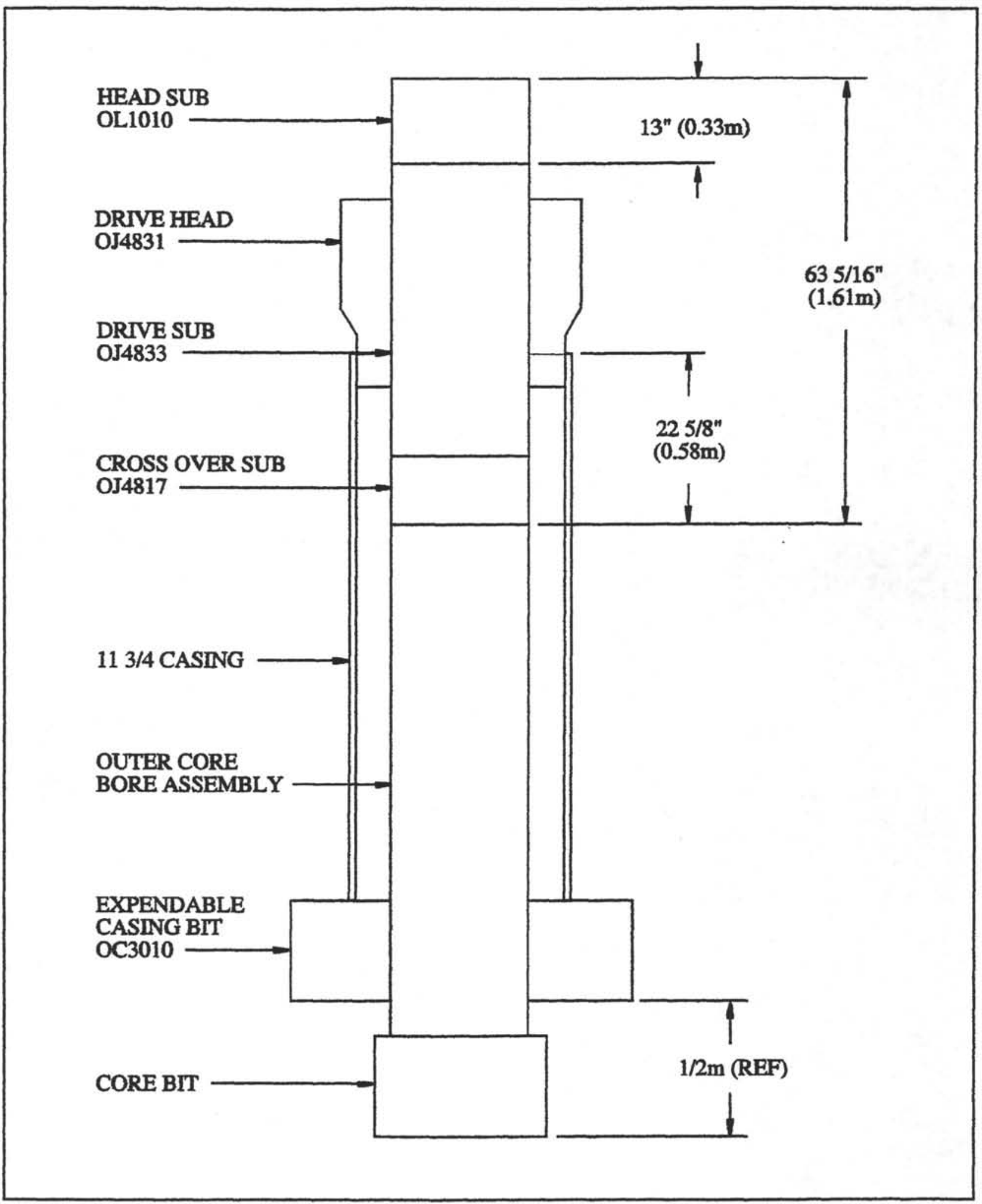

Figure 11: DIC BHA with Casing Assembly Spaced Out 
Appendix A

Present Status of Programs to Overcome Unstable Hole Problems April 27, 1978 


\section{PRESENT STATUS OF PROGRAMS TO OVERCOME UNSTABLE HOLES \\ April 27, 1978}

\section{Introduction}

The Project continues to experience unstable hole conditions which have on many occasions terminated scientific investigations. This paper summarizes present capabilities and technical efforts being made to overcome the problem.

\section{$\underline{\text { Unstable Hole Conditions }}$}

The problem appears to be twofold. One is associated with fractured rock where the sizable pieces become loose and fall into the annulus between the drill string and the drilled hole (see Figure 1). The bottom hole assembly then becomes immobilized when these large pieces become wedged between the hole and an enlarged part of the bottom hole assembly such as the bit. Circulation of sea water continues essentially without restriction, however, the drill string can no longer be reciprocated or rotated. Our field experience would suggest that this is not a common occurrence. Generally, unstable hole conditions are accompanied by restricted circulation of some sort (i.e., increased pump pressure which suggests "packing off" between the drill string and the open hole/and or plugging of the drill string itself by the backflow of cuttings). Actual sticking of the drill string usually occurs when circulation is stopped and/or is being reestablished. This suggest enlargement and the subsequent cuttings buildup due to slower annular fluid velocities and their inability to lift cuttings (see Figure 2). It appears that the hole enlargement is either due to (1) fractured and/or brittle rocks such as the young basalts, volcanic sands, etc., (2) formations that are sensitive to exposure to sea water and with time begin to slough, and/or (3) erosion of soft sediments due to circulation volumes (annular velocity).

\section{Techniques Presently Used to Overcome The Problems}

1. Mud Flushes:

Where cutting build-ups are noted (fill in the bottom of the hole and cuttings in the core barrel), small volumes (500-1000' lineal feet) of thick, high velocity mud "pills' are used to "flush" or carry out the cutting build up.

Note: Fresh water bentonite muds are used as they tend to thicken upon contact with sea water and hence improve the carrying capacity of the fluid. Sea water based fluids tend to thin.

At times, this technique, applied several times each day, has allowed deep penetration to be made despite continued cuttings build-up. 
2. Low Circulation Rates:

At times, lower than normal circulation rates are employed which cause a greater amount of cuttings regrind. These smaller cuttings can then be carried out with lower annual velocities.

3. Drilling of Upper Sections:

In those areas where terriginous shales are present, good results have been obtained at times by penetrating upper intervals quickly by the elimination of coring. (A second hole is used for the required investigation of the upper sections).

Low circulation rates are also used to minimize hole erosion if penetration rates are not compromised too much.

4. Pulling Approximately 30 Meters Off Bottom to Recover Cores:

This technique provides the cuttings a sump in which to fall when the circulation of sea water is stopped. While it has allowed some continuation of operations at times, this type of operation is often required shortly before operations must be stopped (i.e., the drill string becomes irretrievably stick).

\section{Techniques Under Consideration or Development}

An industry panel met at DSDP in October 1976 to consider the possible alternatives available to the Project. They suggested the following:

1. Reverse Circulation

2. High Viscosity Flush (cross-linked long chain polymers)

3. Immobilize the Sloughing and Caving Formations with the following:
a. Gel Forming Material
b. Lightweight Solidifying Polymer or Plastic
c. Lost Circulation Materials (mechanical briding)
d. Cement (last resort)
e. Drillable Liner

\section{$\underline{\text { Reverse Circulation (Air Assisted) - (See Figure 3) }}$}

Other than full return circulation with a marine riser, reverse circulation appears to have the greatest potential in overcoming stability problems. The technique is not in general use, although it has been used with notable success in big-hole drilling for mine shafts and nuclear testing, and recently in the water well drilling industry.

A considerable effort by Project Development Engineering was made in 1977 to evaluate this system and its possible use on the Glomar Challenger. The air requirements were calculated and the compressor equipment studied. This work showed that the reverse circulation would require an expenditure well beyond present funding levels. Because of this, and due to the current engineering workload, the review is now continued at a low priority level. 


\section{High Viscosity Flushes}

A proprietary fluid developed to carry fracturing sand in oilwells was obtained and placed aboard the Glomar Challenger in early 1977. Although this fluid has been used on numerous occasions, it has not produced any known, favorable results.

Approximately $\$ 10,000.000$ was spent on this special fluid and in training personnel to use it. While the Project is testing a similar product as a possible substitute for the normally used fresh water bentonite mud flushes, there are no plans at this time to test additional, exotic flushes or "gunk."

\section{Immobilize the Sloughing and Caving Formations - Third Casing String}

The Project has embarked upon a development program which will allow the setting of longer strings of casing, a need which is anticipated for the 80-81 Program.

In this margin drilling program, the Project hopes to be able to drill and then place behind steel pipe the upper 2,000-3,000 feet of sediment. This, in turn will possible prevent hole deterioration like that in Leg 50.

Note: This system does not allow for casing to be placed through sections that are immediately unstable.

A preliminary engineering concept has been worked out and machine drawings are now being prepared. A prototype system has been budgeted for the second half of this year (1978).

If the prototype is successful, the Project would attempt to schedule Sea Trials of the system during 1979 (if compatible with the scientific schedules). The system uses the same basis cone presently used at multiple entry sites.

\section{Drilled-In Casing}

The Project is presently developing a concept of drilling-in short strings (approximately 60 meters) of casing through unstable zones.

The Project is also presently negotiating with an engineering firm to prepare the necessary drawings. Present schedules, if maintained, will make this system available in October 1978. 


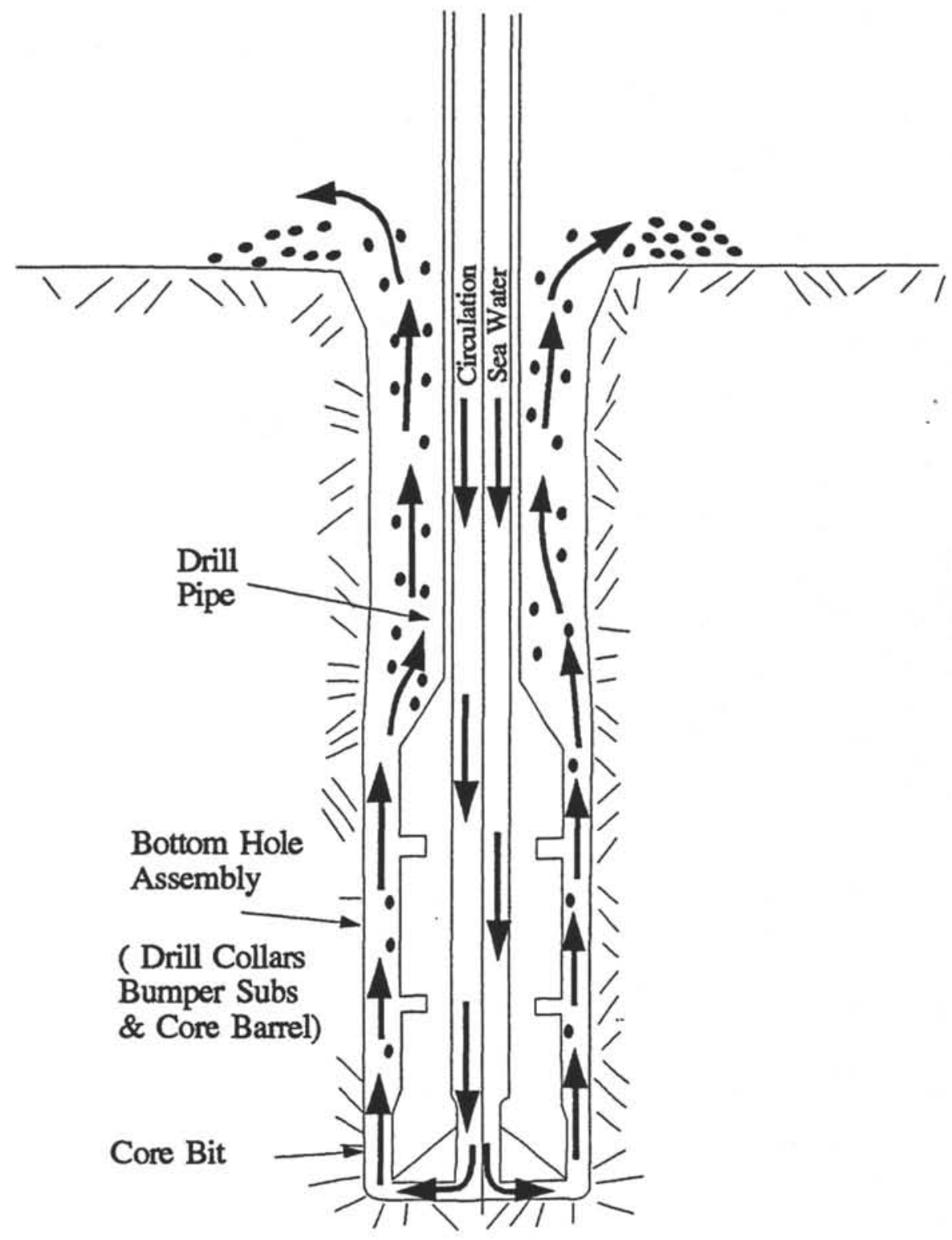

Fig 1: Schematic of Normal DSDP Drilling Hook Up 


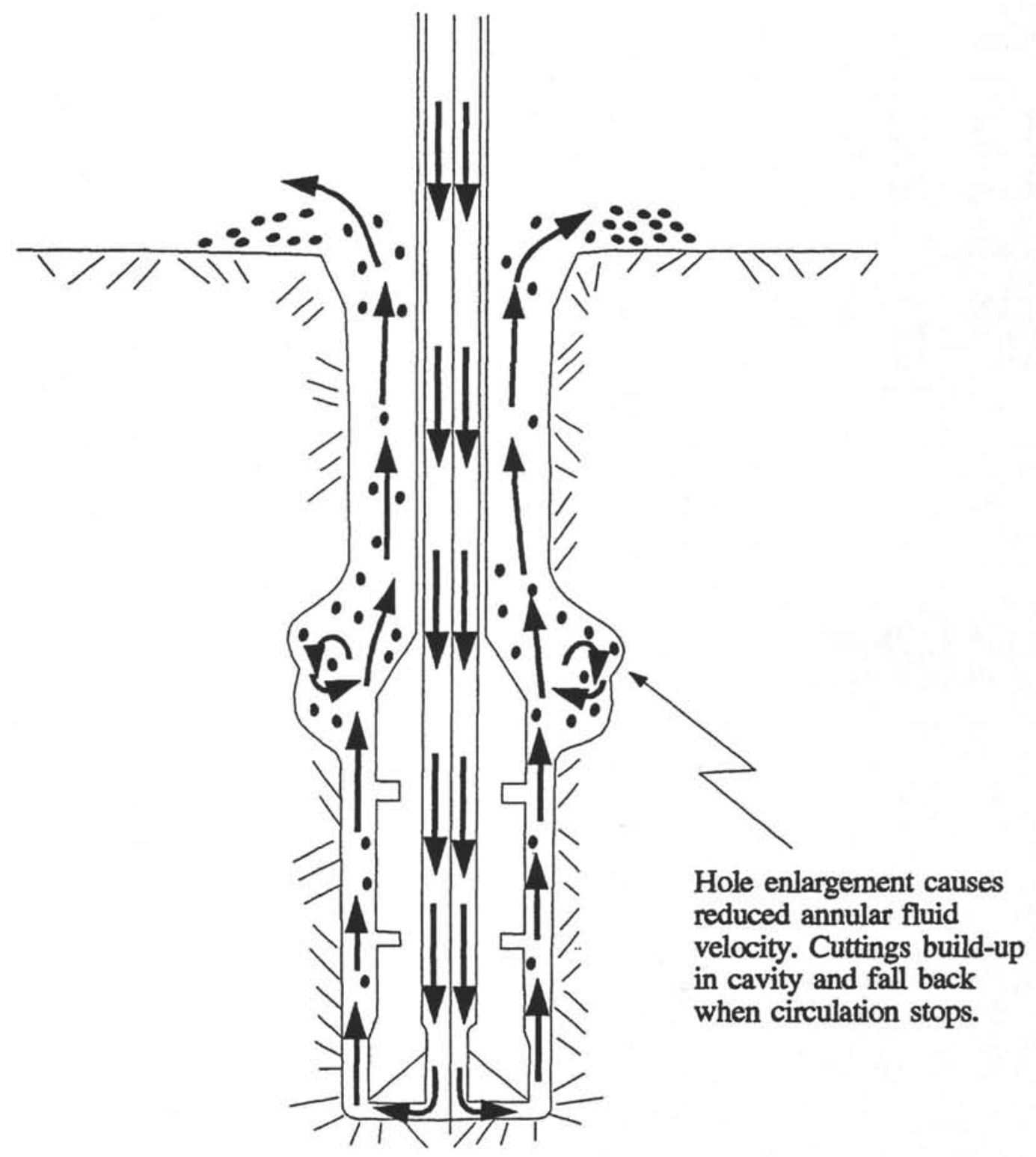

Fig 2: Hole Enlargment and the Cuttings Trap 


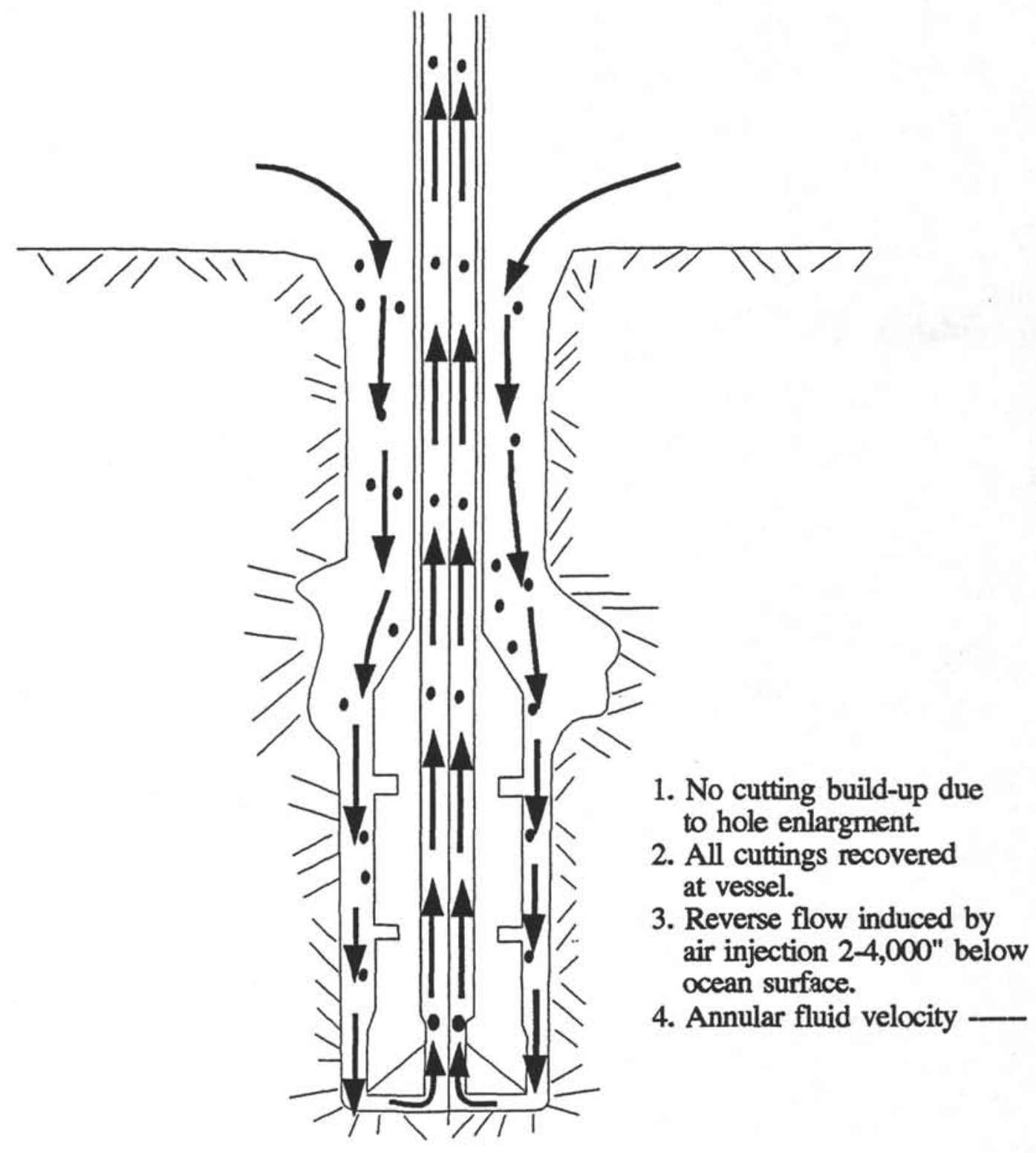

Fig 3: Reversing Circulation 
Appendix B

DIC Operating Procedures 
1. Determine proper subs etc., to space out the DIC BHA/11 3/4" Casing assembly such that the Coring Bit is positioned approximately $1 / 2 \mathrm{~m}$ ahead of the Expendable Casing Bit (ref figs 11 \& 12).

2. Cut bottom $113 / 4 "$ casing joint to proper length as determined by space out calculations.

3. Weld Expendable Casing Bit (0c3010) to bottom casing joint.

4. Make-up casing string running in the hole and hang off at rig floor.

NOTE: Optional - tack weld and/or Baker-Lok all connections.

5. Make-up standard outer Core Barrel assembly running in the hole through the hung off casing string.

NOTE: Optional - tack weld and/or Baker-Lok all connection below DIC.

6. Make-up DIC assembly into the BHA assembly.

7. Make-up DIC assembly to upper casing joint.

8. Ensure all three (3) Drive Bushing Upper Dog Lock Screws (OJ4810) are backed out, in contact with Retaining Rings.

9. Continue to make-up $B H A$ and drill string while running in the hole with DIC assembly.

NOTE: If Optional Reentry Funnel is to be used lower the DIC assembly to the moon pool doors for installation of the funnel. 


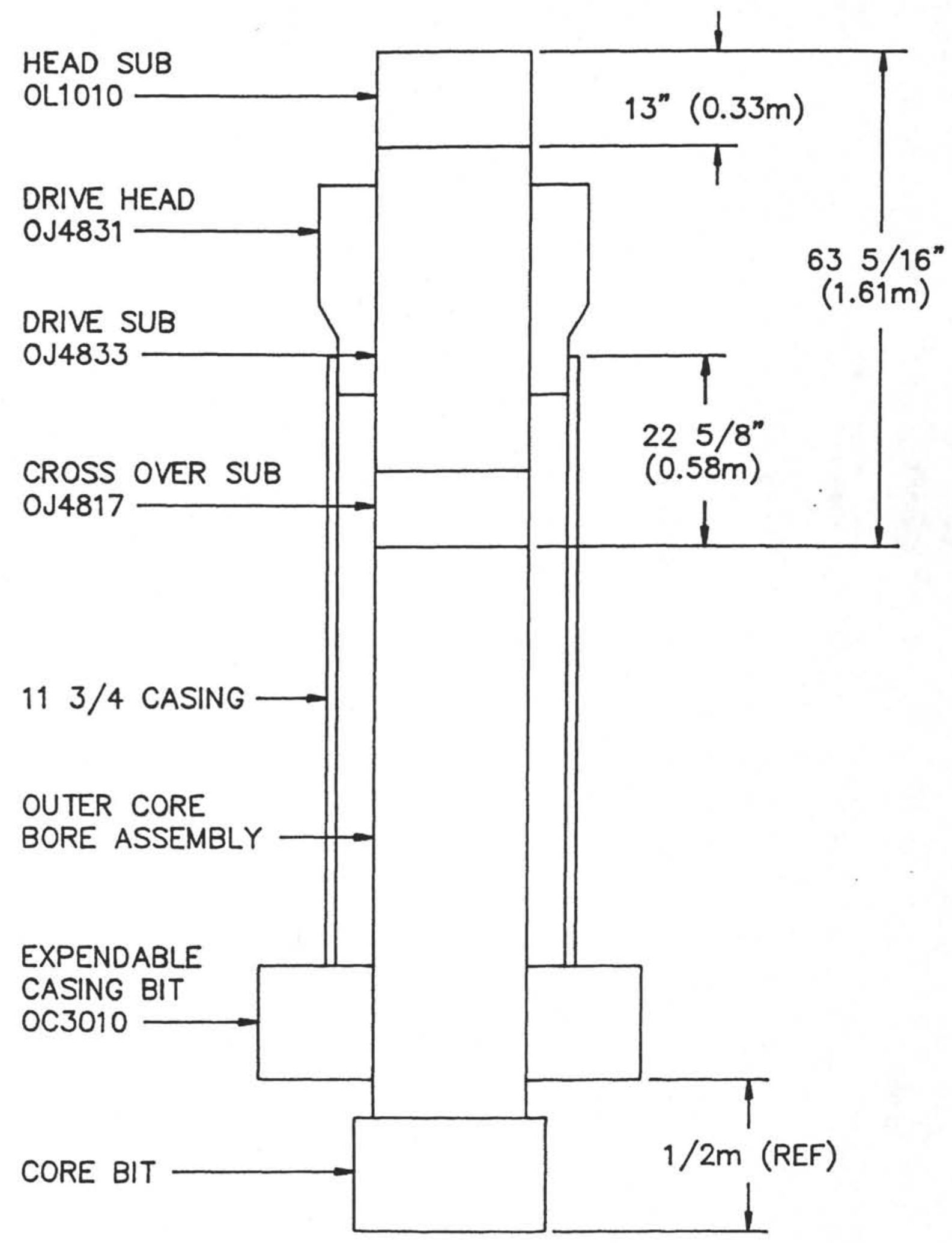

FIG 11: DIC BHA/CSG ASSY SPACE OUT 


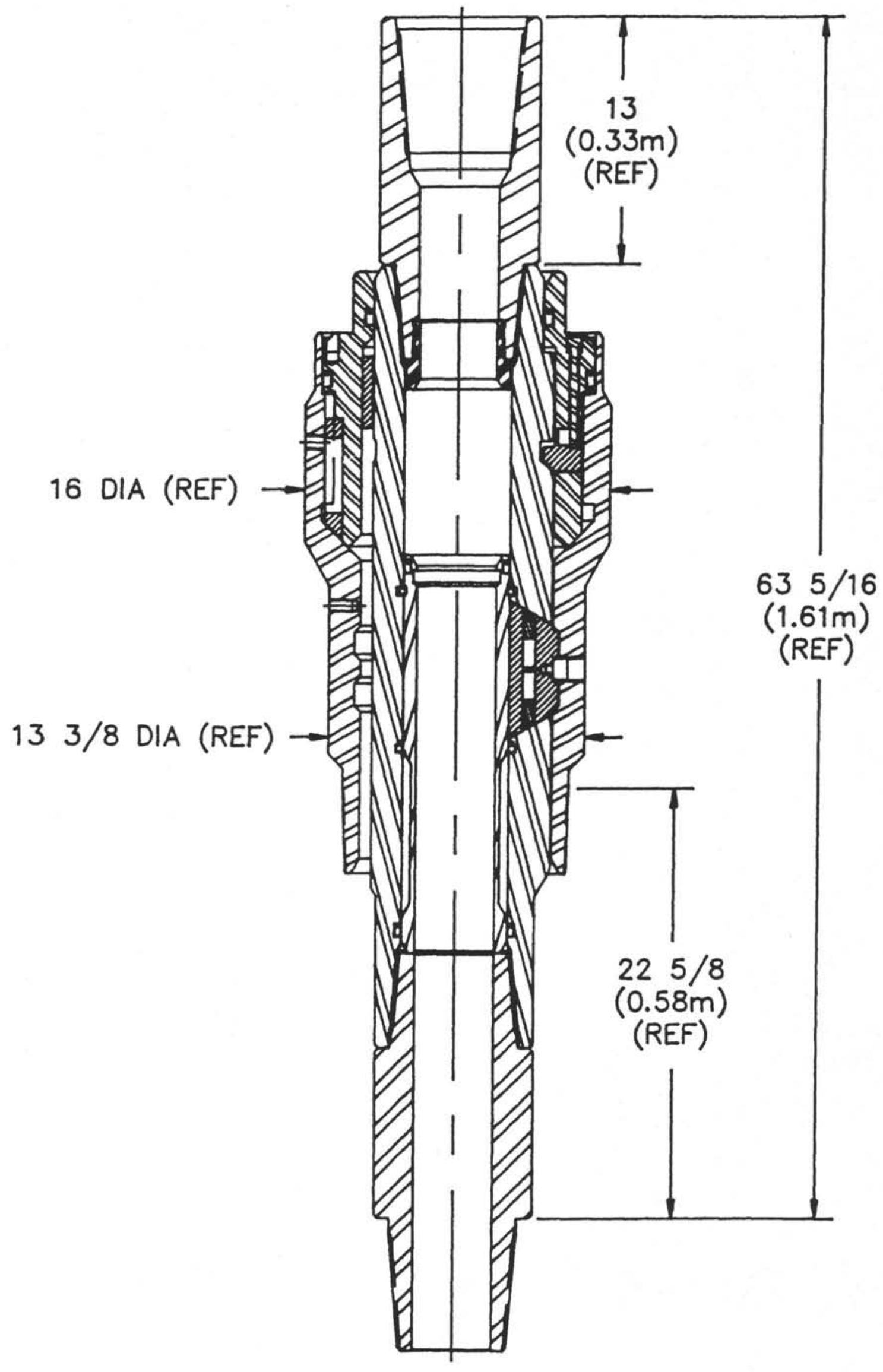

FIG 12: DIC RIH CONFIGURATION 


\section{REENTRY FUNNEL (OJ4852) ASSEMBLY (OPTIONAL)}

(Reference Figure 13)

1. Modify one (1) each Free Fall Funnel (FFF) (OH4600) as indicated on drawing (OJ4852) by removing the $133 / 8^{\prime \prime}$ ID sleeve and installing 16" Split sleeves (ref fig 13). Reentry funnel should be preassembled ahead of deployment time. 

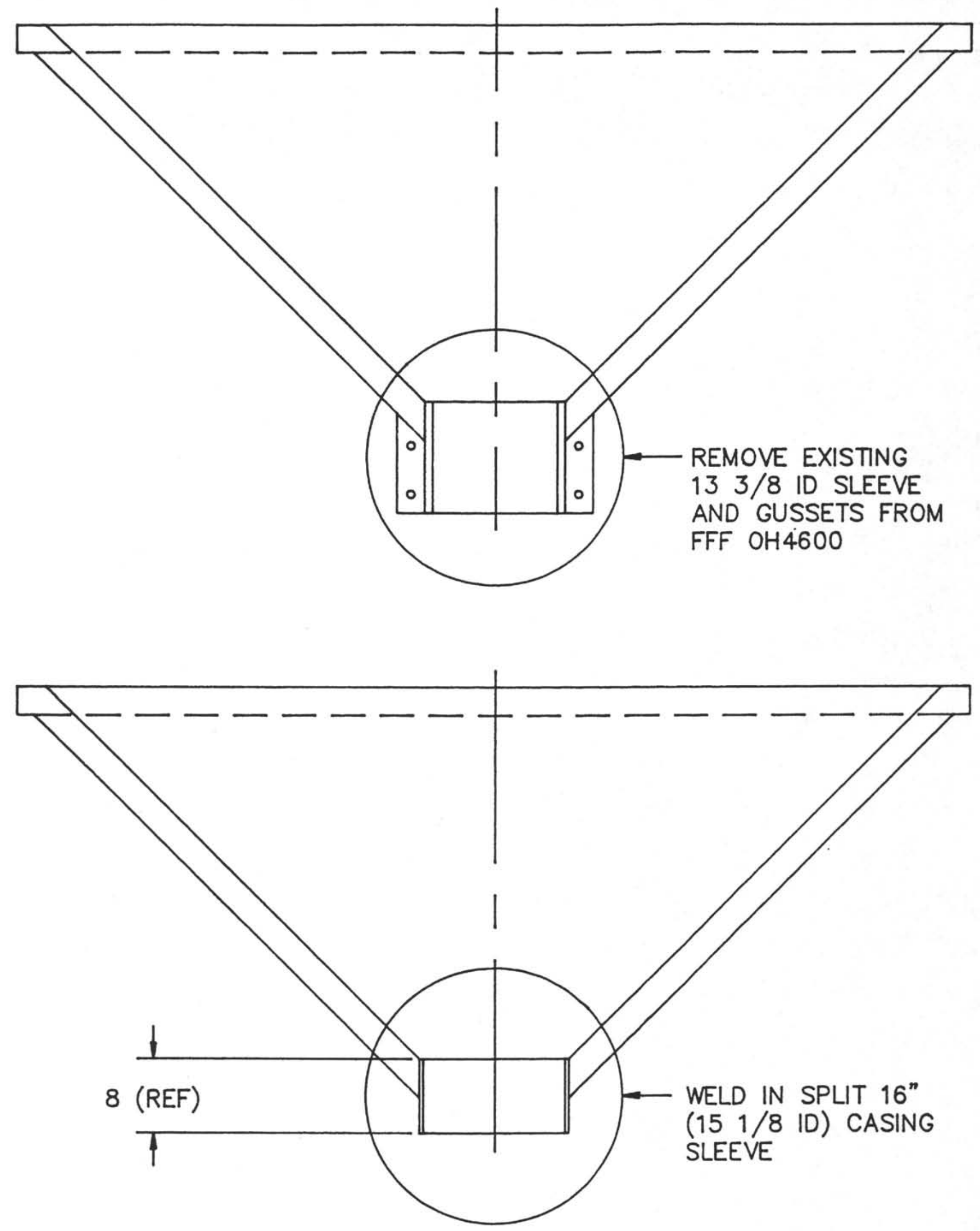

FIG 13: FFF MODIFICATION F/DIC 


\section{REENTRY FUNNEL INSTALIATION}

$$
\text { (Reference Figure 14) }
$$

1. With the DIC assembly positioned in the moon pool, assemble Reentry Funnel halves around DIC Drive Head. Ensure that Reentry Funnel slips over Drive Head neck (ref fig 14).

2. Attach three (3) each Reentry Funnel Braces (OJ4853) to Drive Head using three (3) each 5/8-11 UNC x 1-1/2" hex head bolts (OD7248).

NOTE: Hex head bolts OD7248 are the same bolts as used on the 13-3/8" FFF bolted casing pup. Hex head bolts are only welding and alignment aids and may be omitted.

3. Rotate the Reentry Funnel as necessary until the Funnel Braces are aligned with the funnel angle iron strength members. Weld Funnel Braces to funnel strength members and DIC Drive Head (ref fig 14).

4. Weld Split Sleeve together and to DIC Drive Head. 


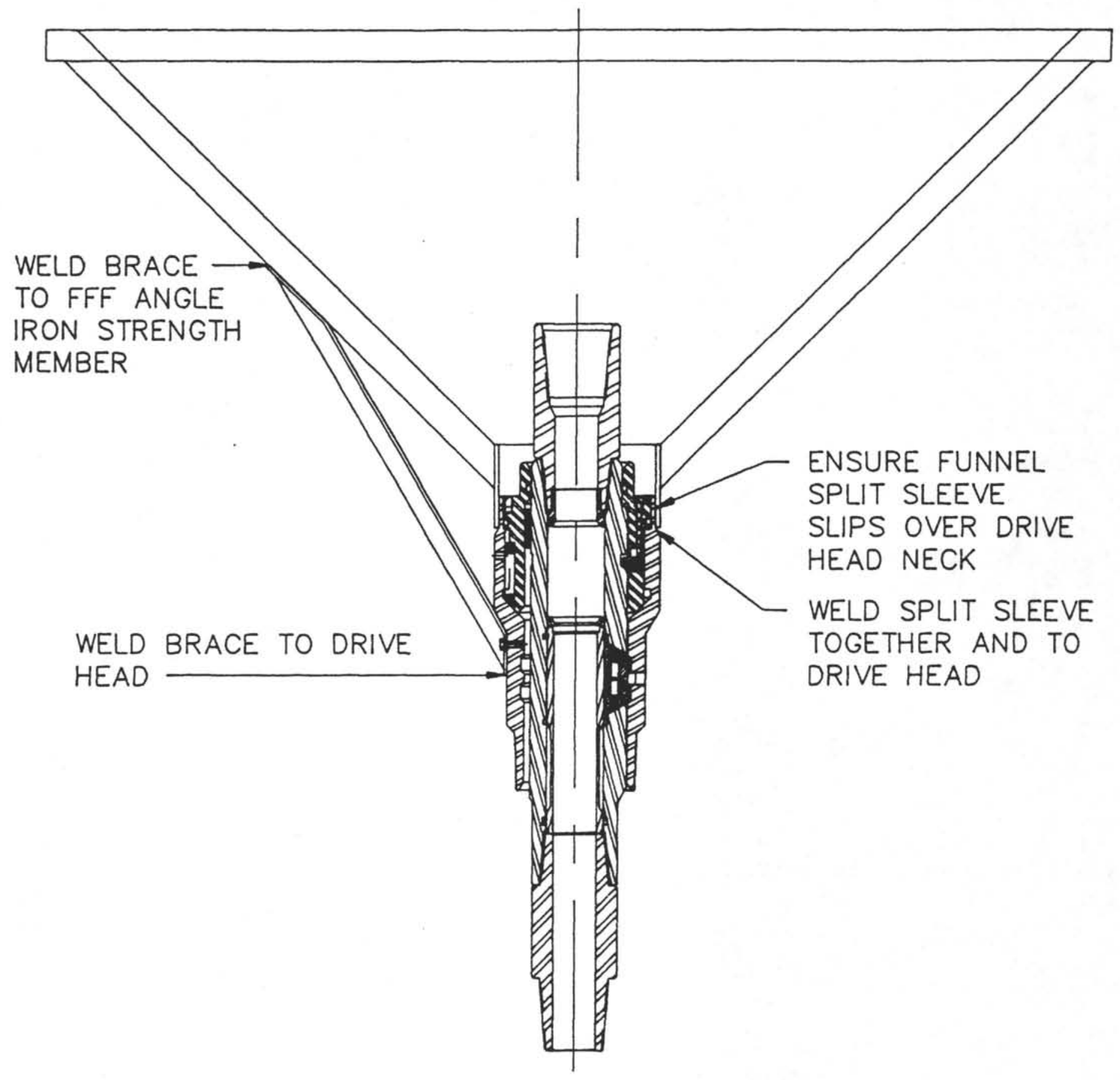

FIG 14: DIC FUNNEL INSTALLATION 


\section{SPUDDING AND RELEASE}

(Reference Figures 15, 16, 17, 18, $19 \& 20$ )

1. RIH with DIC assembly to sea floor (ref fig 15).

2. Jet-in casing to refusal.

3. Begin rotating slowly.

4. Once the DIC has been drilled into place, release it using a standard Rotary Shifting tool (ref fig 16).

NOTE: Use of the Heave Compensator to vary tension in order to position the neutral point at the DIC Lower Dogs during releasing operations will facilitate shifting of the sleeve.

5. Pick up approximately $1 \mathrm{~m}$ with the drill string to release the Drive Bushing (ref fig 17).

5. Lower the coring Bit back to TD and cautiously drill out from under the DIC assembly (ref figs 18 \& 19).

6. Use caution when pulling the BHA back through the DIC (ref fig 20). 


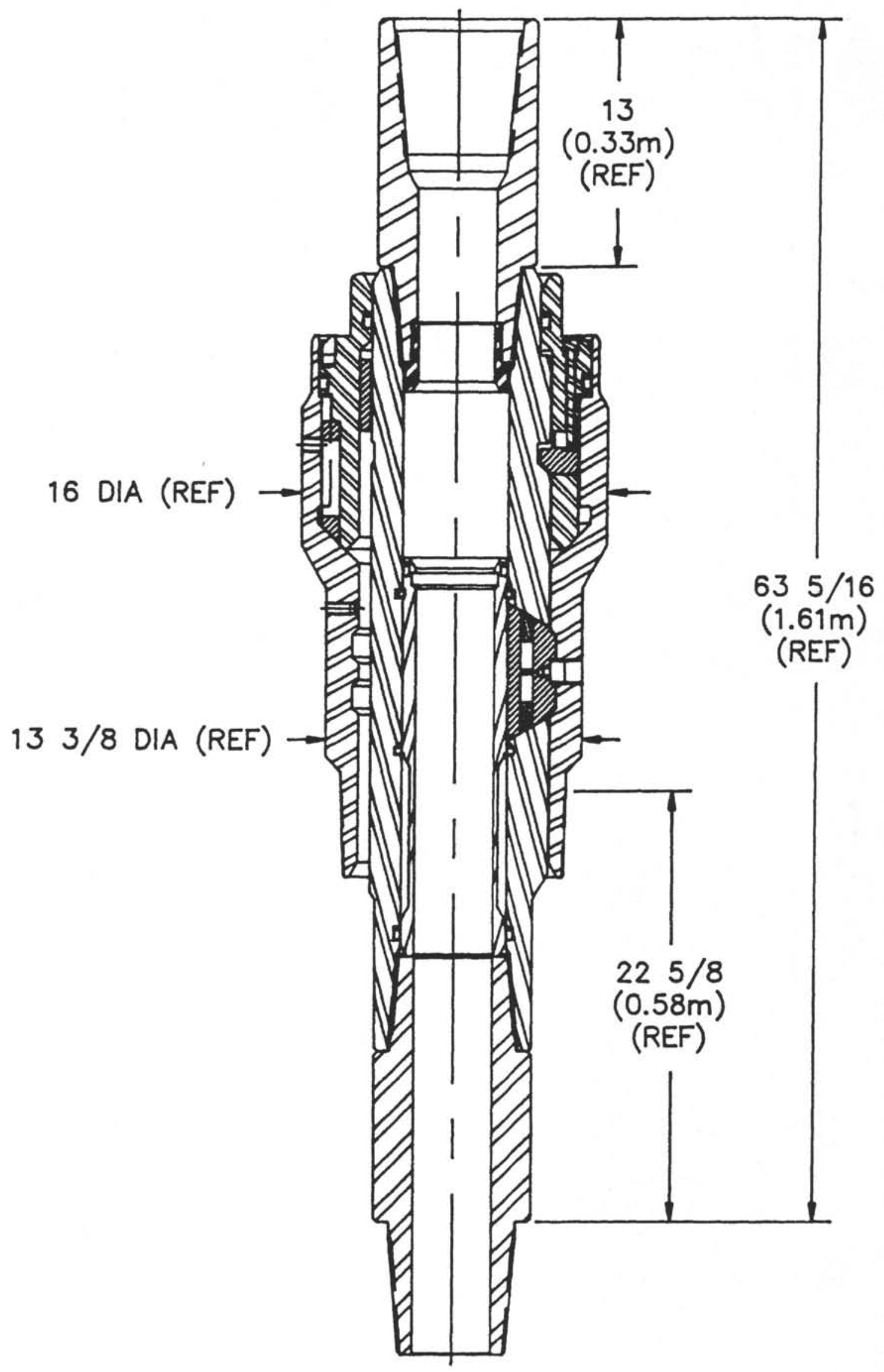

FIG 15: DIC RIH CONFIGURATION 


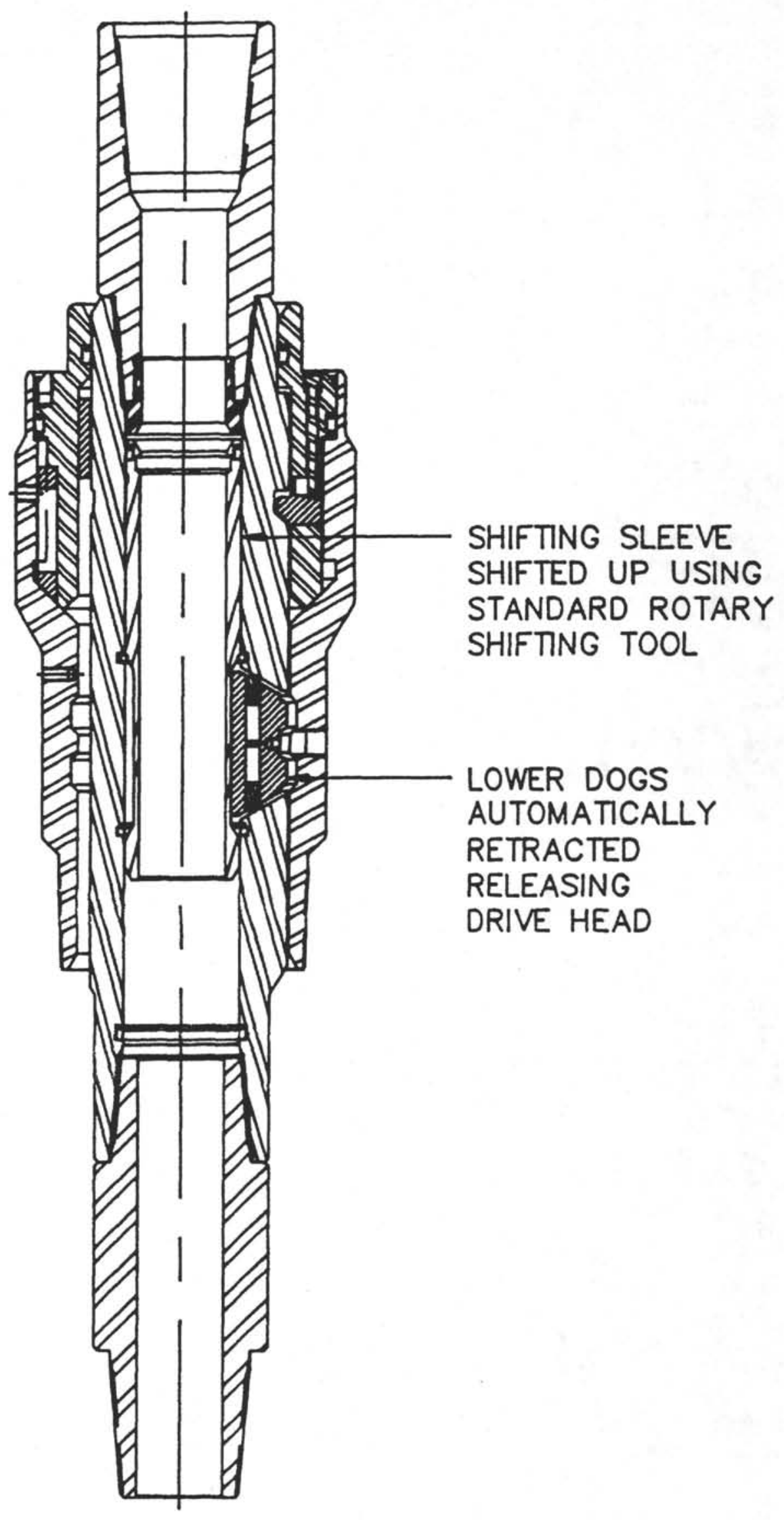

FIG 16: SHIFTING SLEEVE SHIFTED 


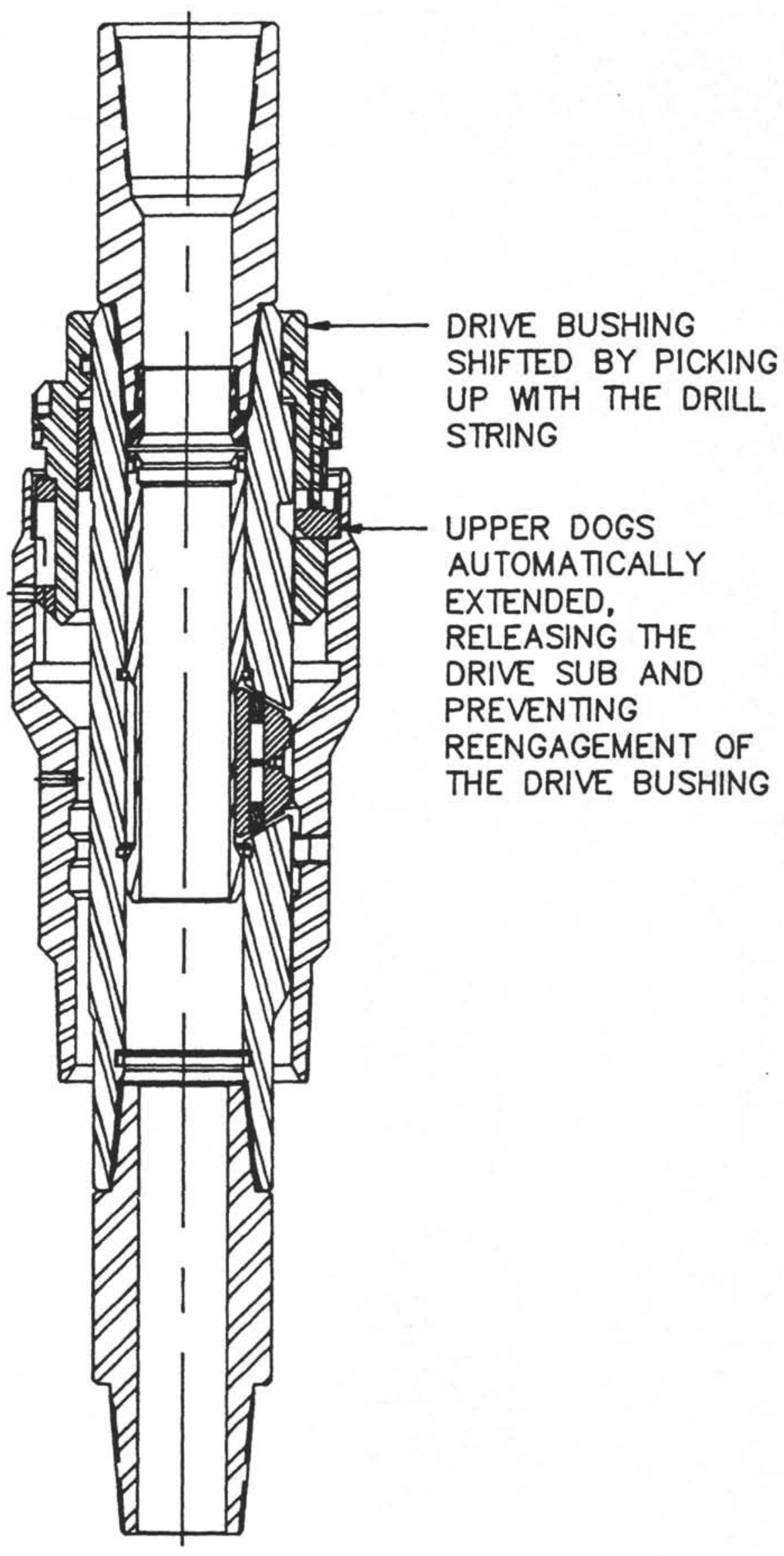

FIG 17: DRIVE BUSHING SHIFTED 
DRIVE BUSHING INSERTS DISENGAGED FORM DRIVE SUB WHEN CORING BIT IS LOWERED BACK TO TD

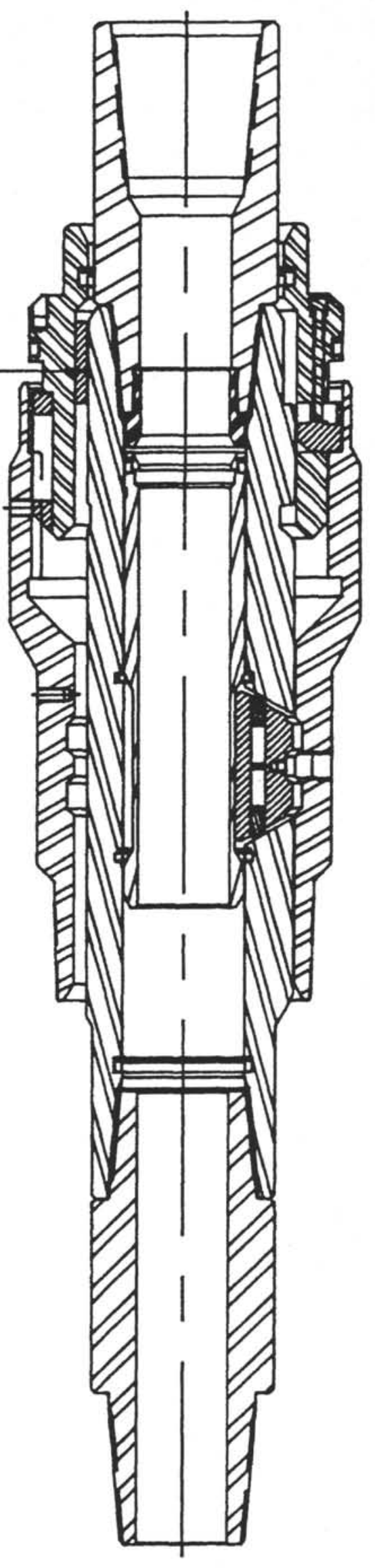

FIG 18: DRIVE BUSHING DISENGAGED 


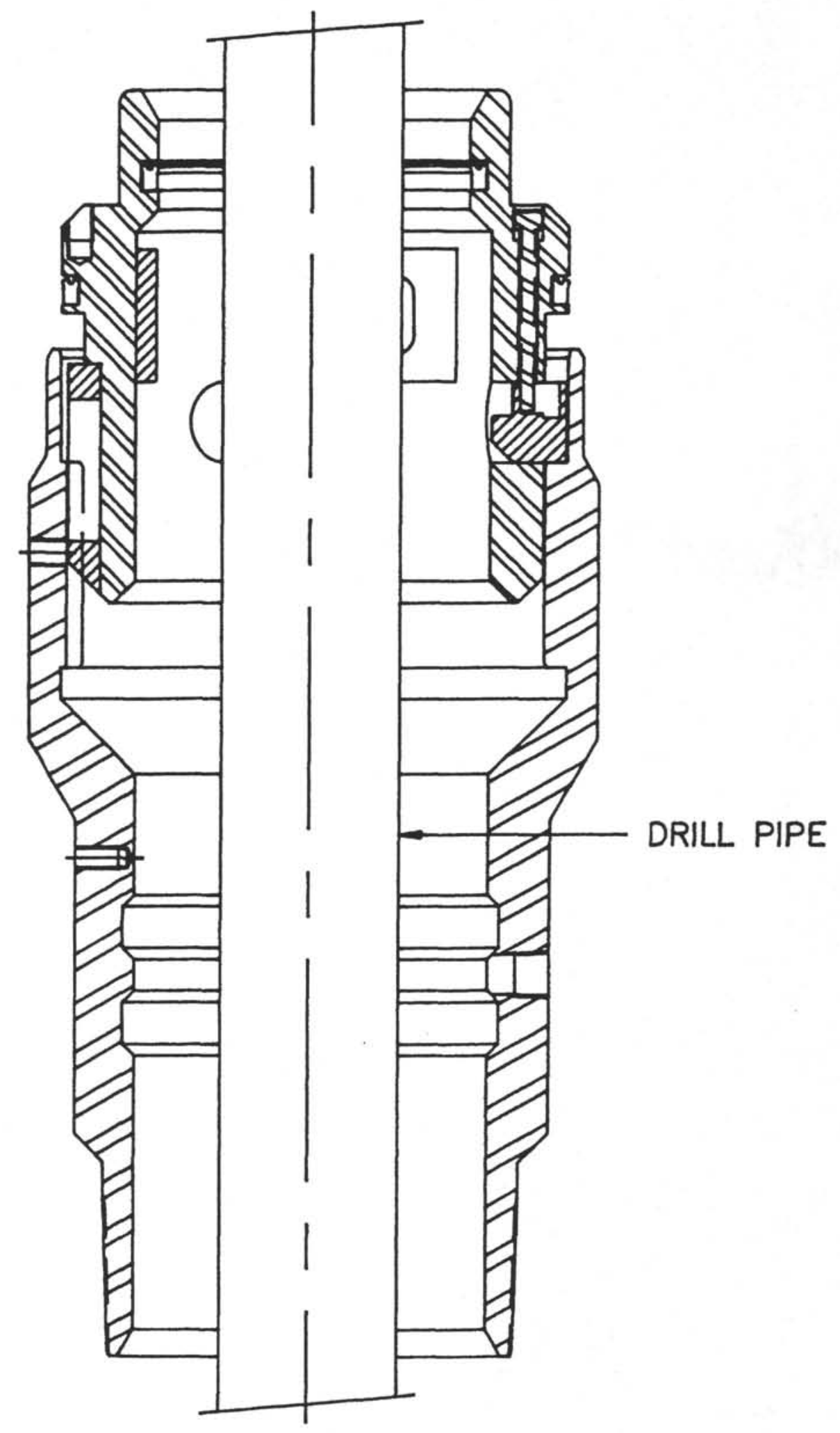

FIG 19: DRILLING THRU THE DIC 


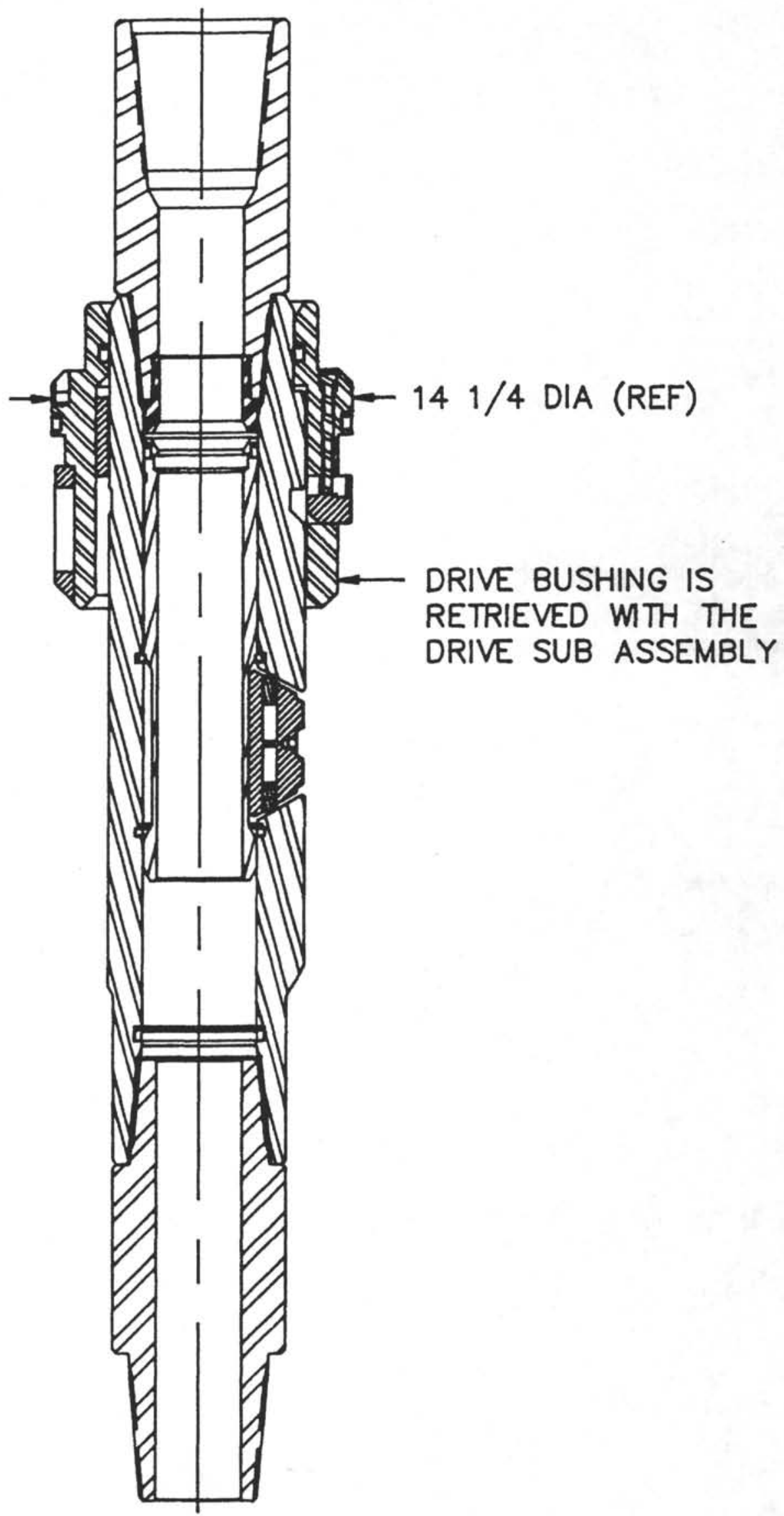

FIG 20: DIC POOH CONFIGURATION 
Appendix C

ODP Proposal

Ultra Deep Water DIC System 
Texas Advanced Technology Research Program

Texas A\&M University

\section{Ocean Drilling Program Proposal Ultra Deep Water Drill-In Casing System}

\section{Introduction}

The need to develop a reliable Drill-In Casing (DIC) system for use in ultra deep water (20,000-30,00 feet) scientific research coring has been apparent for many years. The Deep Sea Drilling Project (DSDP), managed by Scripps Institution of Oceanography (SIO), first recognized this need while attempting to conduct single bit coring operations in faulted and/or unstable formations throughout the world's oceans. Many highly desirable scientific drill sites were found to be impenetrable with conventional single bit coring systems. Attempts to set reentry cones and emplace conventional casing systems to isolate the unstable zones were also unsuccessful. In most areas, hole integrity could not be maintained long enough to land and cement conventional casing strings. This type of operational problem will become more prevalent in the commercial oil industry as drilling and production operations continue to move into deeper water. The need to isolate (i.e., case off) the unstable formation on the first penetration through the problem zone is apparent. DSDP, operating with the research drilling vessel, Glomar Challenger, first attempted to use a single bit DIC system while conducting operations on site 542B, in the Barbados Ridge Complex (see Figures 1-4). The results of this first operational deployment were encouraging but not conclusive (see attached Appendix I - DIC Sea Trials Report excerpted from DSDP Technical Note No. 2). A 57 meter string of 11-3/4", 54-lb/ft casing was drilled in and the casing shoe placed at the desired depth of 323 meters below the sea floor. The casing extended through and isolated an unstable fault zone. Unfortunately, the mechanical release mechanism failed to operate and the drill string ultimately had to be severed, forcing abandonment of the hole.

\section{Proposed Methodology}

Texas A\&M University, through the Ocean Drilling Program's Engineering and Drilling Operations Department, intends to pursue a threefold approach to the design and development of a reliable "ultra deep water" DIC system. First, a detailed review and failure analysis of the DSDP single bit, top drive, drill-in casing system will be performed. Secondly, a "bottom drive" concept, emphasizing the use of state-of-the-art, positive displacement, mud motor technology will be explored. The third concept to be evaluated is a reentry cone "compatible" version of the mud motor DIC system. 
A. DSDP Single Bit Top Drive System:

The mechanical system utilized by DSDP showed promise achieving the desired goal of drilling through an unstable zone and placing the casing string at the desired location. The major identifiable weakness in the initial system was its dependency upon a top drive system for transmission of torque to the cutting structure on the casing shoe (see figures 5-6). ODP intends to evaluate the top drive concept and conduct a detailed design review of the DSDP system. In conjunction with the review, a failure analysis will be performed and torque-up/load testing will be conducted in order to define and correct the failure mode experienced during initial deployment.

B. ODP Single Bit PDM System:

In addition to developing a better understanding of the DSDP system failure mode, ODP intends to pursue an alternative concept. The ODP system will utilize a positive displacement mud motor to drive an expendable cutting structure at the base of the casing string (see figure 7). A splined bearing sub will be used to transfer mud motor torque to the casing shoe cutting structure. This concept has the advantage of eliminating torque transmission through the entire casing string and latch system, a suspected cause of failure in the DSDP deployment.

C. ODP Multiple Bit PDM System:

Development of a multiple bit PDM drill-in casing system (i.e., reentry cone compatible system) will allow the casing off of unstable formations encountered below the conventional shoe on reentry holes. This system would be designed to drill-in and land a "liner" which would isolate the unstable zone prior to drilling ahead (see figures 8-10). 


\section{Drill-In Casing System \\ Sea Trials Report \\ Leg 78A}

\section{Appendix I}

The drill-in casing system has been deployed only once -- on Leg 78A, Hole $542 \mathrm{~B}$, and was a qualified success. A 57 meter string of 11-3/4" casing was drilled in to put the shoe (bit) at the desired depth of 323.5 meters below sea floor with the coring extended through a fault zone which was to be isolated. The release mechanism failed to operate, however, and it was eventually necessary to sever the drilling string above the BHA. The following weaknesses were identified and will need further consideration before a second deployment is attempted:

A. Release Mechanism:

The failure of the release mechanism apparently resulted from the inability to move the release sleeve to the fully shifted position. This is evidenced by the failure of the shifting tool to disengage downhole. Two of the dog hinge pins sheared and the tool was recovered on the first attempt, but the overshot pin sheared on two subsequent attempts, leaving the shifting tool in place.

Since no failed components were recovered, primary failure analysis could not be performed. A design review and further testing of the release mechanism were needed. It would seem possible that the vertical and torsional loading attendant to the 11-hour drilling operation may have caused distortion or failure of components in the drive/lowering system which, in turn, prevented proper actuation of the release mechanism.

B. Torque Transmission:

Exceptionally high and irregular drill string torque was recorded throughout the drilling operation. This was attributed at the time to a "torsional spring" effect in the casing string. Since the casing bit is driven from the top of the casing, it was felt that the energy was alternately stored and released by the casing, causing the drill string to "torque up" and then spring free. A spline or similar arrangement was proposed to key the casing and BHA together torsionally near the bit. The effect may have simply been the result, however, of the high torque produced by $17-1 / 2$ " bit arrangement acting through the long drill string. The "spring" properties of the casing string should be analyzed to determine if this is a problem.

Note: Rotating friction against the wall of the hole will tend to loosen and "back off" the casing collar connections if the casing is driven from the bottom. 
A related problem was the requirement to rotate the string at approximately 60 RPM due to the low torque output of the Glomar Challenger power sub at low speeds.

\section{Locking BHA Connections:}

A tendency for rotary-shouldered connections below the lowering sub to loosen and back off was foreseen due to vibration and irregular torque. To avoid using epoxy glue (Bakerlok) on the connections or tack welding the 4140 drill collars, a locking sleeve system was provided. The sleeve could not be installed on Leg 78A because their diameter was too small, and steel straps were tack welded across the drill collar connections. Observers agreed that the locking sleeve concept was unsatisfactory because: (1) redrilling recesses in the drill collars was too time-consuming and difficult, (2) sleeves would never fir properly due to differences in collar diameter from wear and fabrication specifications, and (3) the device would not be strong enough to resist torque sufficient to "break" a shouldered connection.

All indications are that the drill-in casing system would have been completely successful at site 542 , both in deployment and in isolating the unstable zone for further drilling, had the release failure not occurred. The high torque and low rate of penetration in soft sediments penetrated, leave serious doubts as to the feasibility of penetrating igneous or even indurated sedimentary rock with the system.

Foss/Storms 


\section{Cost Projection}

August 1985

I. DSDP SINGLE BIT TOP DRIVE SYSTEM
A. Inspect DSDP Hardware $(\mathrm{Q} / \mathrm{C})$
B. Review Machine Drawings/Concept Design
$\$ 25,000.00$
$(2 / \mathrm{mm})$
C. Recommend and Provide Design Changes
$\$ 25,000.00$
$(2 / \mathrm{mm})$
D. Modify Existing Set of DIC Hardware
E. Fabricate Second System
$\$ 15,000.00$
$\$ 40,000.00$
F. Conduct Torque/Disengagement Testing
$\$ 15,000.00$

SUB TOTAL

$\overline{\$ 120,000.00}$

II. ODP SINGLE BIT BOTTOM DRIVE PDM SYSTEM
A. Program Development and Preliminary
Design/Feasibility Analysis
$\$ 15,000.00$
B. Detailed Engineering Design
Analytical Design
Machine Drawing Preparation
$\$ 30,000.00$
C. Fabricate 2 Prototypes
(Includes 2 Casing Bits @ 20K each
and 2 Latch Systems @ 10K each)
D. Refurbish Leased ND 9-1/2" Mud Motor
$\$ 100,000.00$
E. Limited Assembly/Actuation/Torque Testing
$\$ 40,000.00$
$\$ 15,000.00$
SUB TOTAL
$\overline{\$ 200,000.00}$

III. ODP MULTIPLE BIT BOTTOM DRIVE PDM SYSTEM

A. Engineer Design/Modification to adapt II above to ODP RE Cone/Liner Hanger compatible system. (Includes Machine Drawings)

$\$ 20,000.00$

B. Fabricate 2 Liner Hangers @ 10K each

$\$ 20,000.00$

C. Assembly/Actuation Tests

$\$ 5,000.00$

SUB TOTAL

$\overline{\$ 45,000.00}$

GRAND TOTAL

$\$ 365,000.00$ 


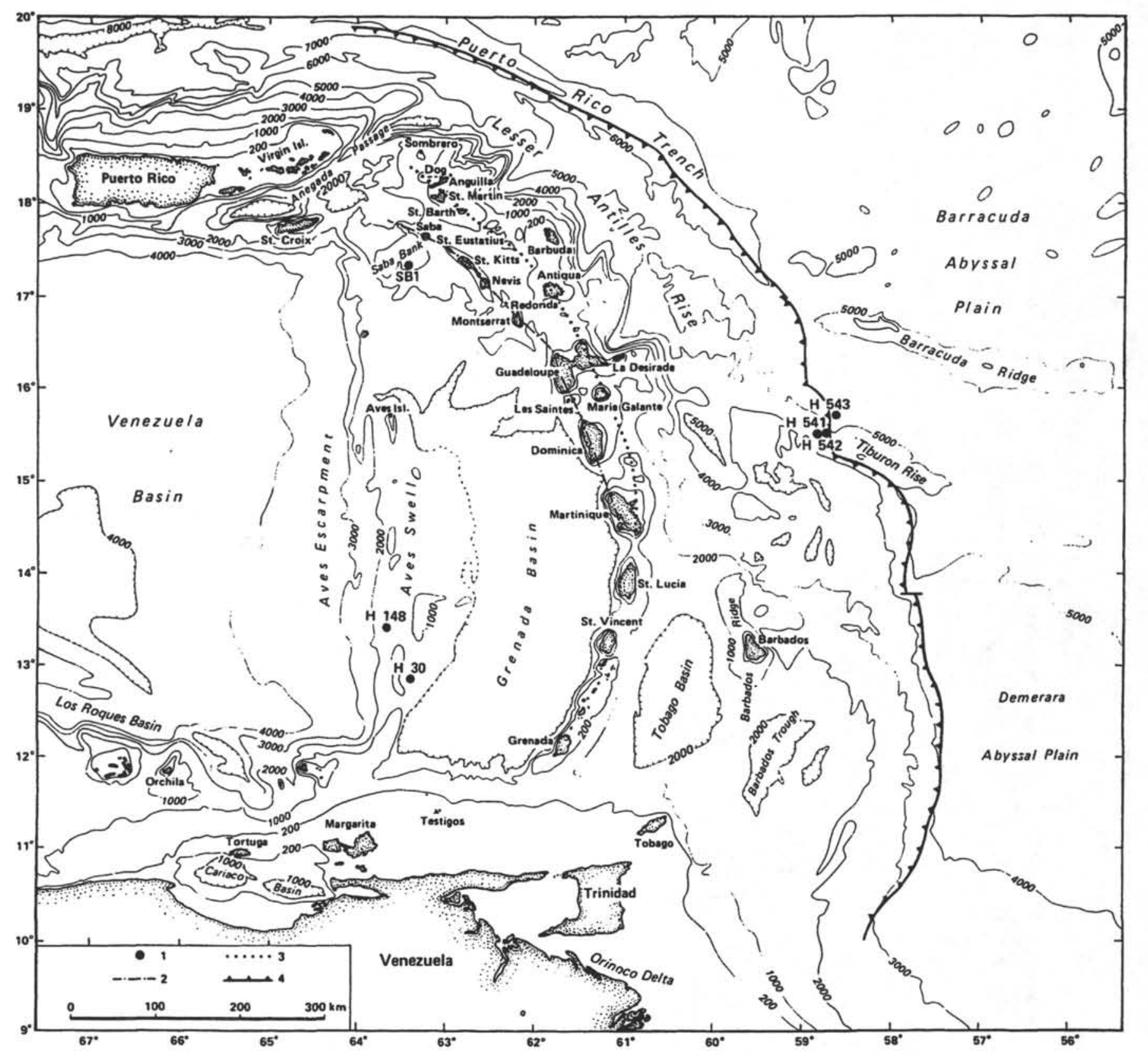

Figure 1.

DSDP Leg 78A

Barbados Ridge Complex 


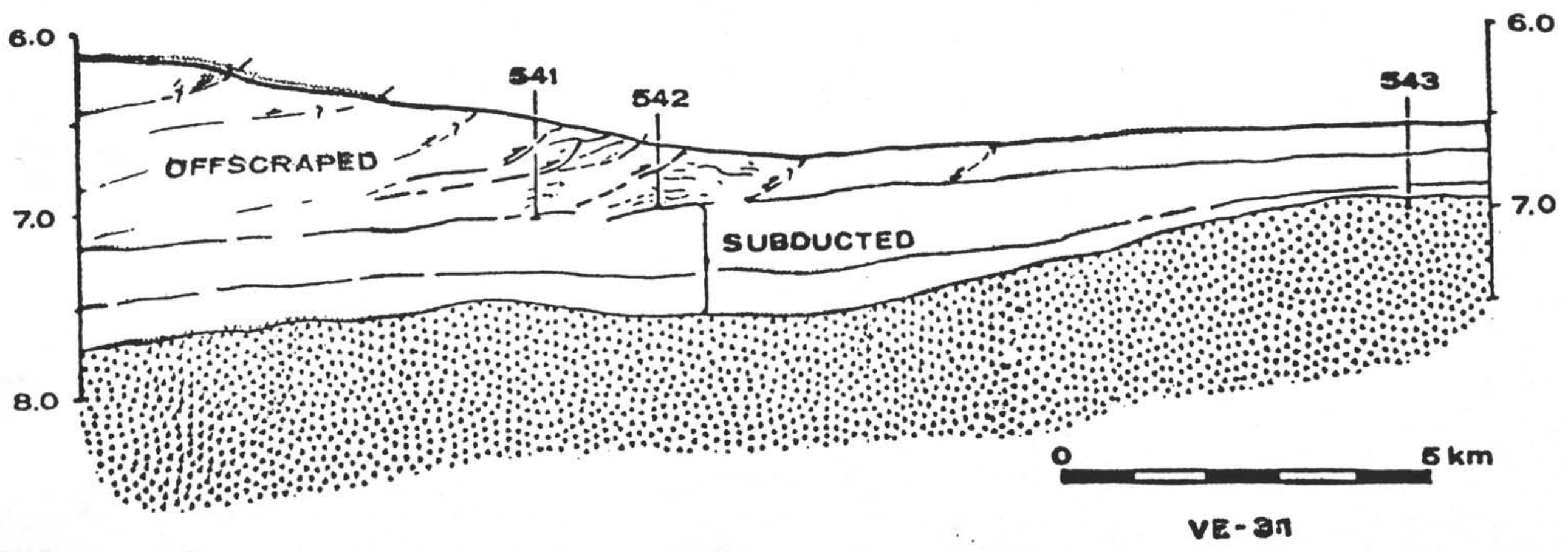

FIGURE 2

DSDP LEG 78A

BARBADOS RIDGE COMPLEX 
$\begin{array}{lll}\text { Site } 541 & \text { Site } 542 & \text { Site } 543\end{array}$

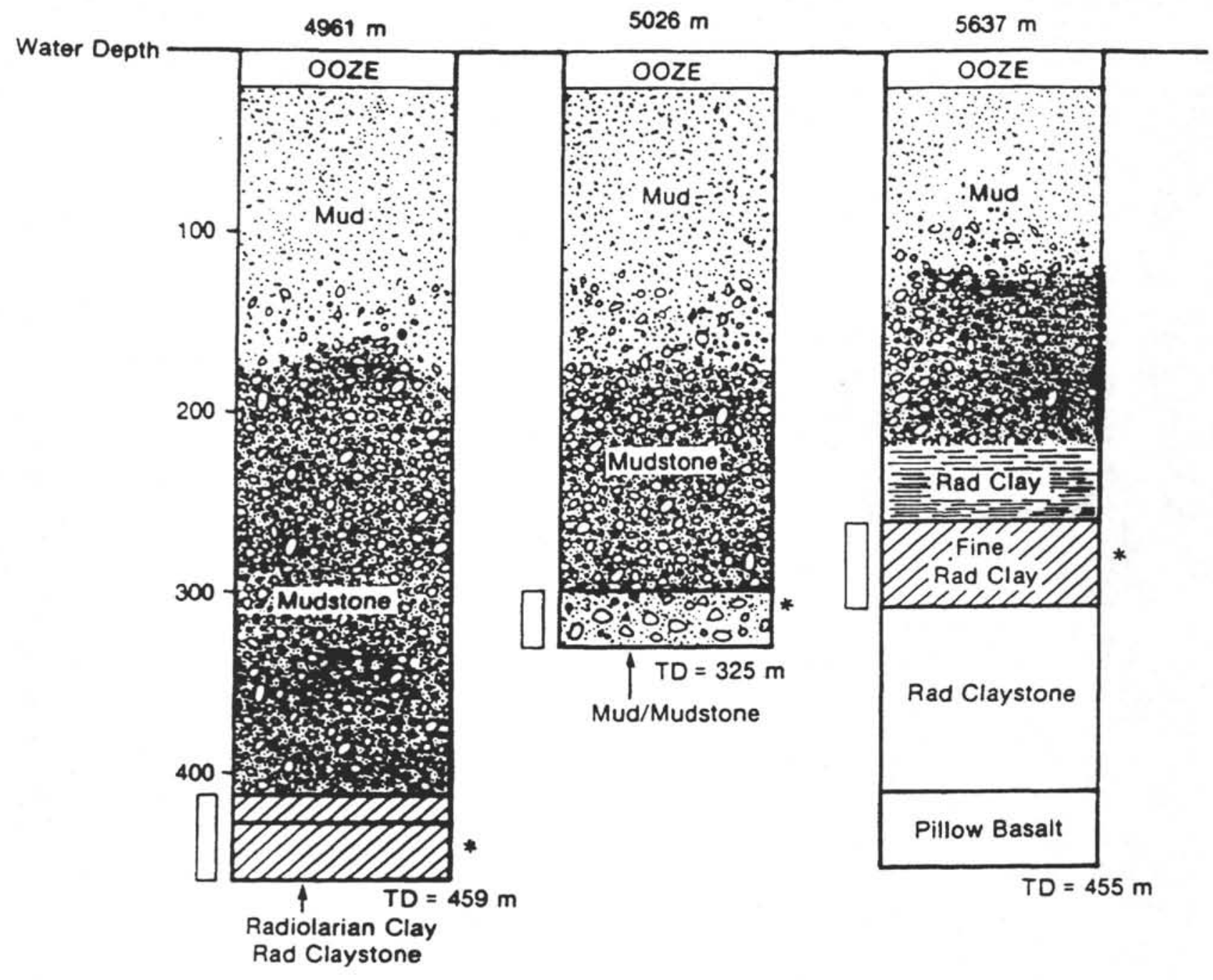

$\begin{aligned} \text {-Problem Zone - } & \text { High Pump Pressure, Low Core Recovery. } \\ & \text { Pipe Sticking, and High Drill String Torque. } \\ & \text { Hole Cavings }\end{aligned}$

FIGURE 3

DSDP LEG 78A

BARBADOS RIDGE COMPLEX

LITHOLOGY 

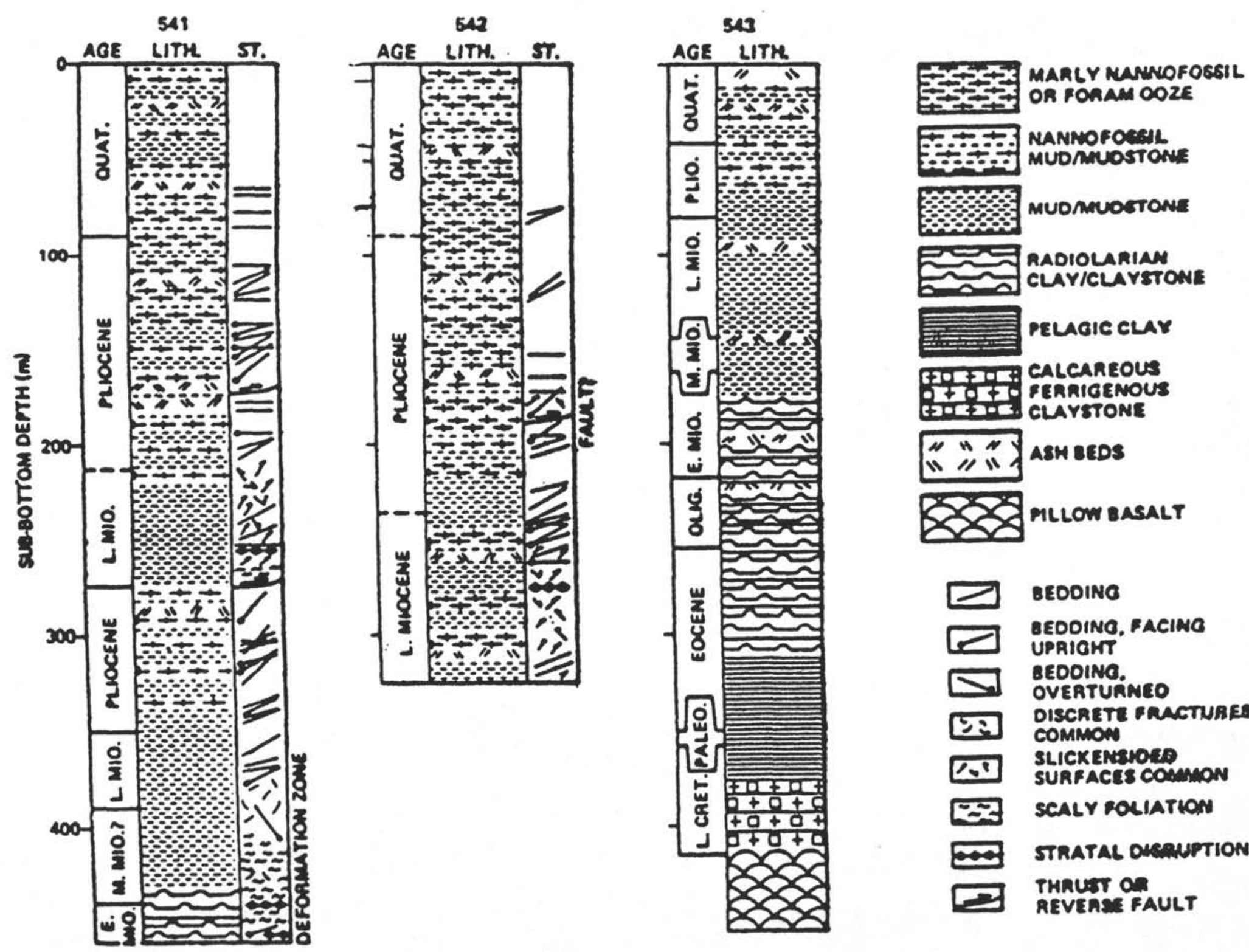
$x-7$ OR FOANM 002

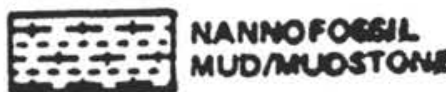

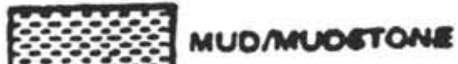
르 RADIOLARINA 들 CLAYICLAVETONE

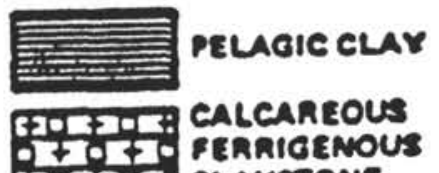
COLED CLAYSTONE

\section{N $\mathrm{N} N$ N 11 N1 AsH EEDS 358 MLLOW BASALT}

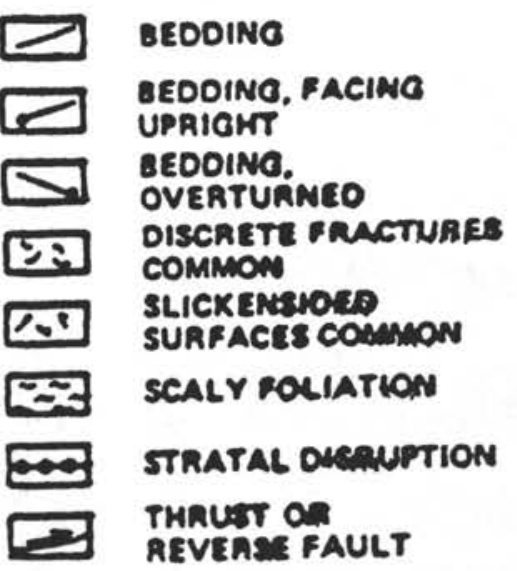

FIGURE 4

DSDP LEG 78A

BARBADOS RIDGE COMPLEX

LITHOSTRATIGRAPHY \& STRUCIURAL GEOLOGY 


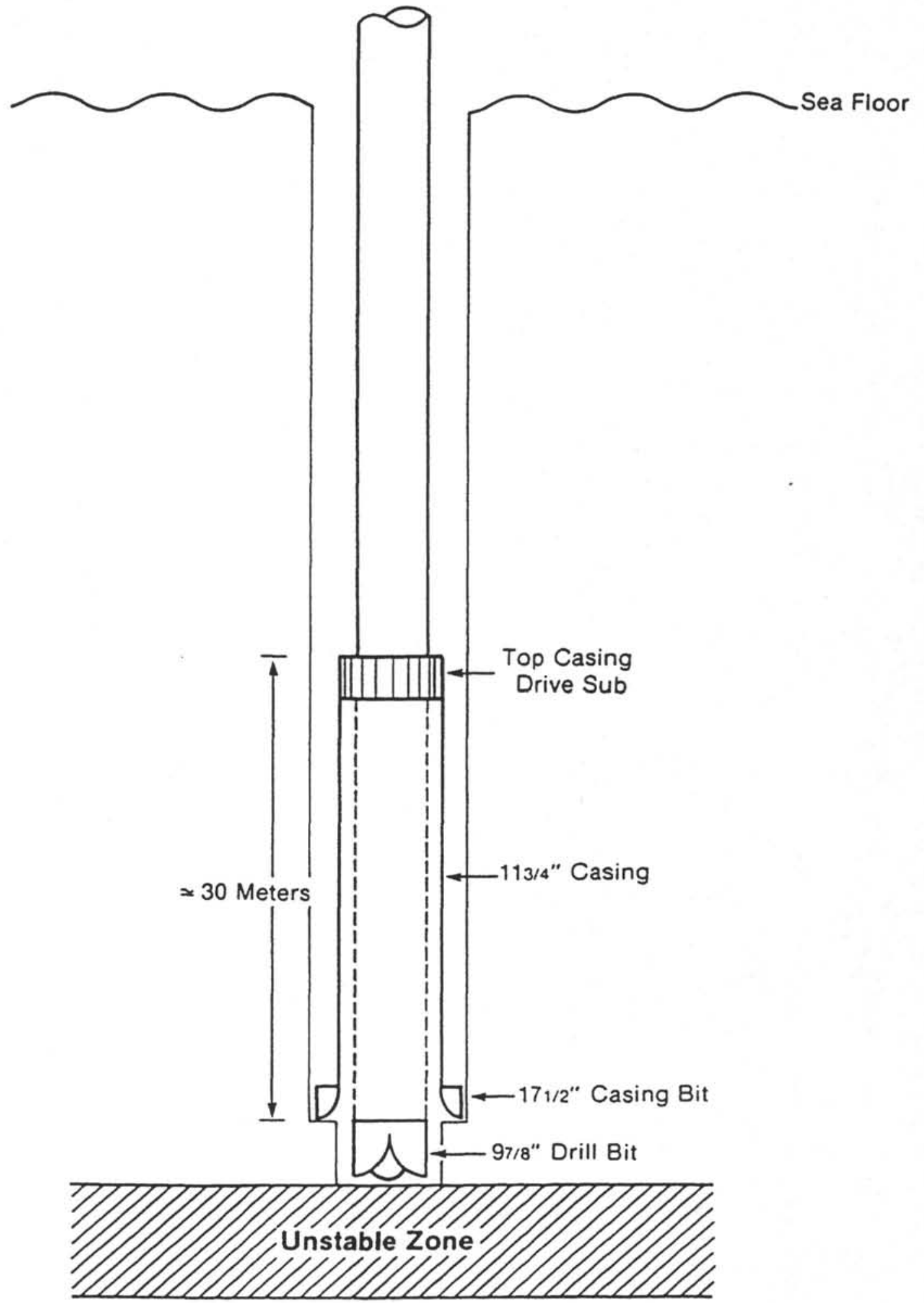

FIGURE 5

DSDP 'TOP DRIVE' SINGLE BIT

DRILL-IN-CASING SYSTEM 


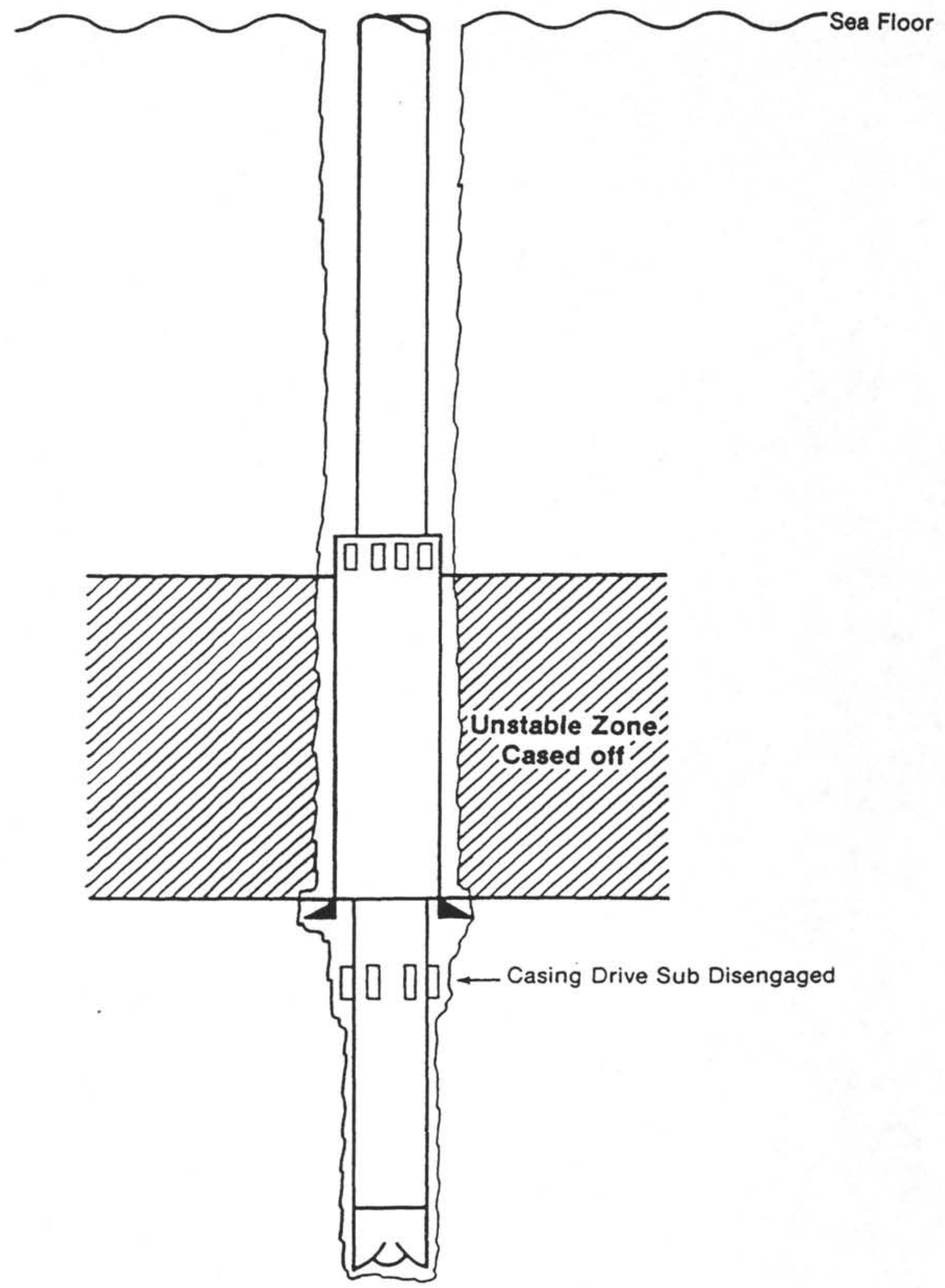

FIGURE 6

DSDP DRILL-IN-CASING SYSTEM

DRILLING/CORE AHEAD 


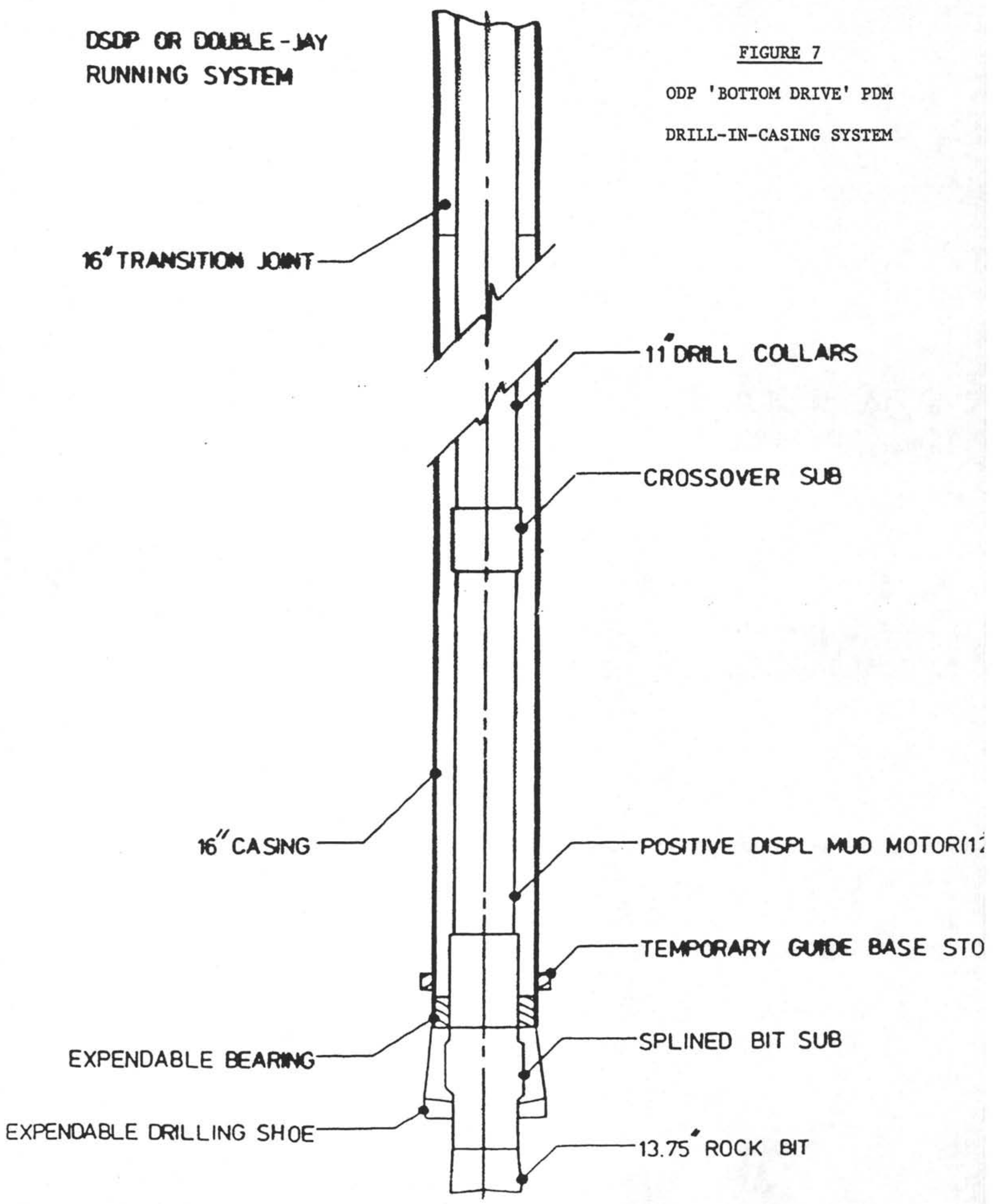




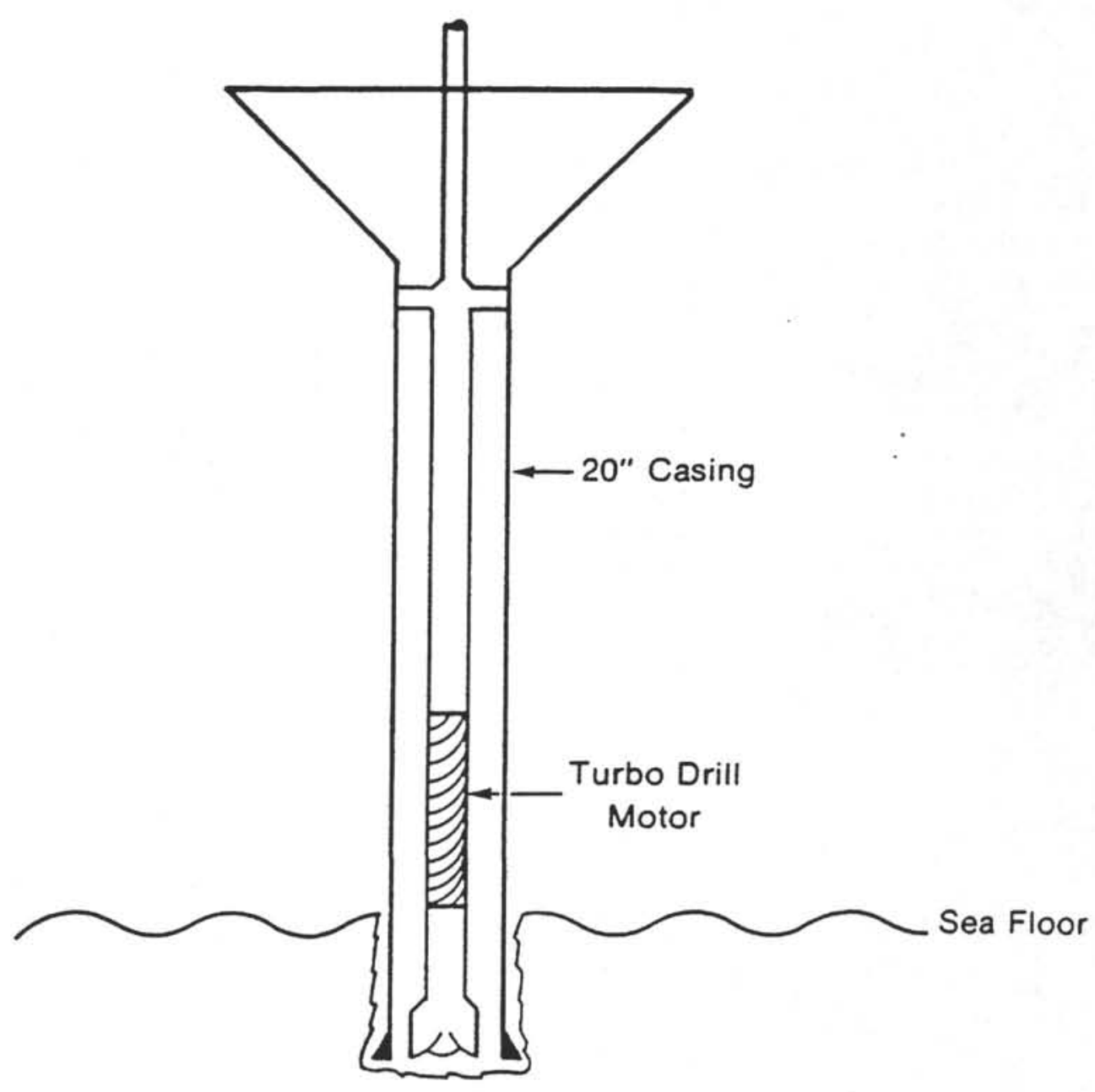

1. Jet/Drill in 20" Casing and Reentry Cone

2. J-Out Running Tool. Drill Ahead for 16" Casing.

FIGURE 8

ODP 'MULTIPLE BIT' PDM

DRILL-IN-CASING SYSTEM

JETTING IN 20" CASING 


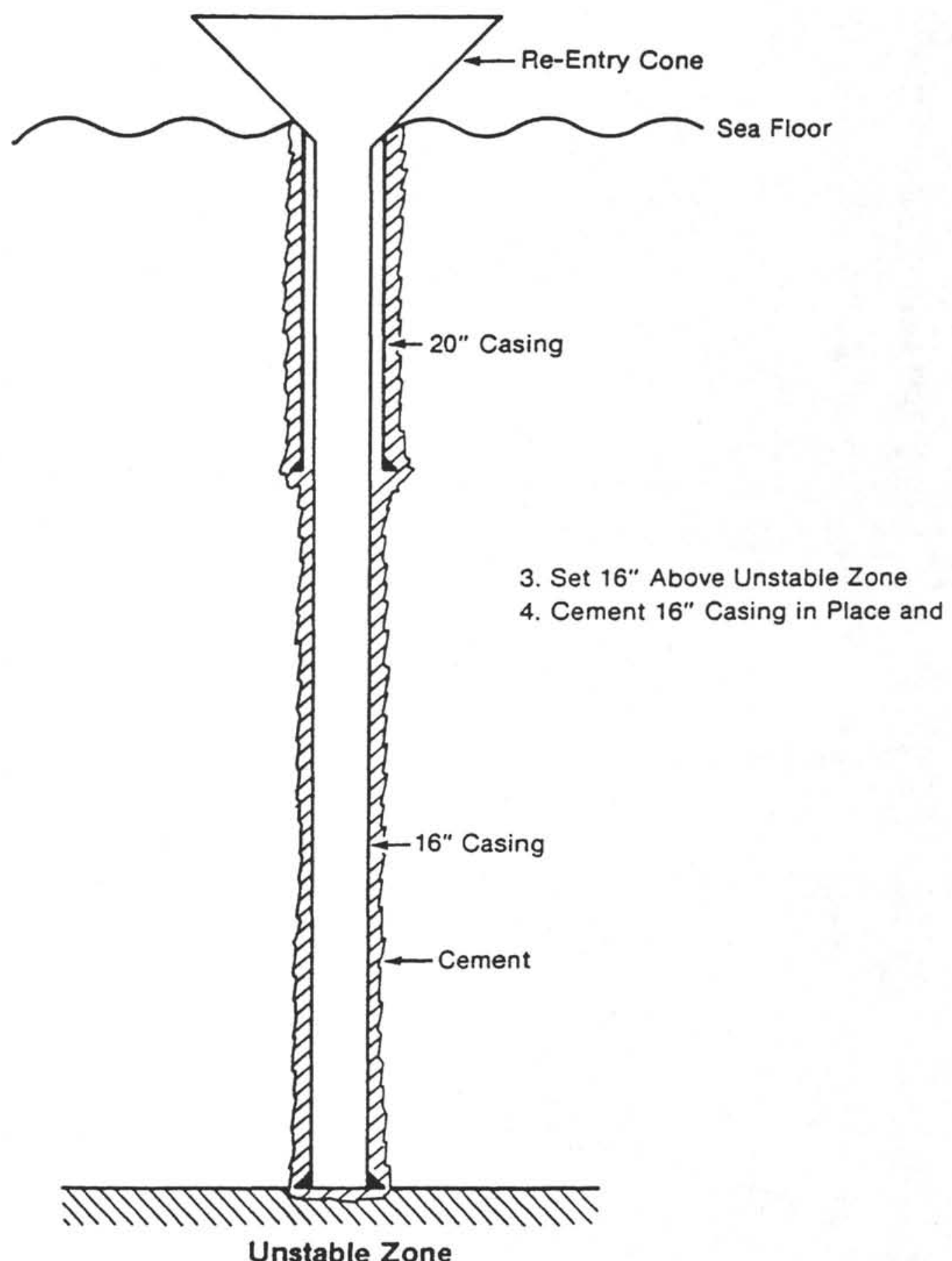

FIGURE 9

ODP 'MULTIPLE BIT' PDM

DRILL-IN-CASING SYSTEM

SETTING \& CEMENTING $16^{\prime \prime}$ CASING 


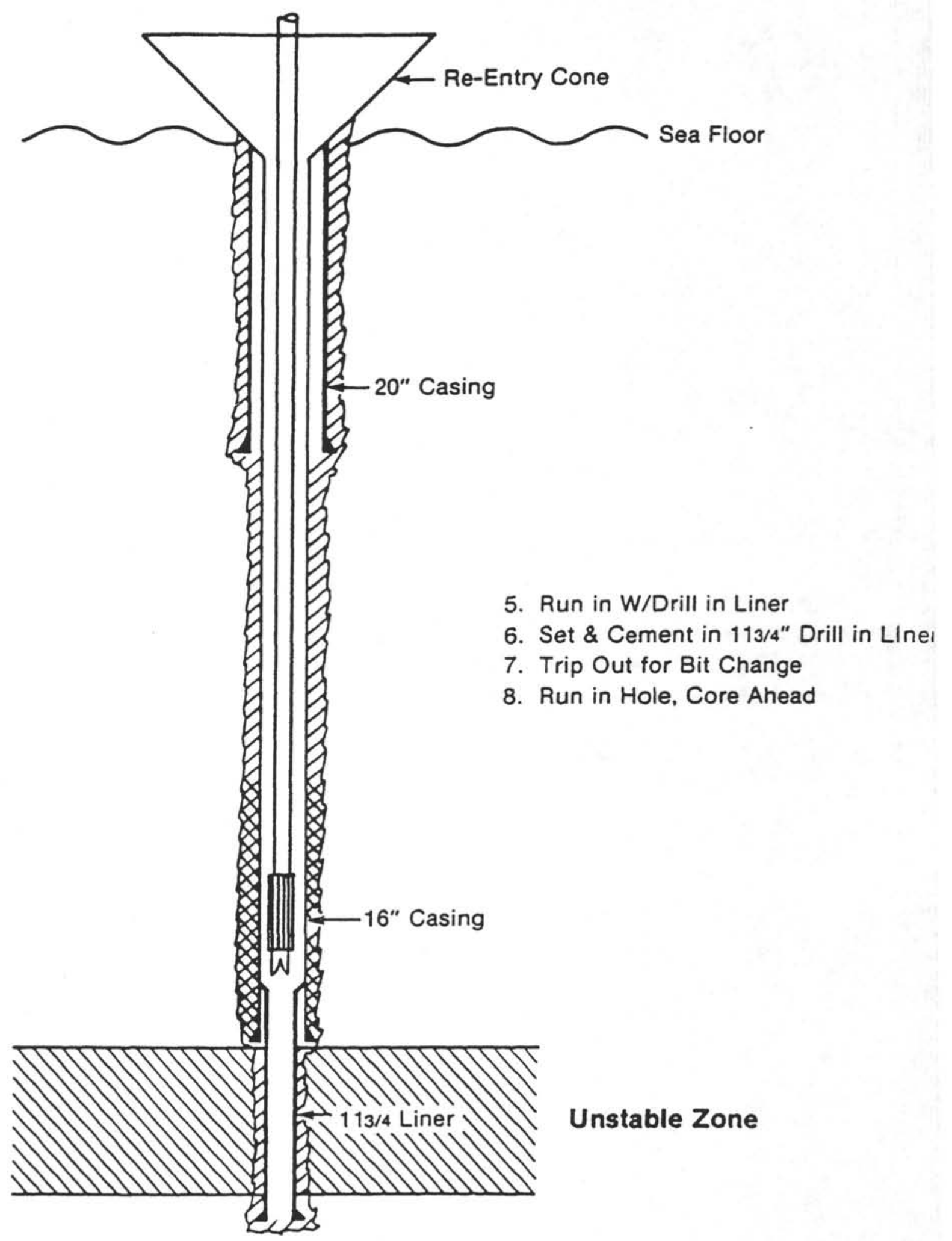


Appendix D

Review of DIC System 
I..NRRY RISSEILL \& ASSO(:IATI:S

COZS EDGEMOOR. SUITE $C$

HOUSTON. TEXAS 77001

(713) 604.5385

(713) 771.0519

March 16,1986

REVIEN OP DRILI-IN CASING SYSTEM

\section{SUMYARY:}

The system, as built, is susceptible to jaming from burrs formed during rough driliing. Fairly simple, inexpensive modifications will suffice to upgrade the system reliability. These modifications are discussed below and indicated on the enclosed drawings.

\section{CONCLOSIONS:}

1. The lower dogs appear somewhat weak. Slightly more hardness and centralization of the string in the lowering assembly (using the lower dog's OD) will help.

2. Provision of small reliefs for burrs will help aid shifting and release. Sleeve clearances should be opened up.

3. Excessive vertical play should be eliminated on the dogs, windows, and latch recesses.

4. Eanging only on the lower dogs permits bouncing loose and forcing the dogs in, over-riding burrs. This also is a simpler, more direct system.

5. Lower dog retraction springs should be independent to ensure balanced retraction.

6. Use of multiple dog bearing faces mating with.multiple grooves alleviates burring due to excessive bearing loads.

7. Paint "RETRACT OPPER DOG SCREWS" all over the tool. Use only specifically trained personnel. Ensure there is a check-off list including retracting screws.

8. Shifting sleeve drag may be excessive. Eliminate metal scraper ring. Use of a wider inside face on the Snap Ring may be needed to protect the 0-Rings on the sleeve.

9. The existing sleeve can relatch the lower dogs if permitted to overtravel by omission of the toggling nose in the first joint above the tool. Ensure this is mentioned in the check-off list.

10. The inner drive flats on the drive bushing are marginal for rough drilling. Doubling their area will avold burr problems. 
Reriey of Drild-in casing System

March 16,1986

Page 2

\section{REHORR:}

The existing hardware can be reworked with most machine work confined to the dog sets. The dogs should be made to conform to the windows now existing. Future parts should be made as shown

in the drawings.

Specific parts requiring rework or remanufacture are: $0 \mathrm{~J} 4801$, 0J4802, 0J4803, 0J4804, 0J4805, 0J4806, 0J4807, 0J4808, $0 \mathrm{~J} 4809$, and $0 \mathrm{~J} 4813$.

\section{DISCOSSION:}

While open operating clearances are desirable, excessive clearances lead to peening, burr formation, cracking, and other problems when shock loadings are present. Given the severe drilling conditions on the unsuccessful run of this tool, along with its excessive clearances, fallure likely was due to sleeve burring. The conclusions above are based on simple stress checks and the desirability of avoiding possible problems.

The existing lower dogs $0 J 4805$ are susceptible to overstress when bending, shock loads, and transverse shifts occur simultaneously in rough drilling. Remaking the dogs to: a) better fit the windows, b) obtain retractive effort on both sides, and c) be harder and have more contact area will enhance the tool. Rather than remaking the drive adapter $0 J 4804$, it can be sleeved to botb closely centralize the lower dogs and give a double bearing surface.

The sleeve 0J4806 needs more clearance, Polypak seal replacement for O-RIngs, and slight oD relief under the dogs to accommodate burrs. The combination lowering/driving sub oJ4803 should have its junk ring $0 J 4815$ replaced with an appropriate (cut) $0-$ Ring.

The upper dogs $0 J 4807$ should have their bearing faces faced off to avoid supporting the whole assembly on the upper dogs, rather than the lower dogs. A simple, single support system is amenable to use of pipe manipulation to aid shifting the lower (release) dogs. The result should be improved reliability.

The drive flats in the drive bushing $0 \mathrm{~J} 4802$ need to be bigger. The existing flats should be supplemented with add-in pieces to achieve approximately twice the bearing area in order to avoid severe burring. 
Appendix E

DIC Computer Stress and Fatigue Analyses 


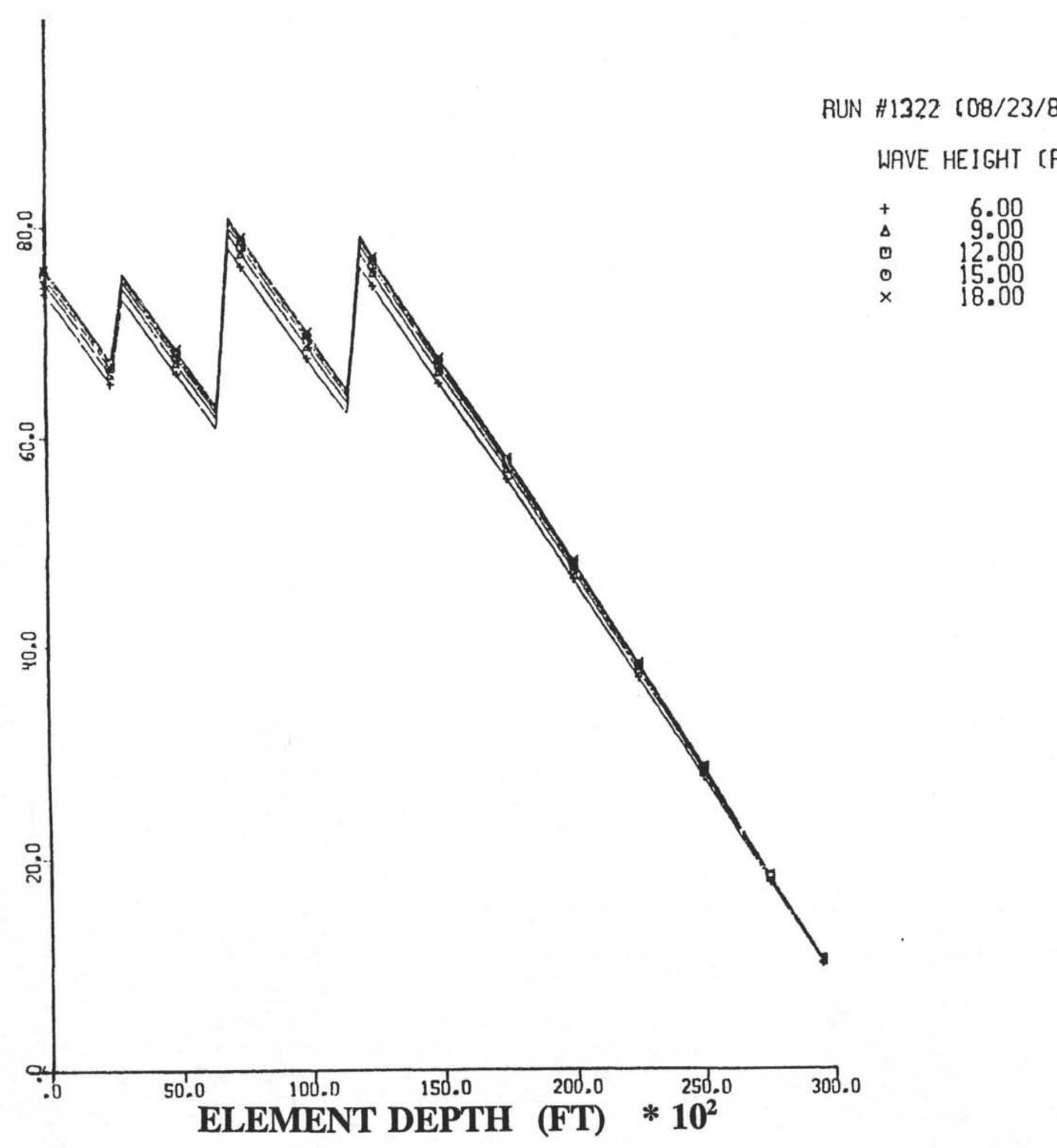




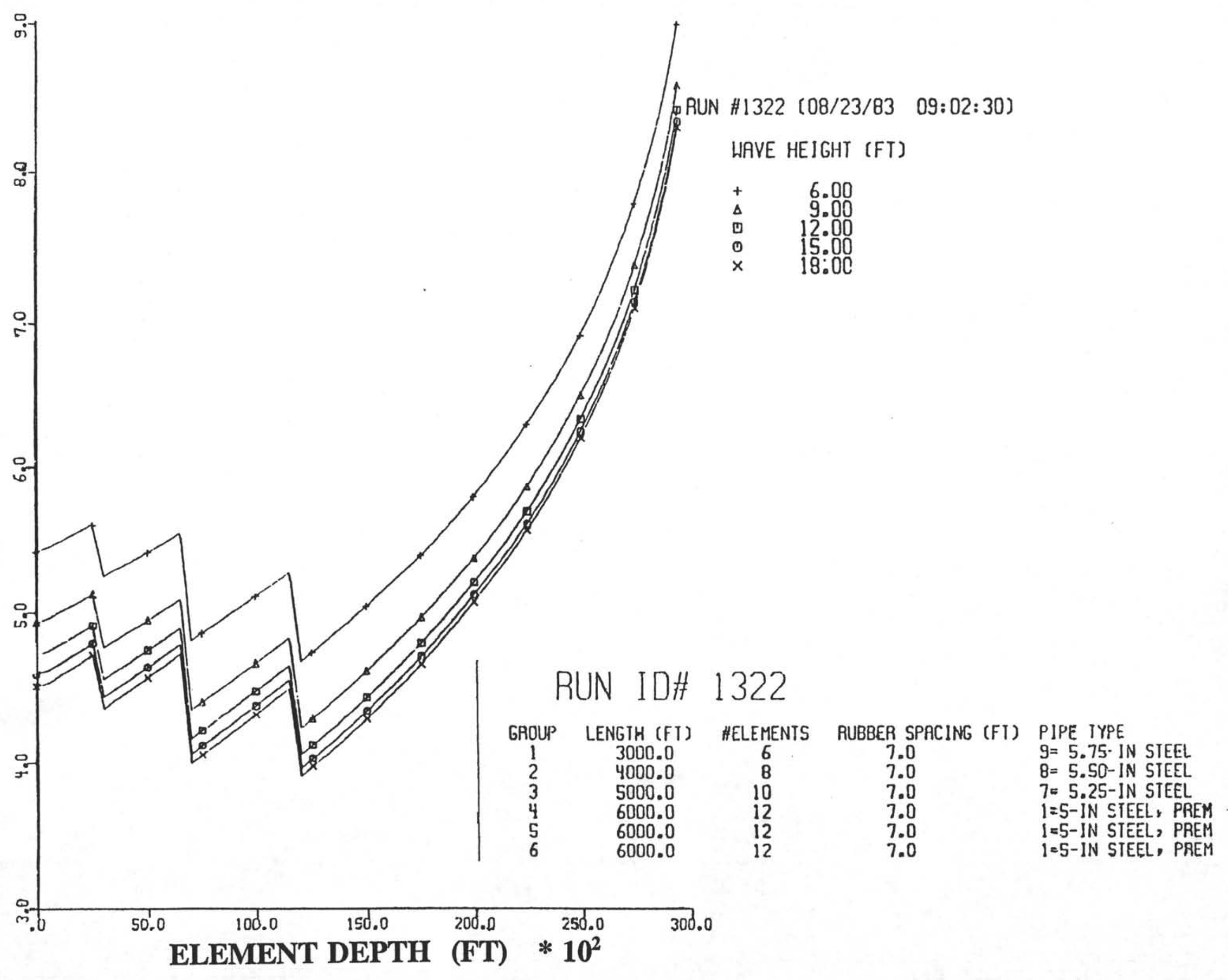




\begin{tabular}{|c|c|c|c|c|}
\hline $\begin{array}{l}\text { GROUP } \\
1 \\
2 \\
3 \\
4 \\
5 \\
6\end{array}$ & $\begin{array}{c}\text { LENGTH (FT) } \\
3000.0 \\
4000.0 \\
5000.0 \\
6000.0 \\
6000.0 \\
6000.0\end{array}$ & $\begin{array}{l}\text { \#ELEMENTS } \\
6 \\
8 \\
10 \\
12 \\
12 \\
12\end{array}$ & $\begin{array}{c}\text { RUBBEER SPACING (FT) } \\
7.0 \\
7.0 \\
7.0 \\
7.0 \\
7.0 \\
7.0\end{array}$ & $\begin{array}{l}\text { PIPE TYPE } \\
9=5.75-\text { IN STEEL. } \\
8=5.50-\text { IN STEEL } \\
7=5.25-\text { IN STEEL } \\
1=5-\text { IN STEEL, PREM } \\
1=5-\text { IN STEEL, PREM } \\
1=5-\text { IN STEEL, PREM }\end{array}$ \\
\hline
\end{tabular}

H.C. TYPE $=$ NONE

BOT ASSY DIAM $=0.867$

INPUT TYPE $=$ RANDOM SEA

HYDRO DRMPG $=$ VELOCITY DEPENDENT

H.C. SPRING RATE $=0.005$

HYDRO DAMP IN HOLE $=0$

ADDED MASS FACTOR FOH JDINTS $=1.41=$

X-AXIS: ELEMENT DEPTH (FT) FROM 0.00 TO $0.00 \mathrm{BY} \quad 0.00$
BOT ASSY $W T=40000$ INPUT LOCTN $=$ TO SHIP

\# INT STEPS $=40$

PIERSON/MOSKOWITZ.

BOI-GRND SFRING RFITE = C

ADDED BOTTOM MASS $=0$

$=0$

$15.00 \quad 18.00$

PLOT \# 1: AMPLITUDE (FT) [1]

$\begin{array}{lll}6.00 & 9.00 \quad 12.00\end{array}$

PLOT \# 2: VELOCITY (FT/SEC) [2]

PLOT \# 3: DYNAIIIC STRESS (LS/SOIN) [3]

PLOT \# 4: FATIGUE LIFE (LOG HAS) (4)

PLOT \# 5* TOTAL STRESS (LB/SOIN) [5] 
Appendix F

\section{Leg 131 Engineering Report}




\section{LEG 131 ENGINEERING REPORT}

The Drill-In-Casing (DIC) system was deployed in Hole 808C. Since the DIC sub drive assembly had been on board since Leg 110 , it was disassembled for inspection and found to be in good condition. The bore through the DIC drive bushing was increased to 8-3/4" diameter (from 8-1/2") to allow clearance for the 8-1/2" O.D. Hydrolex jar. During reassembly, the release sleeve could not be shifted through the snap ring. The snap ring had been displaced to one side, causing the release sleeve to land on the ring without centralizing it. The drive sub was disassembled, and the release sleeve was modified by adding a longer taper to the top. The shoulder of the release position snap ring was also tapered to help centralize the snap ring during installation. During reassembly, minor problems occurred in attempting to shift the release sleeve through the snap ring.

Approximately $83 \mathrm{~m}$ of $11-3 / 4 "$ casing was made up and hung off in the moon pool. The casing collars were welded top and bottom. One meter of casing was cut off the shoe joint and the DIC space out collar was welded on to obtain the correct BHA space-out. The high current (2-3 knots) caused considerable difficulty in making up the casing. The first attempt at lowering the casing in the moon pool with the DIC drive sub assembly had to be abandoned when the casing could not be backed off due to the current. The previously cutoff portion of the casing was rigged with shackles and slings and used to lower the casing into the moon pool.

The BHA (bit, MBR, RCB assembly, 8 - 8-1/4" drill collars, DIC drive sub assembly, head sub, 1 - 8-1/4" drill collar, drilling jar, 2 - 8-1/4" drill collars, 1 - 7-1/4" drill collar, and 5 joints 5-1/2" drill pipe) was made up and lowered through the casing. The BHA was strap welded at the connections to prevent back-off during anticipated torque release by the casing bit. The BHA had to be spudded through the casing due to the current. The casing string was made up to the DIC drive sub assembly in the moon pool using a chain tong for backup and the rig tongs for torquing. The entire assembly was then lowered to the seafloor.

The assembly was jetted-in $14 \mathrm{mbsf}$ before rotation began. Drilling-in went smoothly with little torque variance. Once the neutral point at the DIC drive sub assembly was found, the release sleeve was shifted without incident using the rotary shifting tool. The casing string was left straddling the interval from 19 - 105 mbsf. The casing shoe (17-1/2" bit) was at $4,790.4 \mathrm{~m}$. The hole was drilled to $4,984 \mathrm{~m}$ and normal RCB operations were begun. 
Appendix G

Recommended DIC Modifications 
TO: Glen/Bill/Tim

FM: Tom

REF: DIC MODS

AA. Additions - deletions - comments?

BB. I will have to lengthen the overall assembly 2-3 $\mathrm{ft}$ to make the recommended modifications, any problems with that?

\section{RECOMMENDED DIC MODIFICATIONS}

1. Make Drive Adapter OJ4803 pin down (eliminate having to cut Baker-Loked collar off casing joint).

1a. Provide thread protector for drive adapter thread.

2. Change drive bushing OJ4802 sub assembly to latch onto casing drive head OJ4801 upon release.

2a. Add slot to casing drive head OJ4801 for upper dogs OJ4807 to latch into when released.

2b. Increase ID through drive bushing OJ4802 so lowering/drive sub OJ4803 can pass through during trip out (leave drive bushing in hole).

2c. Redesign drive bushing inner trash barrier seal OD3352 for new design.

3. Provide for better centralization of snap ring OJ4814 during installation of release sleeve OJ4806.

3a. Add better lead-in taper to top of release sleeve OJ4806 (help centralize snap ring during installation of release sleeve).

3b. Space out lower dogs $\mathrm{OJ} 4805$ to incorporate a lead-in taper (for snap ring centralization) to top of lower dog release groove on release sleeve OJ4806.

4. Add blind taped holes for lifting eyes to top of drive bushing $\mathrm{OJ} 4802$.

5. Provide casing running tool (Used $1 \mathrm{~m}$ cut off with shackles and slings).

6. Make lower dogs OJ4805 interchangeable.

7. Explore possibility of "latching-in" an FFF.

8. Lengthen overall assembly $2-3 \mathrm{ft}$. 
Appendix H

Drill-In Data for Leg 131, Hole 808C and Suggestions 
TO: Grout/Storms/Huey

FROM: $\quad$ Foss/Tom P/Matsuoka

The following thoughts and suggestions are offered for the DIC file before recollections of the deployment cool:

1. Several hardware modifications are under consideration, primarily for ease of assembly. Tom $\mathbf{P}$ will carry details.

2. Recommend changing drive adapter OJ4808 from box-down to pin-down configuration. This may be against oilfield convention for running tools, but this one is only used once. Removing a Baker-Loked 11-3/4" casing collar on rig time just isn't productive.

3. Is there a design limitation on length of casing string to be run? If so, what are the limiting factors? Seems to me that the manual on the old system mentioned a length.

4. Step 5 of deployment sequence is omitted from all copies of the manual on board. We obviously got past it, be we wonder what it was.

5. Step 1 is vague about how the casing gets landed in the moonpool with the casing collar already removed. I had assumed we would use the slings and either the casing elevators or the clamp used on reentry casing strings. The clamp is not suitable because its diameter is for $16^{\prime \prime}$ casing or 11-3/4" casing hanger. Elevators are very awkward as the outer ring of the rotary must be pulled -- also, Sedco has not maintained slings for landing $16^{\prime \prime}$ casing because they prefer to land it with the running tool. We tried to land the casing with the drive sub. It probably would have worked under normal conditions, but the current forced it to such an angle that we couldn't back off the threads after landing. We finally took the one-meter casing pup that had been cut off to space out, turn it upside down, cut holes in the sides, and made it up to the up-looking pin. We then put shackles in the holes and used the slings that are normally used with the UGH. This will work if casing strings don't get too long/heavy.

6. We also found that it isn't necessary to bring the lowering sub back up to the floor for final tightening. A set of mega-chain tongs against the mousehole served as backup while the drill collar was turned with rig tongs at the floor. The connections was then tack-welded as were all the casing collars (top \& bottom) and casing bit.

7. We tack-strapped all BHA connections below the drive sub, but Sedco questioned it. They pointed out that they've disconnected strapping because the straps have caused too many problems by coming off in the hole. I wasn't confident that we could ever 
get epoxied drill collar connections apart again -- at least without heat damage. Would like to see the whole back-torque concern have another engineering review.

8. Drilling-in went extremely well. Except for slightly high torque and low ROP, there was no indication that the casing was even there. There is in contrast to the bad torquing experienced on Leg 78A, but we didn't take the casing to over $300 \mathrm{~m}$ either. Though the upper casing joint had a visible bend from the force of the current when it was deployed, the bend was not severe enough to cause extra torquing or other problems when it was drilled in. Recommend the use of both pumps for high circulation rate when drilling in (hole erosion is not a concern at this point). Torque began to build once, but drillers stopped penetration to circulate and clear the annulus before proceeding. It worked.

9. Infer that the core bit is spaced out ahead of the casing bit to provide a pilot. We spaced out the difference to $18 \mathrm{"}$. Concerned that too much separation might result in poor hydraulics around the casing bit cones. We jetted to $14 \mathrm{~m}$ prior to rotation per instructions, but not sure there's any advantage to it. A plugged jet could cause a kickedoff spud with no rotation. A rotating spud should not endanger the BHA as the casing collar is quite stiff.

10. If the casing is drilled across a really "bad" zone, it may well become stuck as soon as the pump stops ( as on 78A). That does not give the luxury of pulling up to break the pipe and put in the shifting tool as we were able to do. One more reason to have the oilsaver ball latch body opened up to full bore. Everything could then be inserted from above and the blocks would not have to be raised after the casing reached its proper position. (We considered putting the tool in the last connection, closing the BOP rams and following it down with the coring winch. the thought of pumping $130 \mathrm{spm}$ past the tool scared us off.)

11. The shifting-toll release went $\mathrm{OK}$ after some breath-holding. The sleeve did not shift at the supposed neutral point or after some weight was picked up. When we slacked off an extra 2000-3000 lb over casing weight, it shifted and released. Explanation may be that some weight is supported by the core bit.

12. The floating bush arrangement at the top could use further scrutiny. Concerned that it restricts flow and hole-cleaning capability. It is also too large in diameter to pass an FFF and the UGH must be pulled before it is recovered through the moonpool. It is inevitable that someone will forget one of these considerations some time.

13. The next logical step would be to marry the DIC and FFF concepts and design a receptacle that would allow the FFF to fall and latch into place at the top of a DIC string that extended to the seafloor.

14. In view of our increased awareness of hole-cleaning and annular-velocity considerations, a close look should be taken at the advisability of setting a short DIC 
string hundreds of meters down the hole. The 17-1/2" hole above will take extremely high circulation rates or massive amounts of mud for hole cleaning.

15. Possibly the most practical use of the DIC would be to case the top $100 \mathrm{~m}$ or so of soft sediment, leaving the top of the casing 3-4 m above the sea floor. That would alleviate the problems of washed-out hole and difficulty getting cuttings away from the hole at the seafloor. Could be especially useful where deep single-bit penetrations are planned. Disadvantage would be that, as currently designed, FFF option would be ruled out.

Below are the drilling-in data as recorded by M. Pottier and H. Matsuoka:

\section{DRILL-IN CASING JOB}

Hole: $\quad 808 \mathrm{C}$

Mud Line: $\quad 4685.61 \mathrm{~m}$

Spud: $\quad$ 00:35 April 17, 1990

Weight of BHA: $\quad 52+16=68$ Kips (BHA Below Driving Sub + Casing)

\begin{tabular}{||c|c|c|c|c|c|c|c|c||}
\hline $\begin{array}{c}\text { M. } \\
\text { Depth }\end{array}$ & $\begin{array}{c}\text { S/B } \\
\text { Depth }\end{array}$ & $\begin{array}{c}\text { WOB } \\
\text { (Kips }\end{array}$ & $\begin{array}{c}\text { Wt. BSF } \\
(\mathrm{lbs})\end{array}$ & SPM & $\begin{array}{c}\text { Press. } \\
\text { (psi) }\end{array}$ & $\begin{array}{c}\text { Torque } \\
(\text { Amps })\end{array}$ & RPM & GPM \\
\hline \hline 4685.61 & $0-6$ & $0-4$ & 3200 & 60 & 500 & - & N/R & 300 \\
\hline & $7-11$ & $0-5$ & 6000 & 70 & 700 & - & N/R & 350 \\
\hline & $11-13$ & $0-5$ & 7000 & 74 & 700 & - & N/R & 370 \\
\hline & $13-15$ & $0-5$ & 8100 & 100 & 1400 & - & N/R & 500 \\
\hline & $15-18$ & $0-5$ & 9700 & 100 & 1400 & $300-350$ & 20 & 500 \\
\hline & $18-27$ & $0-5$ & 10000 & 100 & 1400 & $300-350$ & 25 & 500 \\
\hline & $27-31$ & $0-5$ & 14600 & 100 & 1450 & $250-300$ & 25 & 500 \\
\hline & $31-35$ & 5 & 19000 & 100 & 1450 & $250-300$ & 25 & 500 \\
\hline & $35-40$ & $5-8$ & 21600 & 100 & 1400 & $250-350$ & 25 & 500 \\
\hline 4730.34 & $40-44$ & $8-10$ & 23200 & 100 & 1400 & $250-325$ & 25 & 500 \\
\hline & $44-50$ & $8-10$ & 27000 & 120 & 1800 & $250-350$ & 35 & 600 \\
\hline & $50-55$ & $5-10$ & 30000 & 120 & 1800 & $250-375$ & 35 & 600 \\
\hline & $55-60$ & $7-10$ & 33000 & 120 & 1800 & $250-375$ & 35 & 600 \\
\hline & $60-64$ & $7-10$ & 35000 & 120 & 1800 & $250-375$ & 35 & 600 \\
\hline & $64-70$ & 10 & 38000 & 120 & 1800 & $250-375$ & 35 & 600 \\
\hline & $70-75$ & 10 & 40600 & 120 & 1800 & $250-375$ & 35 & 600 \\
\hline
\end{tabular}

Table cont'd on following page. 


\begin{tabular}{||c|c|c|c|c|c|c|c|c||}
\hline $\begin{array}{c}\text { M. } \\
\text { Depth }\end{array}$ & $\begin{array}{c}\text { S/B } \\
\text { Depth }\end{array}$ & $\begin{array}{c}\text { WOB } \\
\text { (Kips }\end{array}$ & $\begin{array}{c}\text { Wt. BSF } \\
(\mathrm{lbs})\end{array}$ & SPM & $\begin{array}{c}\text { Press. } \\
\text { (psi) }\end{array}$ & $\begin{array}{c}\text { Torque } \\
(\mathrm{Amps})\end{array}$ & RPM & GPM \\
\hline \hline 4730.34 & $75-80$ & 10 & 43000 & 120 & 1800 & $250-375$ & 40 & 600 \\
\hline & $80-82$ & 10 & 45000 & 130 & 2100 & $250-375$ & 40 & 650 \\
\hline 4768.99 & $82-84$ & 10 & 45000 & 130 & 2100 & $250-375$ & 42 & 650 \\
\hline & $84-90$ & 10 & 48000 & 130 & 2100 & $250-375$ & 40 & 650 \\
\hline & $90-93$ & $8-12$ & 49000 & 130 & 2100 & $250-375$ & 40 & 650 \\
\hline & $93-95$ & $10-12$ & 50000 & 130 & 2100 & $250-375$ & 40 & 650 \\
\hline & $95-100$ & $10-12$ & 50000 & 130 & 2100 & $250-375$ & 40 & 650 \\
\hline & $100-102$ & $10-12$ & 51000 & 130 & 2100 & $250-375$ & 40 & 650 \\
\hline & $102-$ & $10-12$ & 51000 & 100 & 1350 & $250-375$ & 40 & 500 \\
& 104.5 & & & & & & & \\
\hline & $104.5-$ & 10 & 51000 & 50 & 400 & $250-375$ & 40 & 250 \\
\hline
\end{tabular}

* (4 Minutes) Flush Hole Clean and Make Connection

** Wt. Indicator at $105 \mathrm{~m}$ in $530 \mathrm{Kips}$

\# Run release tool, set down $18 \mathrm{Kips}$ using compensator, shifted sleeve and released casing from BHA.

\# $\quad$ Picked up and $12000 \mathrm{lbs}$ lost turned string at $15 \mathrm{rpm}$ and had lost 70 Amps.

\# While running down with shifting tool. stopped rotary and pumped $30 \mathrm{spm}$. 
Appendix I

Excerpt from Leg 139 Operations Report 


\section{LEG 139 OPERATIONS REPORT, HOLE 856H}

Though the actual sticking mechanism in Hole $856 \mathrm{G}$ appeared to have been a "ratchet rock" at the bit, the flowing sand and sulfide debris from the uppermost few meters had posed a serious threat to successful deepening of the hole. The $65+\mathrm{m}$ thickness of massive sulfides was a major scientific find and a premium was placed on deeper penetration at or near the $856 \mathrm{G}$ location. The situation appeared to be appropriate for a short length of drill-in-casing (DIC) with a small reentry funnel attached to the top to provide the option of future reentries was appropriate. The hardware was on board for one such installation, and preparations were made quickly to deploy it.

The new BHA was spaced out and equipped with special DIC subs. A MBR was included to enable logging the hole without a round trip and drilling jars were included against the possibility of reoccurrence of BHA sticking. A single 12-meter joint of 11-3/4" casing was equipped with a special 20 " drilling shoe and attached to the lower BHA with the 9-7/8" bit and MBR protruding $1.25 \mathrm{~m}$ beyond the casing shoe. When the DIC/BHA had been assembled, the reentry funnel was attached in the moon pool area as the last step before lowering the drill string.

The VIT frame again was deployed to help in pinpointing a spud location near Hole $856 \mathrm{G}$. The underwater television proved to be useless for this purpose because light reflecting from the reentry funnel caused the iris of the camera lens to restrict and nothing could be seen beyond the funnel. The Mesotech sonar was invaluable, however, as the drill string did not reach the seafloor in the immediate vicinity of the previous drill hole. The sonar showed a higher bathymetric elevation nearby (which experimental moves demonstrated to be north). After tentative spud found the seafloor about $20 \mathrm{~m}$ too deep, the sonar was used to guide a move to higher ground to the north. Eventually the sulfide outcrop was crested on offsets 35 $\mathrm{m}$ north of those used for Hole $856 \mathrm{G}$, and Hole $856 \mathrm{H}$ was spudded at $3,434.5 \mathrm{~m}$, only one meter deeper than $856 \mathrm{G}$. Pump circulation jetted-in the bit approximately $2.5 \mathrm{~m}$. Again, motion compensation and circulation were maintained while the VIT was recovered and until rotation could begin. (That was made more interesting by large swells that produced heave to \pm four feet.

The drilling-in operation proceeded with a good ROP. That was well-received at first because there was concern that the hard sulfides below $5-6$ mbsf would be penetrated with great difficulty by the 20 " casing bit (considering the extremely limited BHA weight available. When high ROP continued until the casing shoe reached the release point of $12 \mathrm{mbsf}$ (bit at $13.5 \mathrm{~m})$, concern shifted to whether enough casing had been run to isolate all the loose pyrite debris. It took only 75 minutes to drill to the release point with very low bit weight and rpm. The RST was run, and the casing was released without incident. As the RST was being retrieved, the drill string became temporarily plugged off. (Circulation was regained after pressure was bled off at the standpipe bleeder valve, but the incident was not a good omen.) A second wireline trip was then made to recover core $1 R$, which contained about four meters of pyrite sand.

Core $2 \mathrm{R}$ encountered an additional five meters of easy drilling before the ROP decreased in 
harder material. The core barrel recovered about $40 \mathrm{~cm}$ of sulfide core and about four meters of fill accumulated in the hole during the wireline trip and connection. Hole-cleaning problems were reduced over the next few cores, as high-viscosity mud sweeps and high circulation rates were used to remove the heavy debris, and the section of the hole below the casing apparently stabilized. Drilling rate again increased below about 50 mbsf and hole problems returned, apparently as a second unstable zone was penetrated. Inability to keep the hole clean increased with depth despite all measures, including the use of both mud pumps up to $1,000 \mathrm{gpm}$ and sweeps of up to $50 \mathrm{bbl}$ of ultra-high-viscosity mud.

During the retrieval of core $17 \mathrm{R}$ from $93.8 \mathrm{mbsf}$, the pipe became stuck vertically, though rotation and circulation were maintained. After two hours were required to work the drill string free, efforts to deepen the hole further were abandoned.

A logging run with the JAPEX "PTF" logging tool was then requested. Because the tool was small in diameter, it did not require release of the core bit. A modified inner core barrel assembly was rigged to help the very light logging tool down the drill string and to hold the float valve open at the bit so that the tool could be retrieved back into the pipe. About two hours were lost when a 4 " landing shoulder on the core barrel assembly became wedged in the 4 " i.d. of the circulating head. Results of the PTF log showed that seawater was flowing down the hole and into the formation and were generally of such interest that additional (full diameter) logs were then requested. That added requirements for release of the bit and a reentry. The VIT was refitted with a large-diameter sleeve so it would pass over the DIC bushing on the BHA while the special "logging" inner core barrel was reconfigured for running the RST to release the bit. A malfunction of the Mesotech sonar tool cost about an hour while the VIT was recovered and the transducer head was replaced.

The core bit was then pulled clear of the reentry funnel, the rig was offset $20 \mathrm{~m}$, and a wireline trip was made to release the bit. During the release operation, the VIT was started down the exterior of the drill string. When the RST had been recovered, preparations began for Schlumberger logging. The VIT arrived at seafloor depth before assembly of the logging tools began, so a seafloor sonar/TV survey was conducted at no cost in operating time. Ample time for the survey was provided when about two extra hours were required to replace worn and broken caliper springs on the logging tool.

The funnel was reentered while the first logging tool was being lowered down the drill string, so no operating time was spent on reentry. The initial log (induction/sonic) came to rest on hole fill at 70 mbsf, indicating that material was continuing to flow in from the borehole walls. Following a successful run, geochemistry and FMS logs also were recorded with good results. The logging sheaves then were rigged down for the pipe trip.

Repairs to the piperacker delayed the pipe trip 3/4 hour. When the drill string had been recovered to the BHA, the positioning beacon was acoustically switched to standby status, and offsetting in DP mode to the next site began. At 1845 on $26 \mathrm{July}$, after a move of 1.3 n.m., a new beacon was launched at prospectus site MV-3 while the conversion of the BHA to $\mathrm{APC} / \mathrm{XCB}$ coring continued. 
Appendix $\mathbf{J}$

DIC System Technical Manual 


\section{OCEAN DRILLING PROGRAM \\ DRILL-IN-CASING (DIC) SYSTEM \\ TECHNICAL MANUAL}

February 1992 


\section{OCEAN DRILLING PROGRAM \\ DRILL-IN-CASING TECHNICAL MANUAL \\ TABLE OF CONTENTS}

February 1992

I. DESCRIPTION

General Description

Design/Development History

II. ASSEMBLY

Shifting Sleeve Assembly

Drive Bushing Assembly

Drive Sub Assembly

Drive Bushing Installation

Drive Head Installation

Head Sub/Release Ring Assembly

III. OPERATION

BHA/11 3/4 Casing String Assembly

Reentry Funnel Assembly (Optional)

Reentry Funnel Installation

Spudding and Release

IV. NOTES

General Notes

Parts List

General Tool

Service Tools

V. DRAWINGS

Assembly Drawing

Machine Drawings 


\section{OCEAN DRILLING PROGRAM \\ DRILL-IN-CASING (DIC) SYSTEM \\ GENERAL DESCRIPTION}

February 1992

\section{GENERAL}

The Drill-In-Casing (DIC) system is designed to allow deployment of an 11-3/4" casing string to support unstable zones in single bit holes without having to round trip the drill string. The DIC system allows the casing string with its own expendable bit and the bottom hole assembly to be "drilled-in" as a unit. The DIC system utilizes a complex series of latches that enable the drilling torque applied from the rig floor by the top drive to be transmitted to the casing string and bottom hole assembly (BHA) simultaneously. Once the DIC system has been drilled into place the BHA is released from the casing string and drilling or coring operations are continued. The casing string is left "up hole" supporting the unstable zone thus preventing drill pipe sticking and premature loss of the hole.

The DIC system has been designed for two main objectives. The first objective is to support unconsolidated sediments near the sea floor. In this case, the DIC system is drilled-in and left at the sea floor to support the unconsolidated upper sediments. With the addition of an optional reentry funnel, multiple reentries are possible. The second objective of the DIC system is to support unstable zones below the sea floor. In this case the DIC system is drilled in below the sea floor an left straddling the unstable zone.

Note that deployment of the DIC system with the optional reentry funnel does not replace the full reentry cone installation. In most cases, the DIC system is not capable of drilling-in a casing string from the sea floor to basement. Also, the casing string can not be cemented in place and is therefore only a last resort method of achieving scientific objectives located below an unstable zone. Note also that coring operations can not be carried out while the casing string is being drilled into place.

\section{DESIGN/DEPLOYMENT HISTORY}

The DIC system was originally designed during the Deep sea Drilling Project and successfully deployed on Leg 78. The DIC system was subsequently redesigned by the ocean Drilling Program for Leg 110 but was not deployed until Leg 131. After successful deployment of the DIC system on Leg 131 it was modified by adding an optional reentry funnel (a modified Free Fall Funnel). The modifications also included increasing the DIC drive bushing inside diameter from $81 / 2 "$ to $83 / 4 "$ to allow $81 / 2 "$ drilling jars and drill collars to pass through. After successfully deploying the 
DIC with optional reentry funnel on Leg 139 the DIC was again modified by changing the expendable casing bit to a "slip-on-weld" configuration, reducing the Drive Head OD to 16 " and combining the Drive Head and Drive Adapter into one part. 


\section{OCEAN DRILLING PROGRAM \\ DRILL-IN-CASING (DIC) SYSTEM \\ ASSEMBLY PROCEDURES}

December 1991

Reference: $\quad$ DIC Assembly Drawing OJ4830

DIC with Reentry Funnel Assembly Drawing OJ4850

NOTE: All rotary shouldered connections should be torqued up on the rig floor prior to RIH. 


\section{SHIFTING SLEEVE (OJ4836) ASSEMBLY}

(Reference Figure 1)

1. Install one (1) each Polypak Seal (OD3302, 3750-4750-625B) heel first, onto Shifting Sleeve (OJ4836) (ref fig 1). Remove energizer ring from Polypak before installation. 


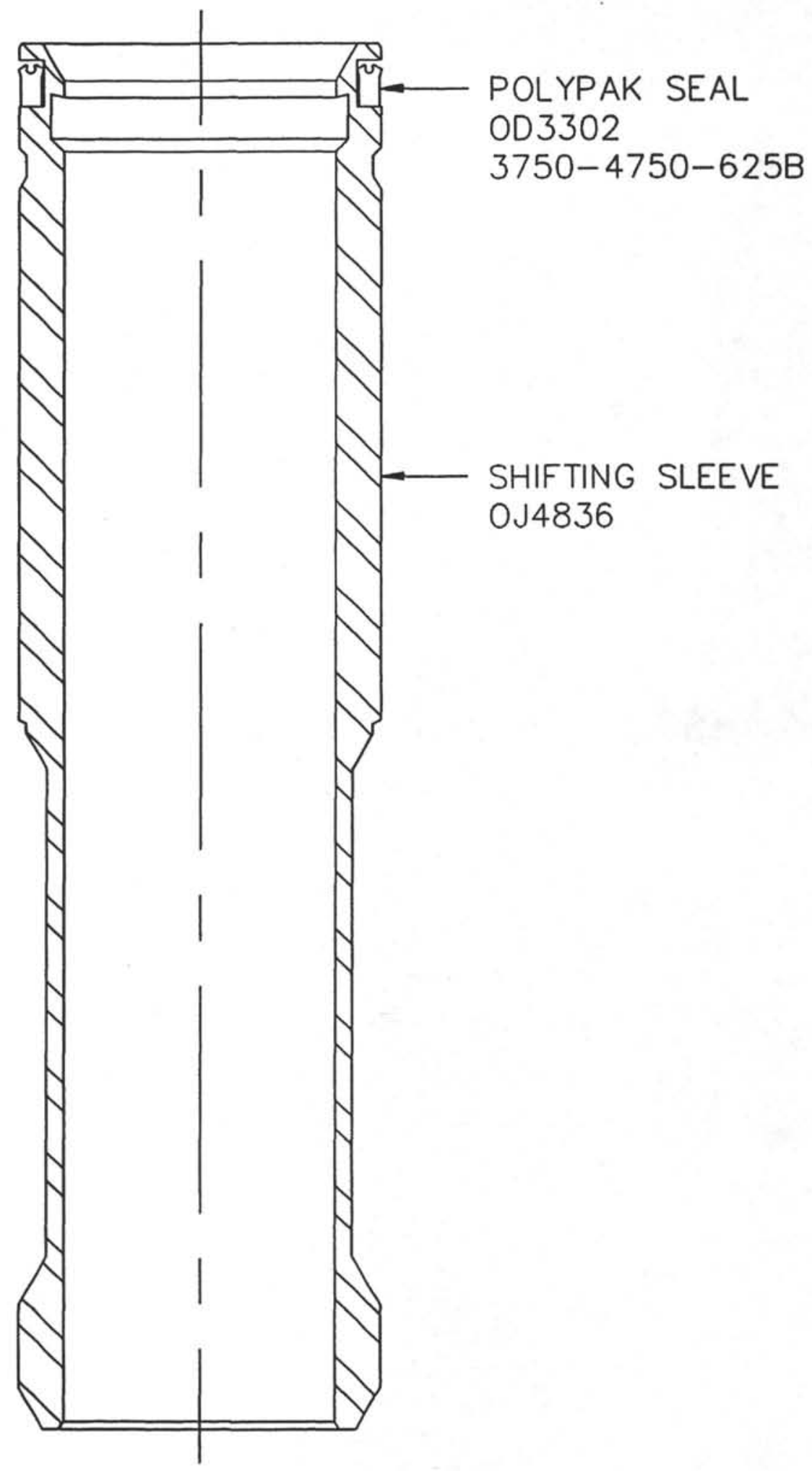

FIG 1: SHIFTING SLEEVE ASSEMBLY 


\section{DRIVE BUSHING (OJ4832) ASSEMBLY}

(Reference Figure 2)

1. Grease Drive Bushing (OJ4832) Upper Dog pockets.

2. Grease spring pockets of three (3) each Upper Dogs (OJ4837) and install two (2) each Upper Dog Springs (OJ4816) per dog.

3. Install Upper Dogs (with springs) in Drive Bushing.

4. Install three (3) each Lock Screws (OJ4810) in Drive Bushing (OJ4832) to hold Upper Dogs in place. Do not tighten Lock Screws.

5. Install three (3) each Retaining Rings (OD7192, \#N-5000-81 Waldes Truarc) in Drive Bushing Lock Screw head counter bores.

6. Back out Lock Screws until contacting Retaining Rings. Dogs should extend past the Drive Bushing oD (ref fig 2).

7. Install one (1) each Drive Bushing inner Polypak Seal (OD3358, \#5000-8750-750B). Remove energizer ring from Polypak before installation.

8. Install one (1) each Drive Bushing outer Polypak Seal (OD3350, \#5001-3250-750). Remove energizer ring from Polypak before installation. 


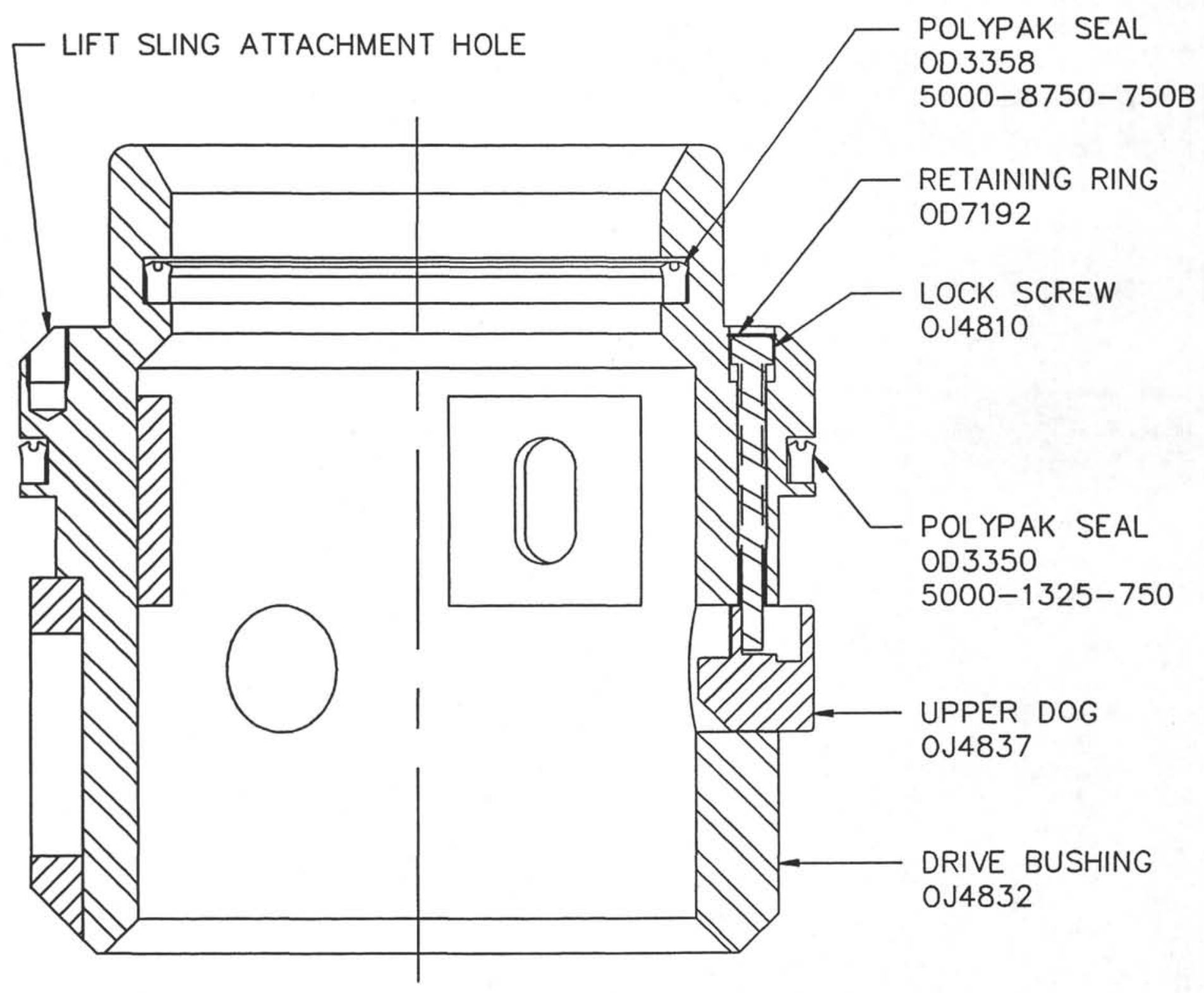

FIG 2: DRIVE BUSHING ASSEMBLY 
1. Install one (1) each Snap Ring (OJ4814) in Drive Sub (OJ4833) from Drive Sub top end. Snap Ring is symmetrical and cannot be installed backwards.

2. Cut out one (1) each Wiper Ring (OD5050, \#D5500) to prevent a pressure seal and install oriented with lip up hole or towards Lower Dog Pockets.

NOTE: A Special seating Tool (OJ4822) has been provided to help seat the Wiper Ring. When used, drive Seating Tool through Drive Sub from bottom end.

3. Install one (1) each Polypak Seal (OD3308, \#3750-5500-625B). Remove energizer ring before installation.

4. Make-up one (1) each Crossover Sub (OJ4817) to lower end of Drive Sub.

5. Grease spring and pin pockets of three (3) each Lower Dogs (OJ4835) and install two (2) each Lower Dog springs (OJ4839) and two (2) each Lower Dog Pins (OJ4838) per Dog.

6. Install Lower Dogs with springs and pins, in Drive Sub and secure with Retraction Jigs (OJ4820) (ref fig 3 ).

7. Grease Drive Sub bore.

8. Grease preassembled Shifting sleeve and install in Drive Sub. This step will be more easily done with subs in a vertical position. Do not shift shifting sleeve into the full down position. Only install sufficiently to trap the Lower Dogs (OJ4835) in the loose or released position. Top of Shifting Sleeve should be approximately $613 / 16 "$ below top of Drive Sub (ref fig 4 ).

9. Remove Retraction Jigs. If Lower Dogs are not flush with Drive Sub OD with Retraction Jigs removed (ref fig 5), move Shifting sleeve up and/or down slightly.

10. Install three (3) each 1/2" NPT Socket Pipe Plugs (OD7255).

11. Install Special Grease Fitting (OJ4824) in remaining 1/2" NPT tapped hole and pump grease into Drive Sub assembly until forced out through Lower Dog pockets (ref fig 5).

12. Remove Special Grease Fitting and install one (1) each 1/2" NPT Socket Pipe Plug (OD7255). 


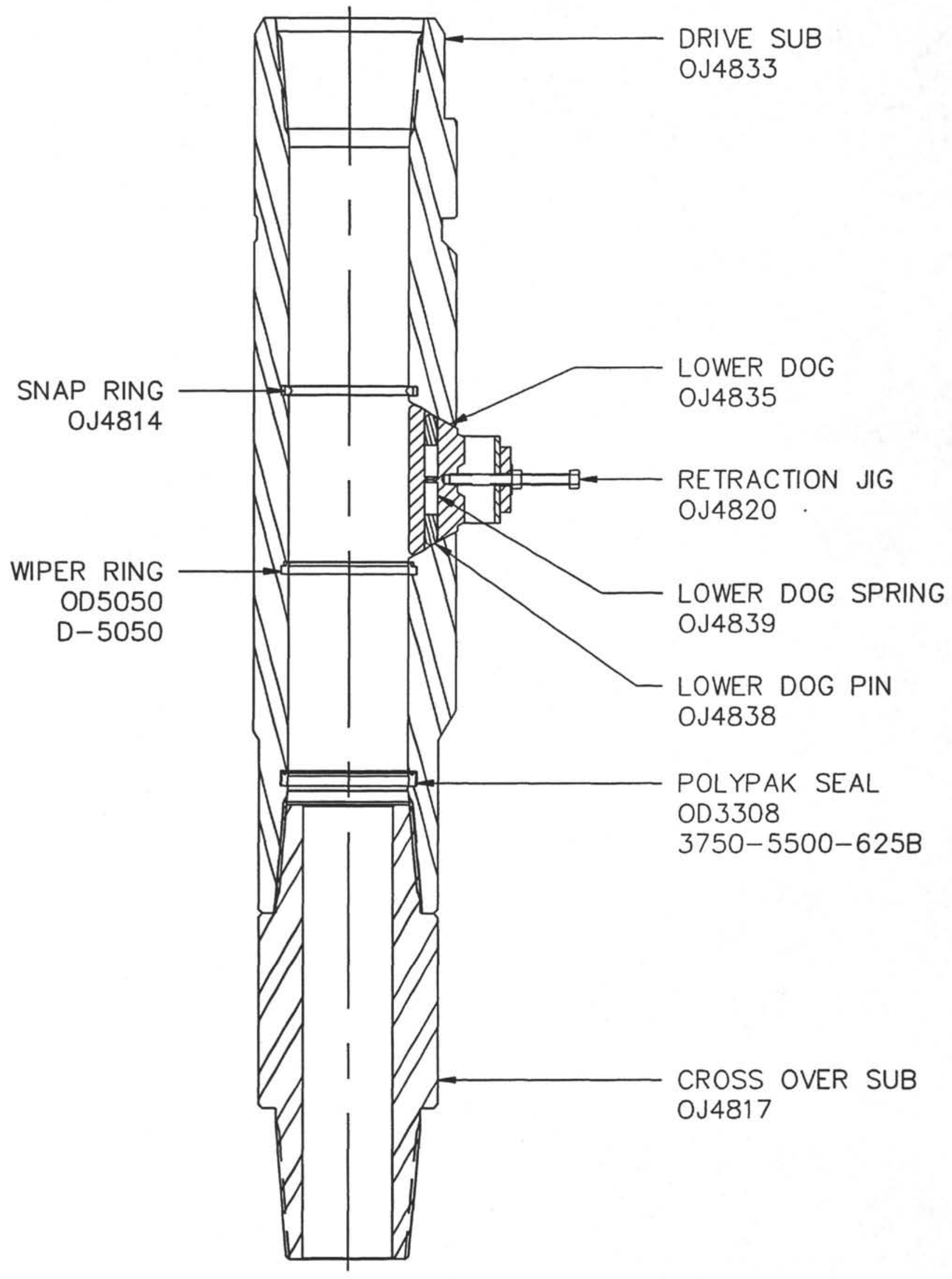

FIG 3: DRIVE SUB ASSEMBLY 


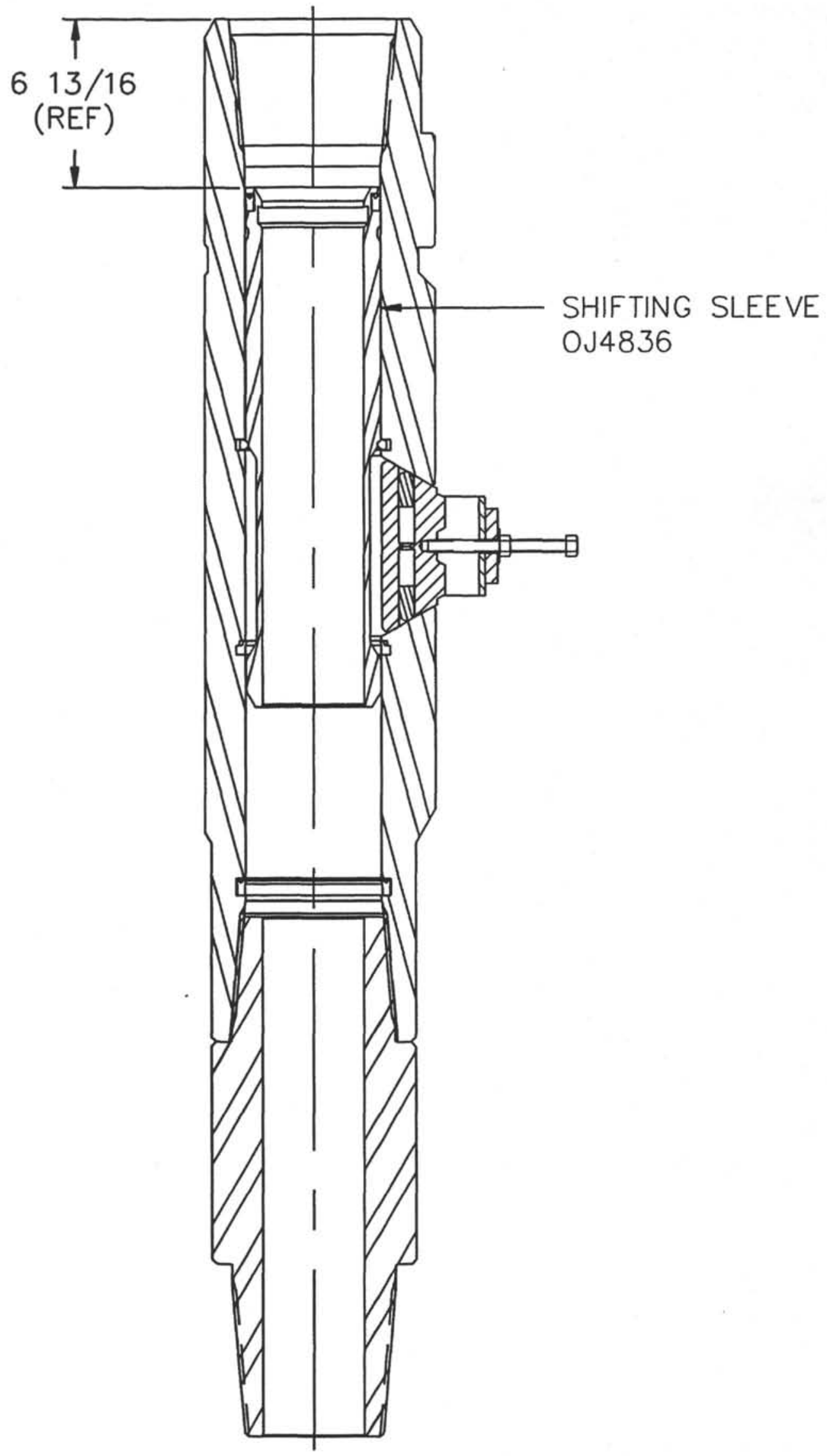

FIG 4: SHIFTING SLEEVE INSTALLATION 


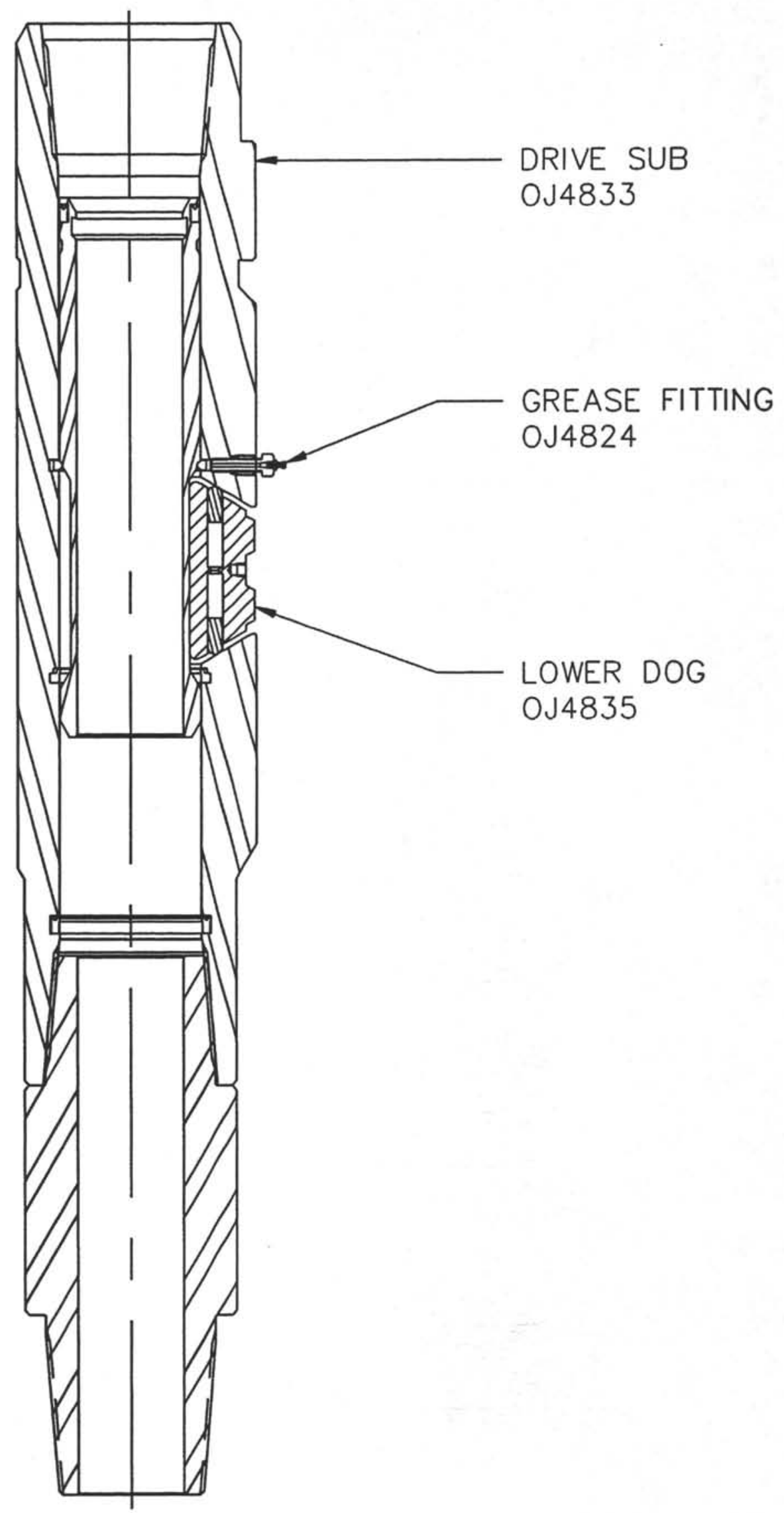

FIG 5: DRIVE SUB ASSEMBLY GREASING 


\section{DRIVE BUSHING INSTALLATION \\ (Reference Figure 6)}

1. Grease top OD of Drive Sub.

2. Grease Drive Bushing assembly ID.

4. Install Drive Bushing onto Drive Sub (ref fig 6).

NOTE: Three 3/4-10UNC tapped holes on top of Drive Bushing are for lifting sling attachment.

5. Compress Upper Dogs into Drive Bushing pockets until flush with OD and lock in-place by tightening Lock Screws.

NOTE: Drive Bushing may have to be picked up slightly to allow Upper Dogs to seat in Drive Sub Upper Dog groove. 


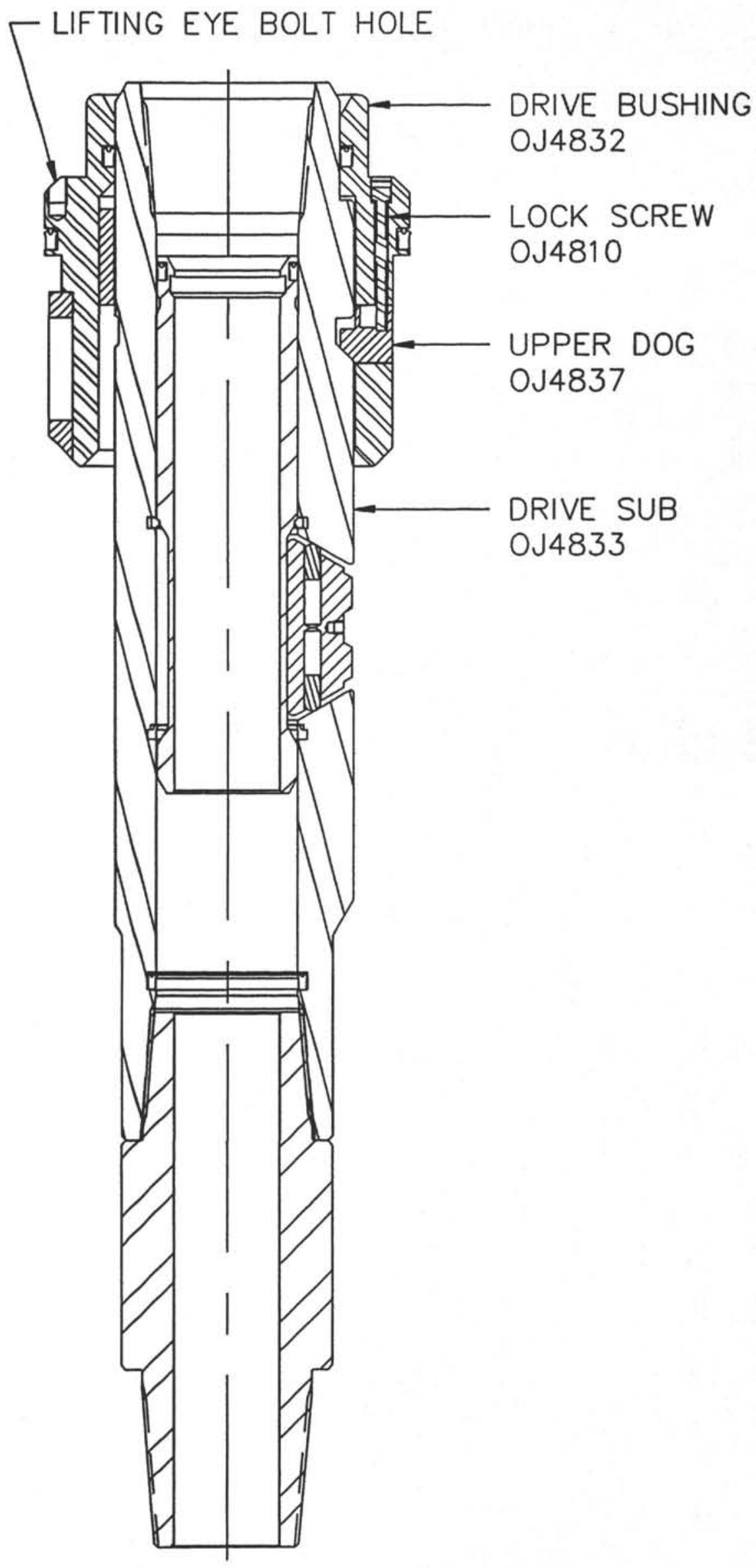

FIG 6: DRIVE SUB/DRIVE BUSHING ASSEMBLY 
DRIVE HEAD INSTALLATION

(Reference Figures 7, $8 \& 9$ )

1. Grease Drive Head (OJ4831) ID.

2. Grease Drive Sub/Drive Bushing assembly OD.

3. Carefully pick up Drive Sub/Drive Bushing assembly and lower through Drive Head until seated in Drive Head (ref fig 7).

NOTE: Drive Head will have to be raised to allow Drive Sub/Drive Bushing assembly to seat properly.

Three 3/4"-10unC tapped holes on Drive Head sides near the top are for lifting sling attachment.

4. Install Lower Dog Retraction Jigs through 1" NPT tapped holes in Drive Head. Retraction Jig U-Channel not required (ref fig 8 ).

5. Rap Casing Drive Head sides with sledge hammer while tightening Retraction Jig bolts. Continue until bolts will not tighten further after repeated "rapping".

6. Drive Shifting Sleeve down until shouldered against the Crossover sub (ref fig 9).

NOTE: Use brass bar so as not to damage Drive Sub internal seal surface.

When seated properly top of shifting sleeve should be approximately 15 5/16" from top of Drive Sub (ref fig 9).

CAUTION: If Shifting sleeve will not shift down, loosen all Retraction Jig bolts and repeat procedure (steps 5 and 6 ). Drive Head may need to be moved up and/or down slightly.

7. Remove Retraction Jigs.

8. Install three (3) each 1" NPT Socket Pipe Plugs (OD7258).

9. Install three (3) each 3/4-10 UNC X 3/4 Set Screws (OD6587) into Drive Head lifting sling holes. Set screws should be Baker-Loked and set flush with Drive Head OD.

NOTE: 3/4-10 UNC hex head cap screws (bolts) cut off to no longer than $7 / 8 "$ long may be substituted for the 3/4-10 UNC $X 3 / 4$ set screws. The set screws/cap screws are to keep detritus from entering the DIC assembly during drill-in. 
10. Back out all Drive Bushing Upper Dog Lock Screws until contacting Retaining Rings (ref fig 9). 


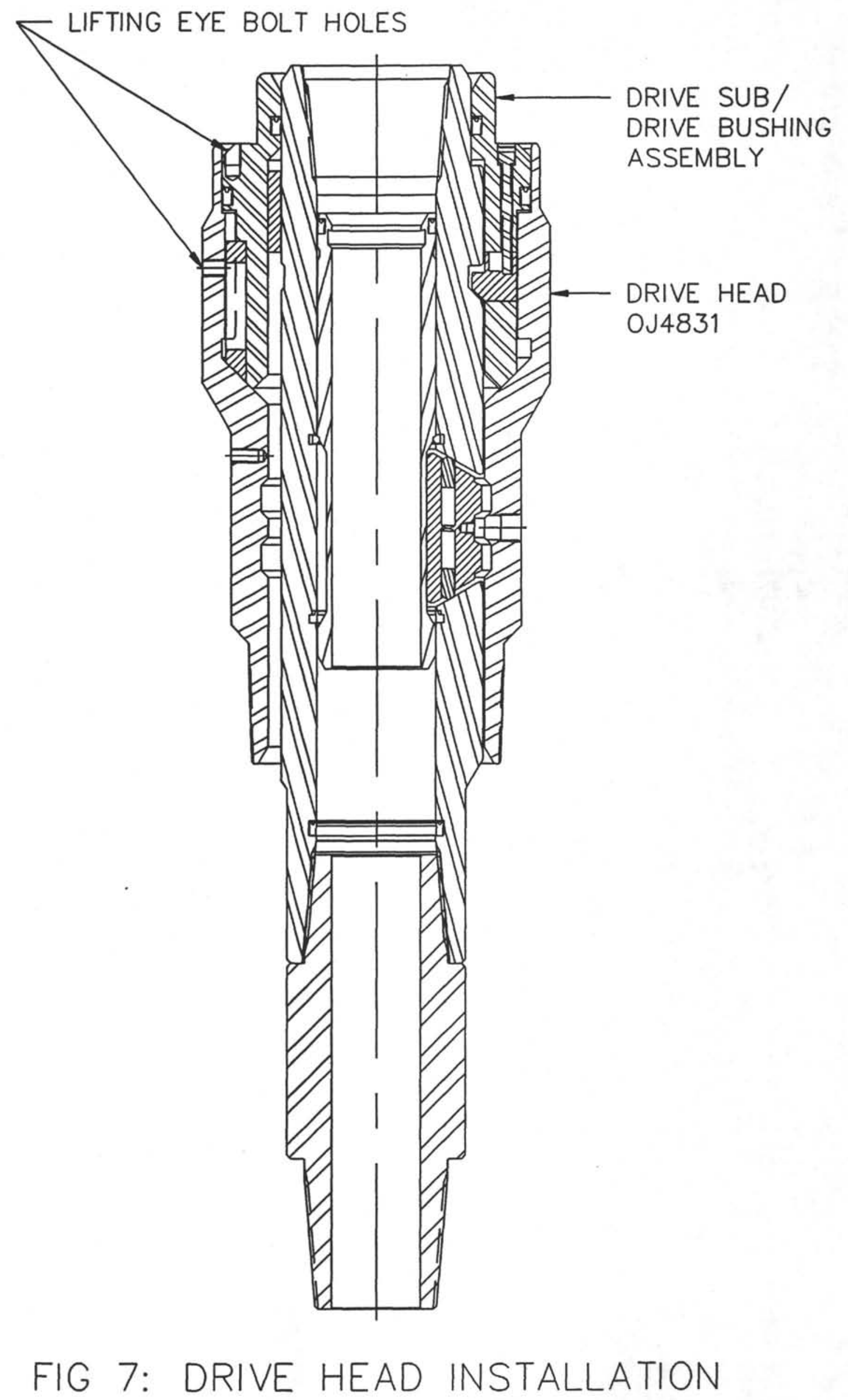




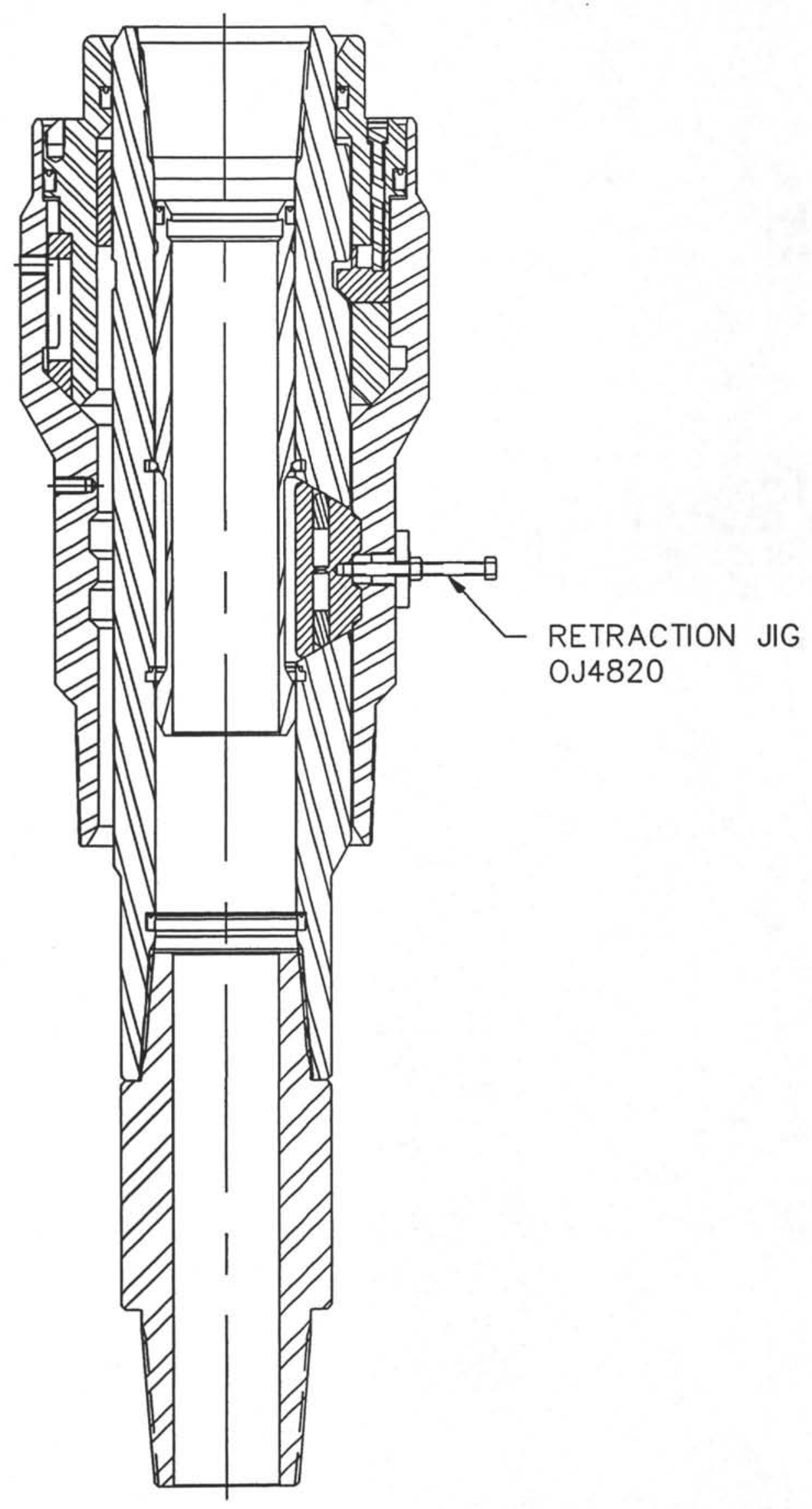

FIG 8: RETRACTION JIG INSTALLATION 


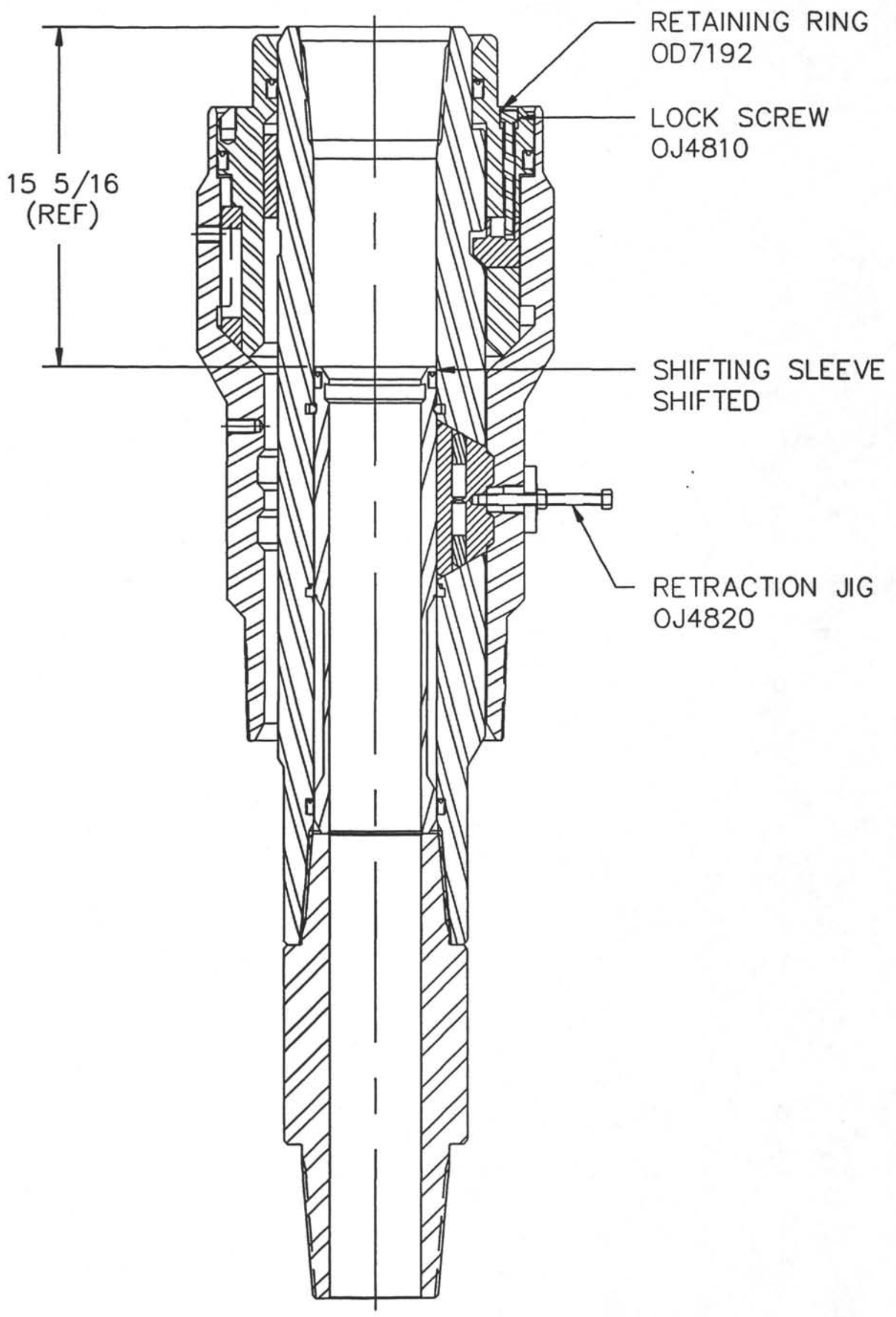

FIG 9: SHIFTING SLEEVE SHIFTED 


\section{HEAD SUB/RELEASE RING ASSEMBLY}

(Reference Figure 10)

1. Make-up one (1) each Release Ring (OH3420) to one (1) each Head Sub (OL1010) and tack weld in place.

2. Make-up Head Sub/Release Ring assembly to top of Drive Sub (ref fig 10). 


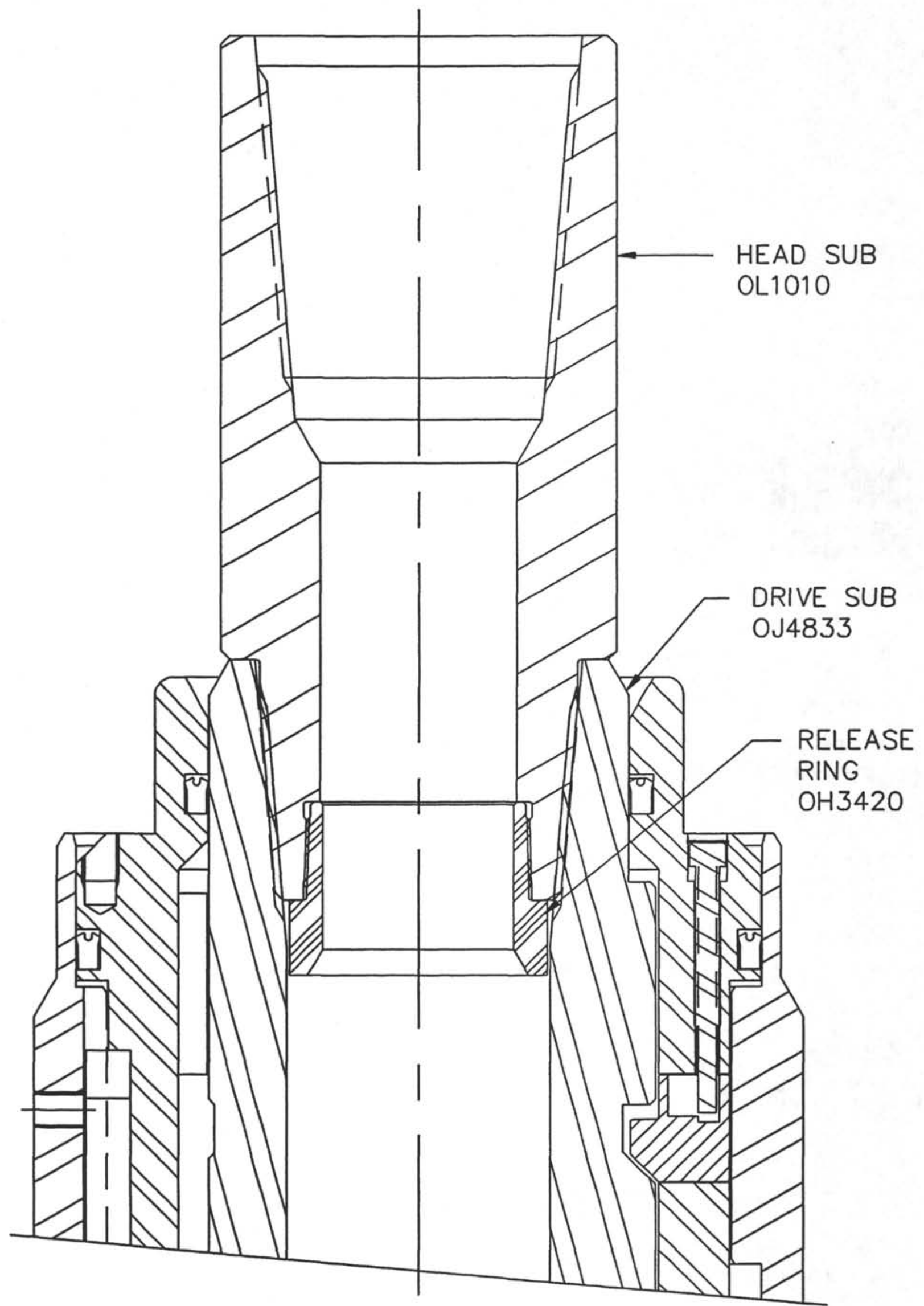

FIG 10: HEAD SUB/RELEASE RING INSTALLATION 


\section{BHA/11 3/4" CASING STRING ASSEMBLY}

(Reference Figure $11 \& 12$ )

1. Determine proper subs etc., to space out the DIC BHA/11 3/4" Casing assembly such that the coring Bit is positioned approximately $1 / 2 \mathrm{~m}$ ahead of the Expendable Casing Bit (ref figs 11 \& 12).

2. Cut bottom $113 / 4 "$ casing joint to proper length as determined by space out calculations.

3. Weld Expendable Casing Bit (0c3010) to bottom casing joint.

4. Make-up casing string running in the hole and hang off at rig floor.

NOTE: Optional - tack weld and/or Baker-Lok all connections.

5. Make-up standard Outer Core Barrel assembly running in the hole through the hung off casing string.

NOTE: Optional - tack weld and/or Baker-Lok all connection below DIC.

6. Make-up DIC assembly into the BHA assembly.

7. Make-up DIC assembly to upper casing joint.

8. Ensure all three (3) Drive Bushing Upper Dog Lock Screws (OJ4810) are backed out, in contact with Retaining Rings.

9. Continue to make-up BHA and drill string while running in the hole with DIC assembly.

NOTE: If optional Reentry Funnel is to be used lower the DIC assembly to the moon pool doors for installation of the funnel. 


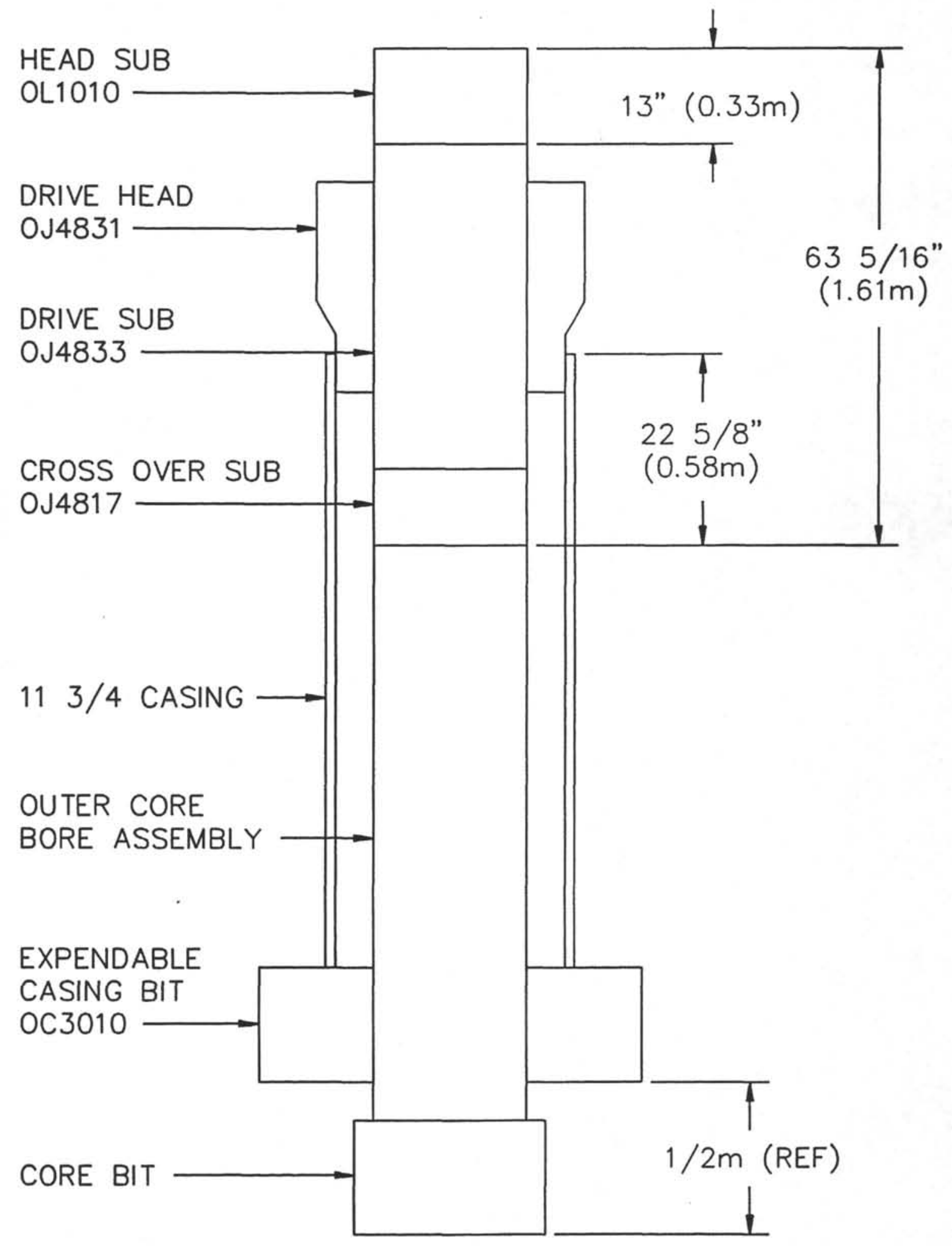

FIG 11: DIC BHA/CSG ASSY SPACE OUT 


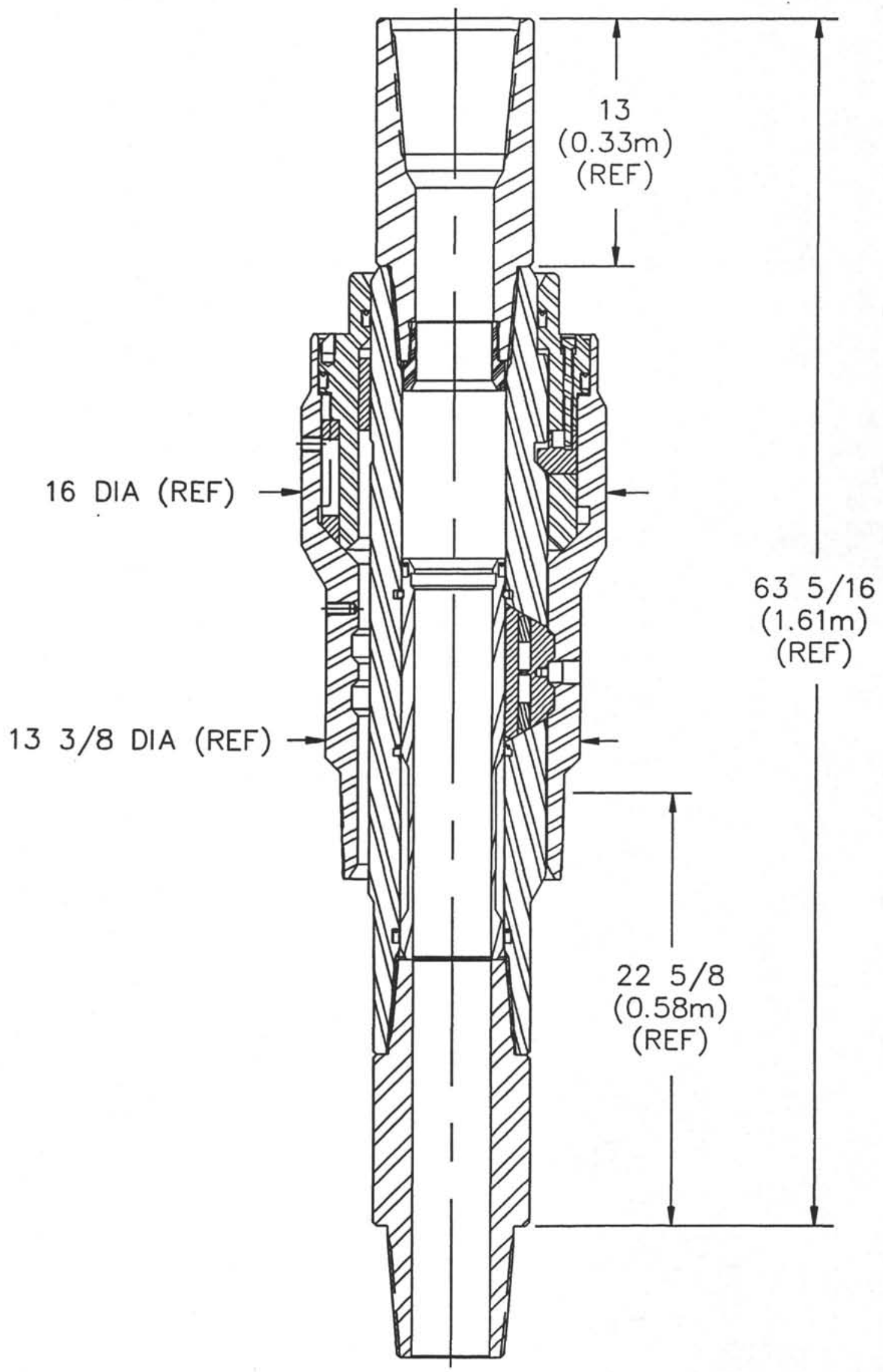

FIG 12: DIC RIH CONFIGURATION 


\section{REENTRY FUNNEL (OJ4852) ASSEMBLY (OPTIONAL)}

(Reference Figure 13)

1. Modify one (1) each Free Fall Funnel (FFF) (OH4600) as indicated on drawing (OJ4852) by removing the 13 3/8" ID sleeve and installing 16" Split sleeves (ref fig 13). Reentry funnel should be preassembled ahead of deployment time. 

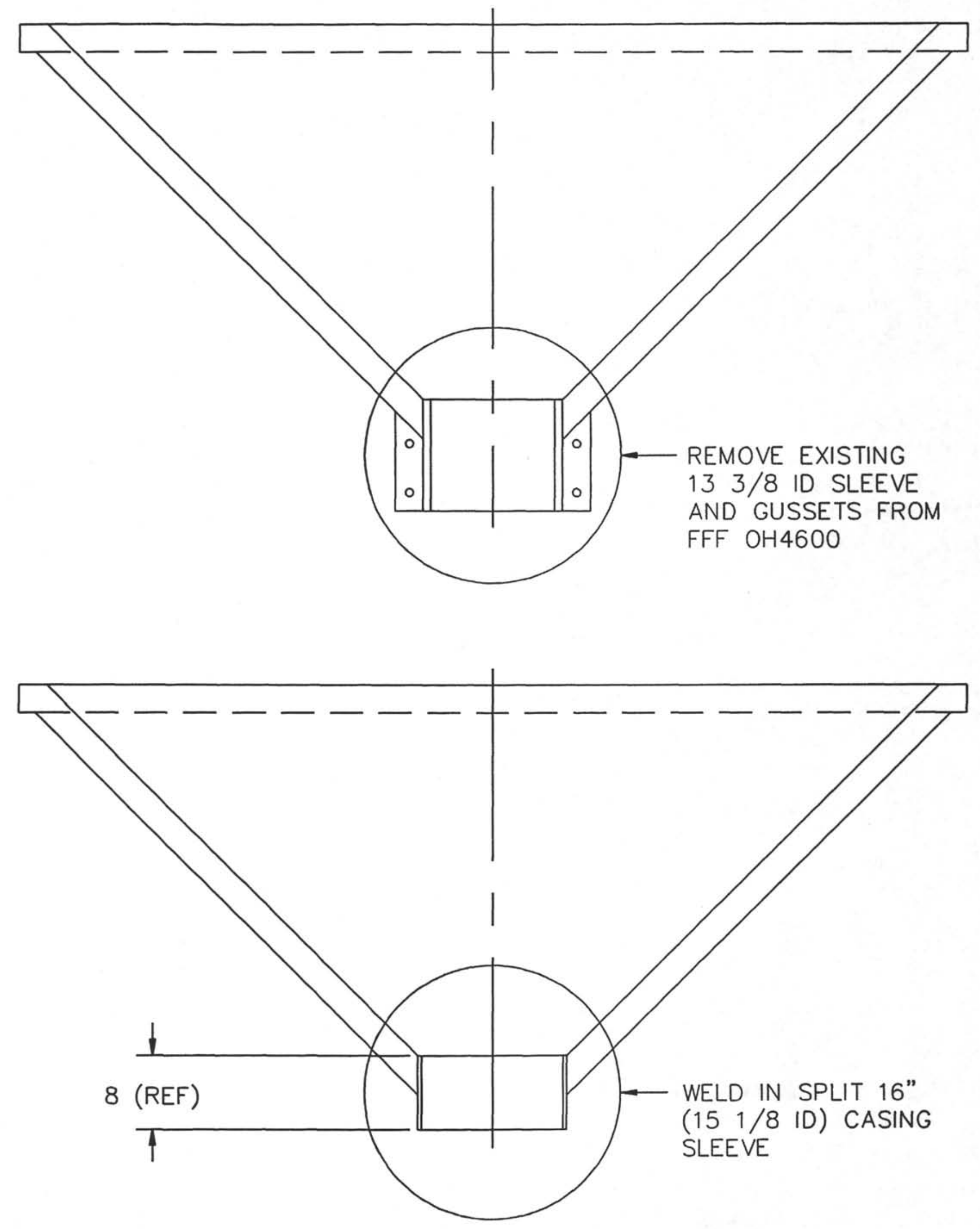

FIG 13: FFF MODIFICATION F/DIC 


\section{REENTRY FUNNEL INSTALLATION}

$$
\text { (Reference Figure 14) }
$$

1. With the DIC assembly positioned in the moon pool, assemble Reentry Funnel halves around DIC Drive Head. Ensure that Reentry Funnel slips over Drive Head neck (ref fig 14).

2. Attach three (3) each Reentry Funnel Braces (OJ4853) to Drive Head using three (3) each 5/8-11 UNC x 1-1/2" hex head bolts (OD7248).

NOTE: Hex head bolts OD7248 are the same bolts as used on the 13-3/8" FFF bolted casing pup. Hex head bolts are only welding and alignment aids and may be omitted.

3. Rotate the Reentry Funnel as necessary until the Funnel Braces are aligned with the funnel angle iron strength members. Weld Funnel Braces to funnel strength members and DIC Drive Head (ref fig 14).

4. Weld Split Sleeve together and to DIC Drive Head. 


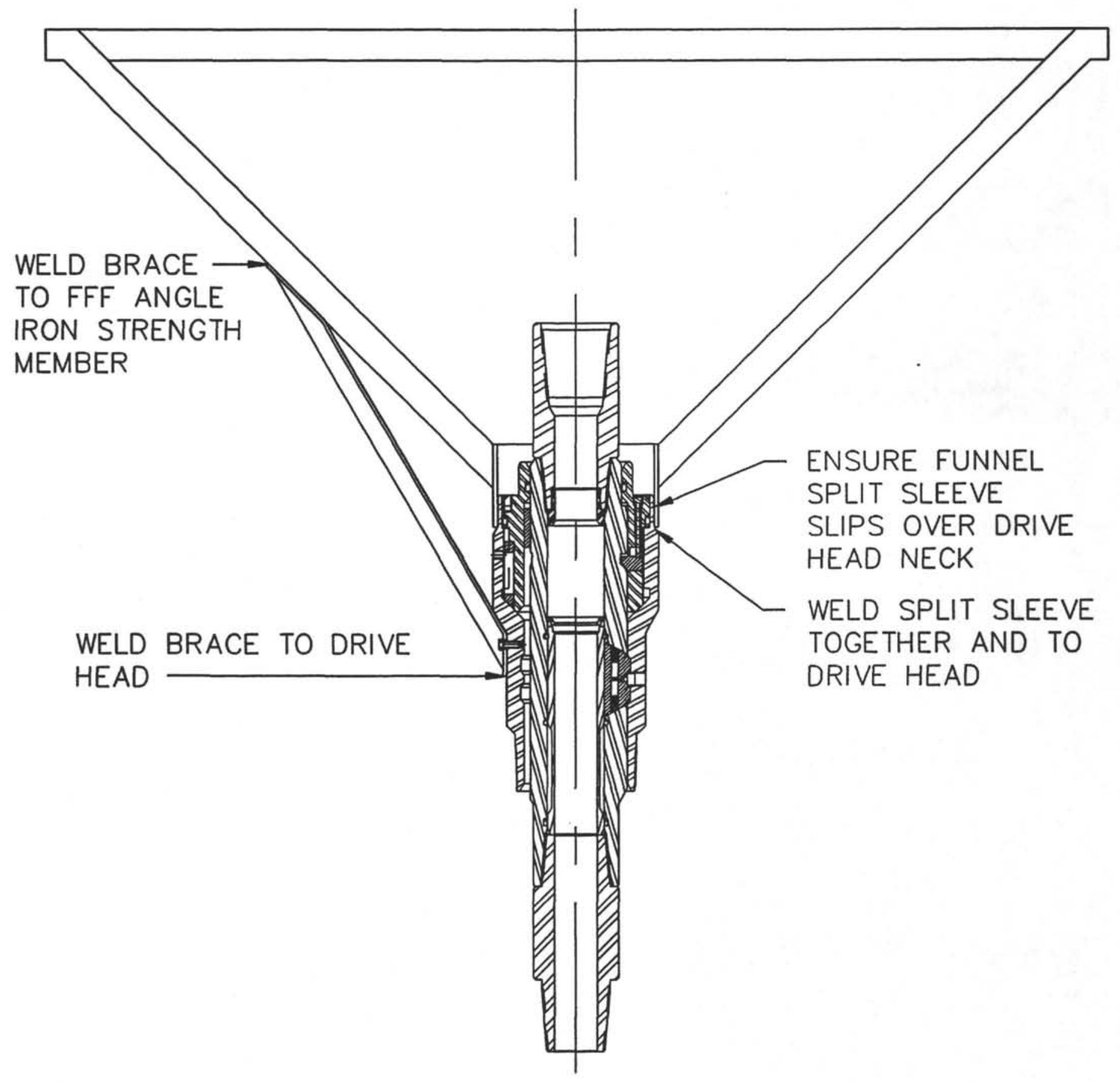

FIG 14: DIC FUNNEL INSTALLATION 
1. RIH with DIC assembly to sea floor (ref fig 15).

2. Jet-in casing to refusal.

3. Begin rotating slowly.

4. Once the DIC has been drilled into place, release it using a standard Rotary Shifting tool (ref fig 16).

NOTE: Use of the Heave Compensator to vary tension in order to position the neutral point at the DIC Lower Dogs during releasing operations will facilitate shifting of the sleeve.

5. Pick up approximately $1 \mathrm{~m}$ with the drill string to release the Drive Bushing (ref fig 17).

5. Lower the Coring Bit back to TD and cautiously drill out from under the DIC assembly (ref figs 18 \& 19).

6. Use caution when pulling the BHA back through the DIC (ref fig 20). 


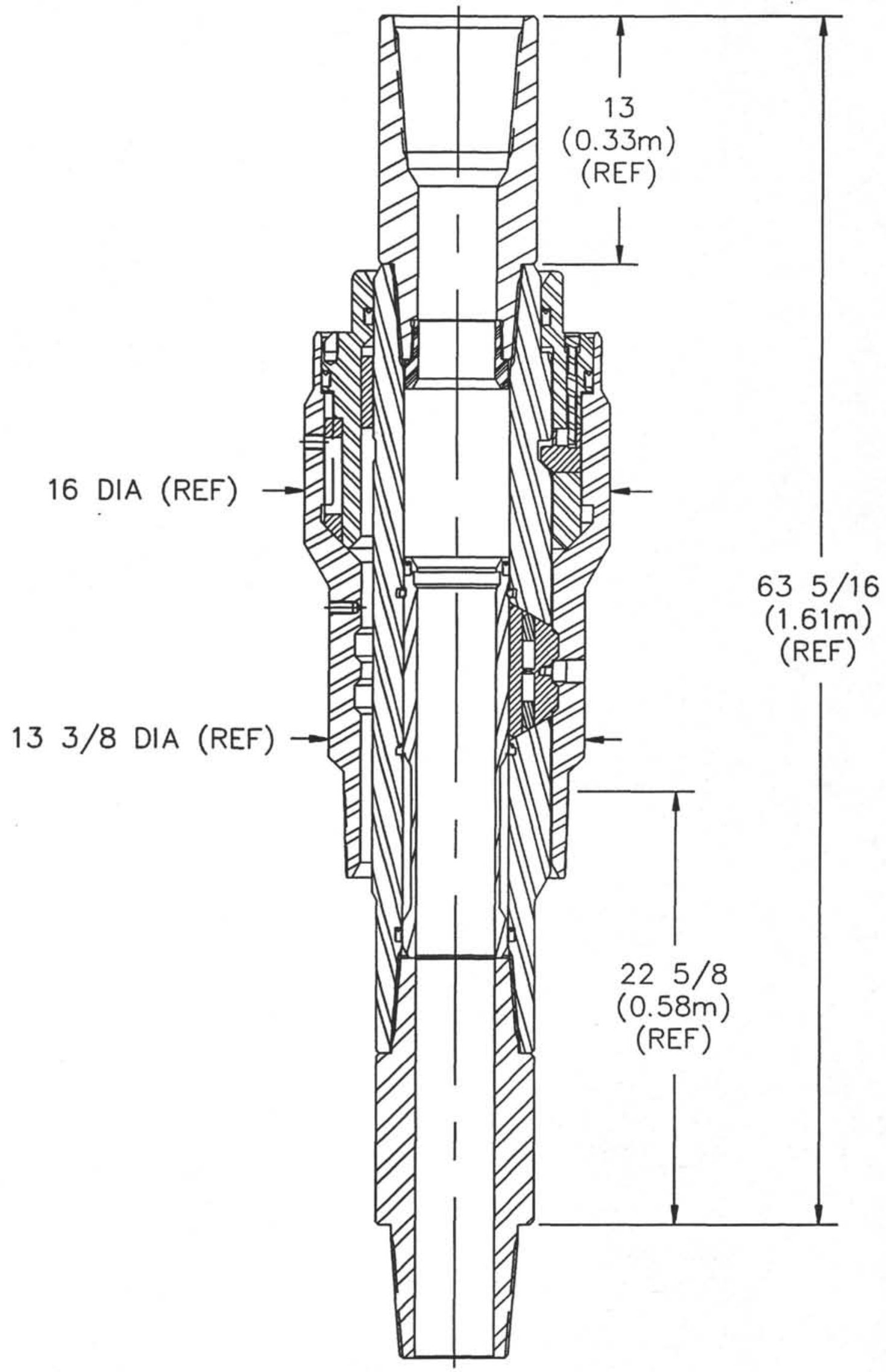

FIG 15: DIC RIH CONFIGURATION 


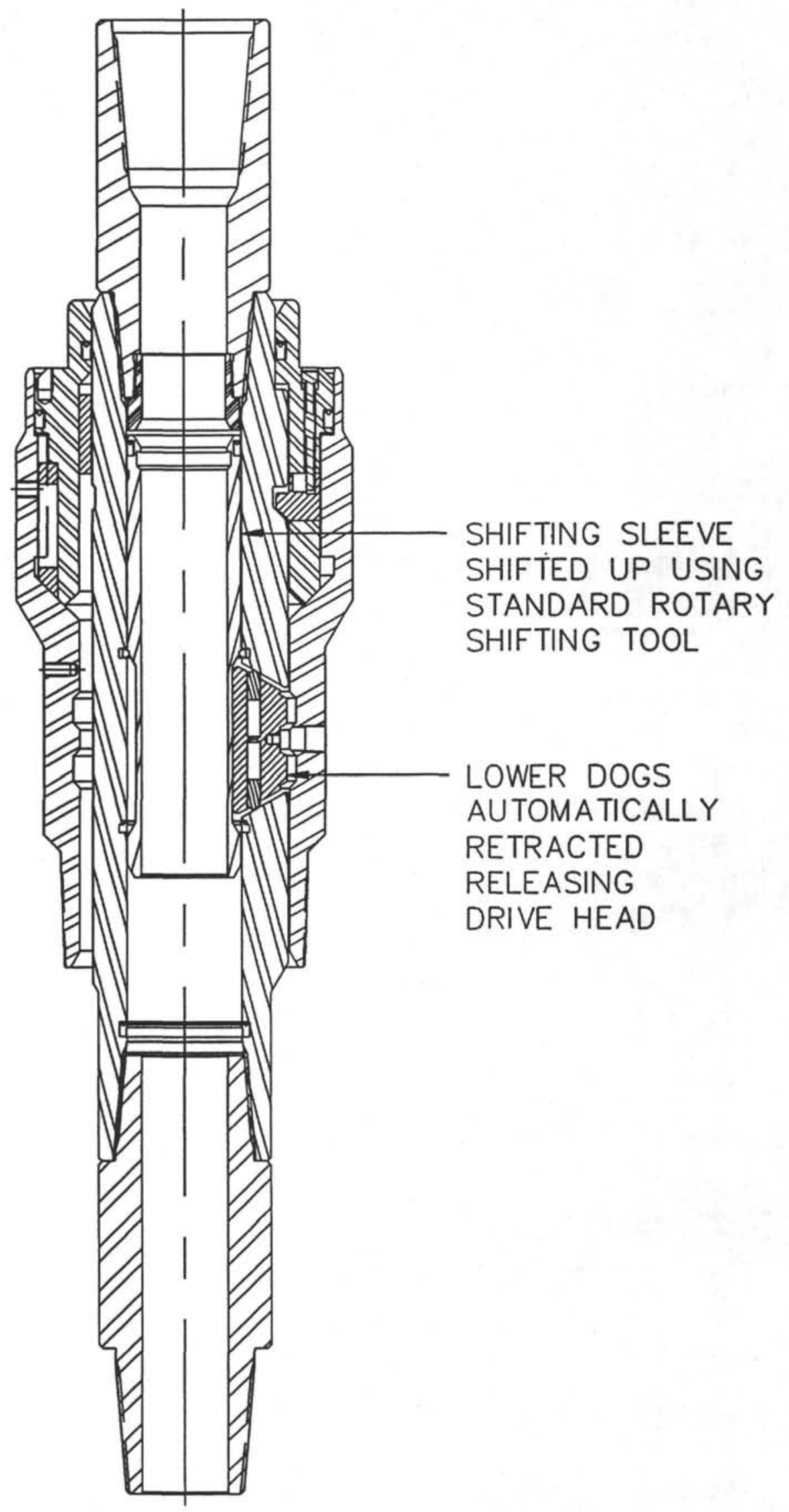

FIG 16: SHIFTING SLEEVE SHIFTED 


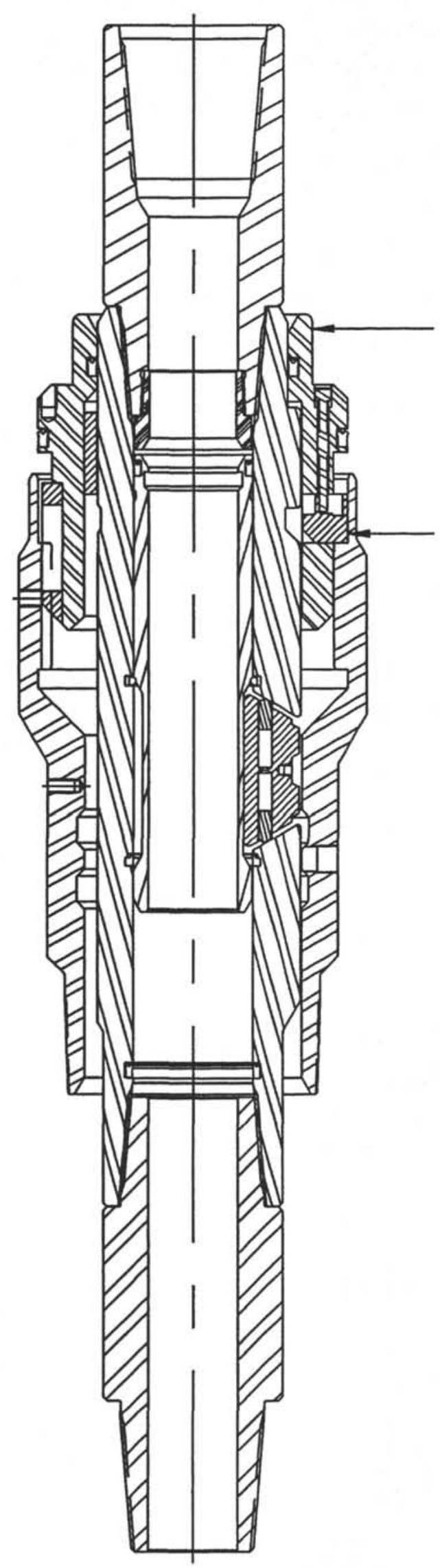

DRIVE BUSHING SHIFTED BY PICKING UP WITH THE DRILL STRING

UPPER DOGS AUTOMATICALLY EXTENDED, RELEASING THE DRIVE SUB AND PREVENTING REENGAGEMENT OF THE DRIVE BUSHING

FIG 17: DRIVE BUSHING SHIFTED 
DRIVE BUSHING INSERTS DISENGAGED FORM DRIVE SUB WHEN CORING BIT IS LOWERED BACK TO TD

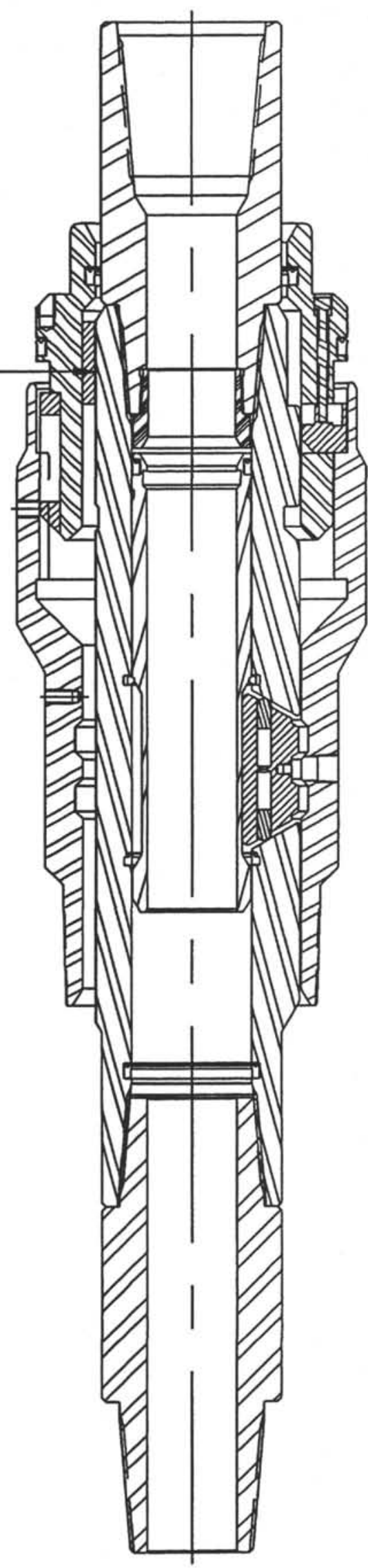

FIG 18: DRIVE BUSHING DISENGAGED 


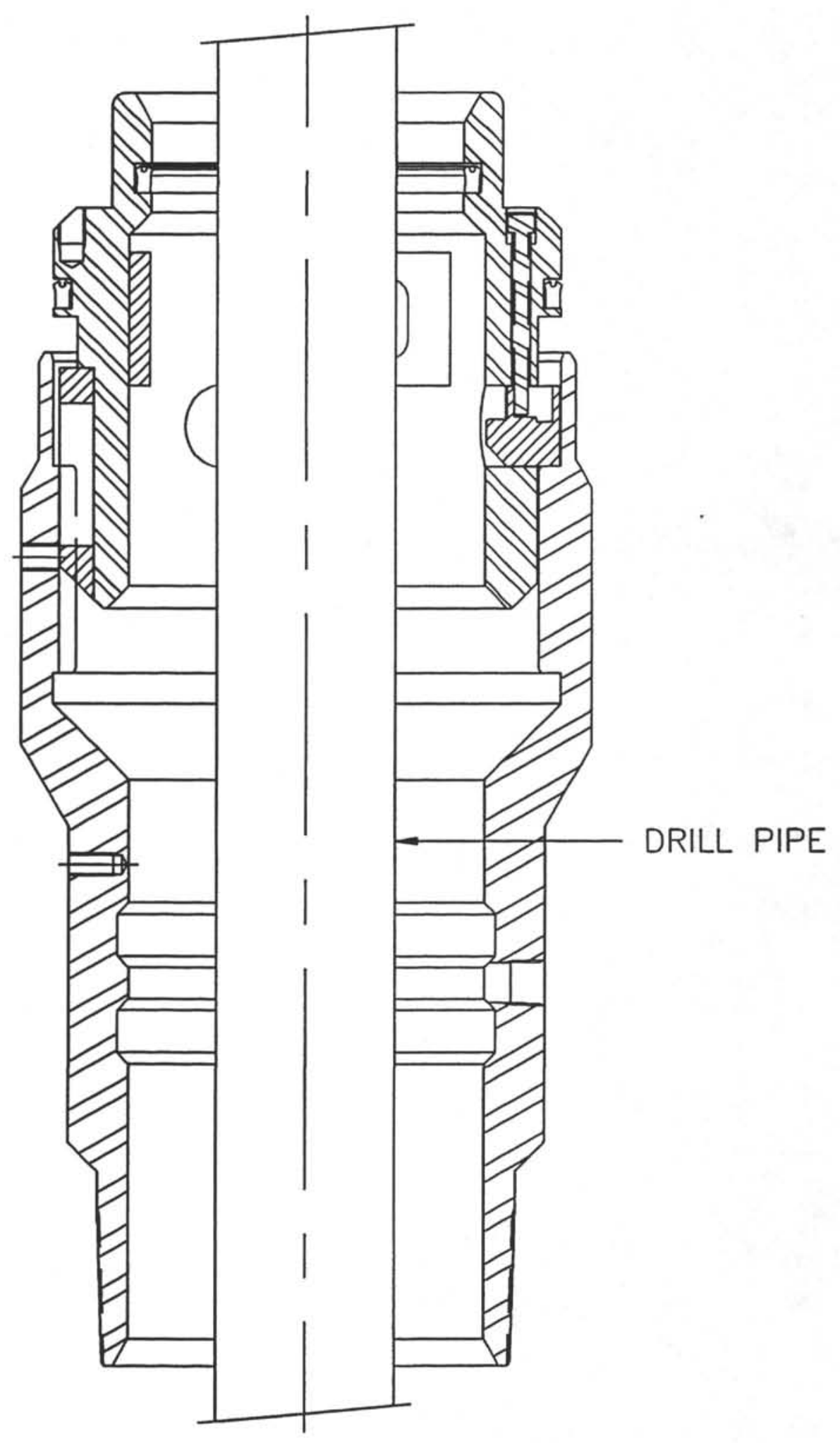

FIG 19: DRILLING THRU THE DIC 


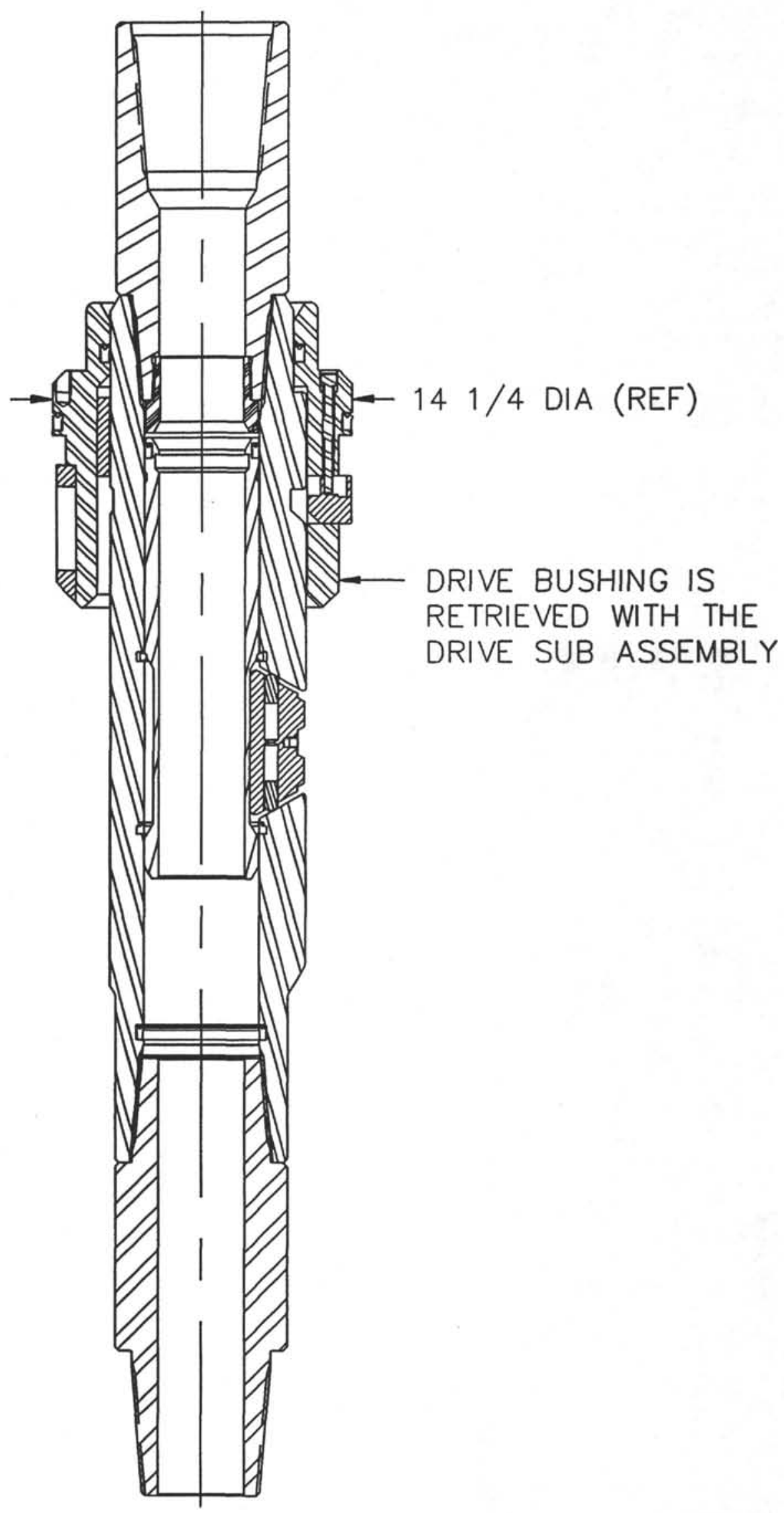

FIG 20: DIC POOH CONFIGURATION 


\section{OCEAN DRILLING PROGRAM \\ $113 / 4$ DRILL-IN-CASING SYSTEM OJ4850 \\ NOTES}

February 1992

\section{DRIVE SUB/SHIFTING SLEEVE INCOMPATIBILITY}

Beginning with Leg 144 two different drive sub/shifting sleeve combinations will exist (ref fig 21). The difference is placement of the shifting sleeve lower seal. The new design drive sub/shifting sleeve (Leg 144 shipment) has the seal as and integral part of the drive sub. The original design (Leg 141 version, currently on board) has the seal as an integral part of the shifting sleeve. The new design configuration eliminates having to "jump" the snap ring and wiper ring with a seal groove while installing the shifting sleeve. To standardize the parts, replace the original shifting sleeve (one with the seal groove around the bottom) with the new design (no seal groove around the bottom). The old drive sub will have to be reworked by adding the seal groove if it is still usable after being deployed. All future drive sub/shifting sleeves will be made to the new design.

\section{RECONFIGURED DRIVE HEAD}

Beginning with the Leg 144 shipment, a newly configured drive head will make its first appearance. The drive head and drive adapter have been combined into one part. The outer configuration of the drive head has also changed. The old design, 17 1/2" OD quasi triangular cross section configuration has been replaced by a 16" circular cross section. This means that little if any stabilization will be provided by the drive head. Please report any stability problems which occur while drilling-in with the new design. 
"NEW DESIGN"

SHIFTING SLEEVE LUWER SEAL IN DRIVE SUB

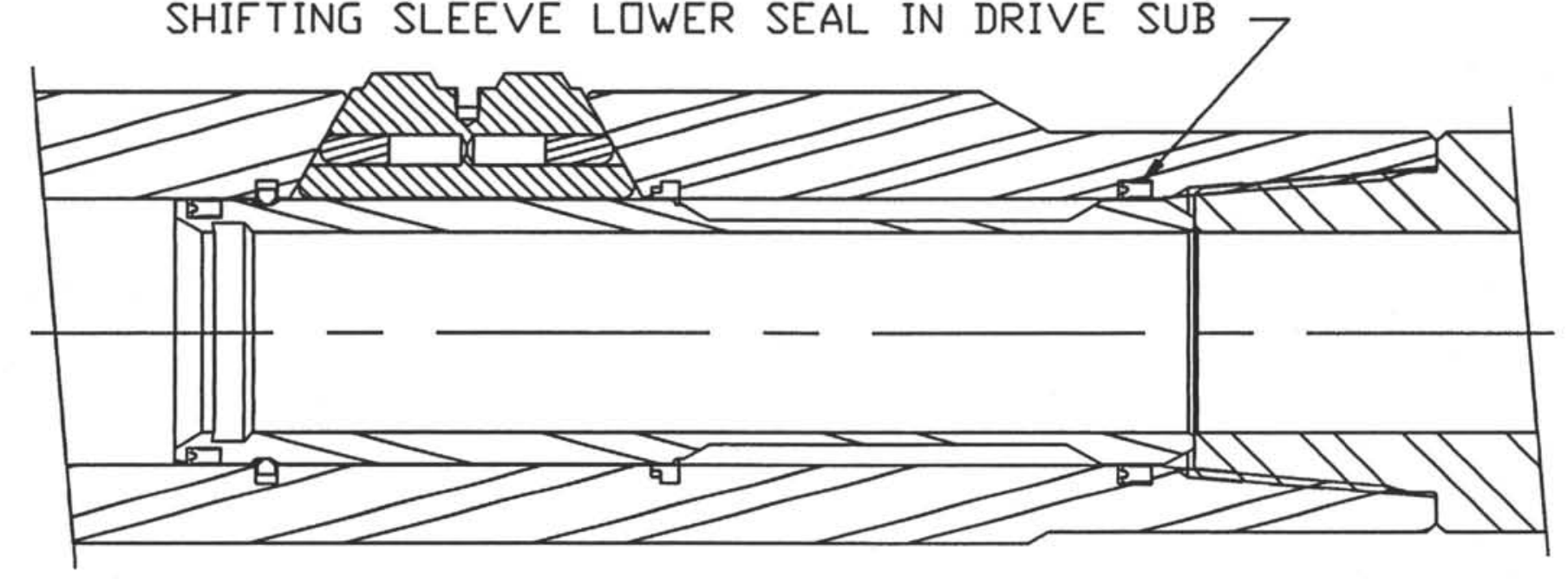

"ILD DESIGN"

SHIFTING SLEEVE LOWER SEAL QN SLEEVE

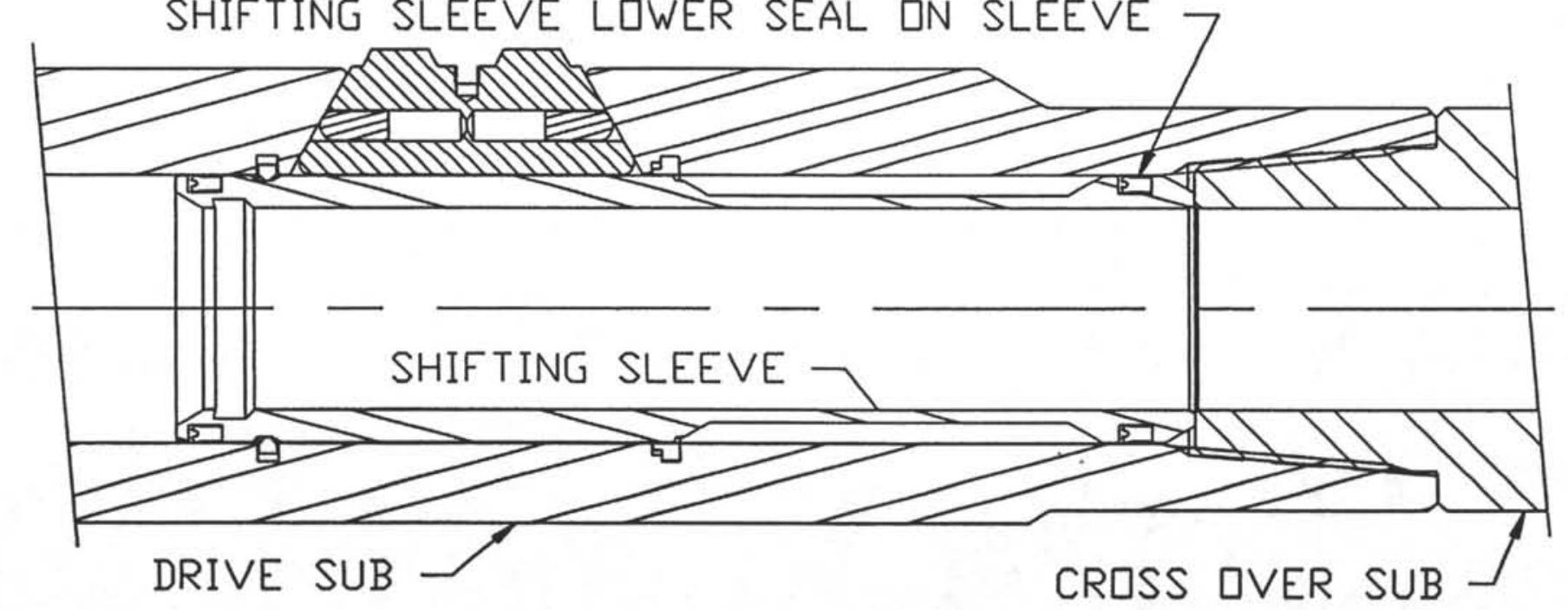

FIG 21: SHIFTING SLEEVE LUWER SEAL CDNFIGURATIDN 
OCEAN DRILLING PROGRAM

$113 / 4$ DRILL-IN-CASING SYSTEM OJ4850

PARTS LIST OJ4851

December 1991

\begin{tabular}{|c|c|c|}
\hline PART NO & QTY & DESCRIPTION \\
\hline oc3010 & 1 & Expendable Casing Bit, slip-on Weld \\
\hline OD3302 & 1 & Polypak (3750-4750-625B) \\
\hline OD3308 & 1 & Polypak (3750-5500-625B) \\
\hline OD3350 & 1 & Polypak (5001-3250-750) \\
\hline OD3358 & 1 & Polypak (5000-8750-750B) \\
\hline OD5050 & 1 & Wiper Ring (5500) \\
\hline OD6587 & 3 & Set Screw, 3/4-10UNC X 3/4, socket Head \\
\hline OD7192 & 3 & Snap Ring (Truarc N-5000-81) \\
\hline OD7248 & 3 & $\begin{array}{l}\text { Bolt, } 5 / 8-11 \times 1 / 2 \text {, Hex Head } \\
\text { (Optional reentry funnel) }\end{array}$ \\
\hline OD7255 & 4 & Pipe Plug, $1 / 2$ NPT, Flush Type \\
\hline OD7258 & 3 & Pipe Plug, 1 NPT, Flush Type \\
\hline ОН 3420 & 1 & Release Ring \\
\hline OJ4810 & 3 & Lock Screw \\
\hline OJ 4814 & 1 & Snap Ring \\
\hline OJ4816 & 6 & Spring, Upper Dog \\
\hline OJ 4817 & 1 & Cross Over Sub \\
\hline OJ4831 & 1 & Drive Head \\
\hline OJ4832 & 1 & Drive Bushing \\
\hline & & $\begin{array}{lll}\text { OJ4842 } & 3 & \text { Drive Bushing Insert } \\
\text { OJ4843 } & 3 & \text { Drive Bushing Key } \\
\text { OJ4844 } & 1 & \text { Drive Bushing Body }\end{array}$ \\
\hline OJ4833 & 1 & Drive Sub \\
\hline OJ4835 & 3 & Lower Dog \\
\hline
\end{tabular}




$\begin{array}{lll}\text { OJ4836 } & 1 & \text { Shifting Sleeve } \\ \text { OJ4837 } & 3 & \text { Upper Dog } \\ \text { OJ4838 } & 6 & \text { Pin, Lower Dog } \\ \text { OJ4839 } & 6 & \text { Spring, Lower Dog } \\ \text { OJ4852 } & 1 & \text { Reentry Funnel (Optional) } \\ \text { OJ4853 } & 3 & \text { Reentry Funnel Brace (Optional) } \\ \text { OL1010 } & 1 & \text { Head Sub }\end{array}$




\section{OCEAN DRILLING PROGRAM}

\section{3/4" DRILL-IN CASING SYSTEM \\ SERVICE TOOLS \\ PARTS LIST}

November 1991

\begin{tabular}{|c|c|c|}
\hline PART NO & QTY & DESCRIPTION \\
\hline OJ4819 & 4 & Release Screw \\
\hline OJ4820 & 3 & Retraction Jig \\
\hline OJ4822 & 1 & Wiper Ring seating Tool \\
\hline OJ4824 & 1 & Special 1/2-13UNC Grease \\
\hline
\end{tabular}


Appendix K

DIC System Parts List 
OCEAN DRILLING PROGRAM

11 3/4 DRILL-IN-CASING SYSTEM OJ4850

PARTS LIST OJ4851

$$
\text { January } 1992
$$

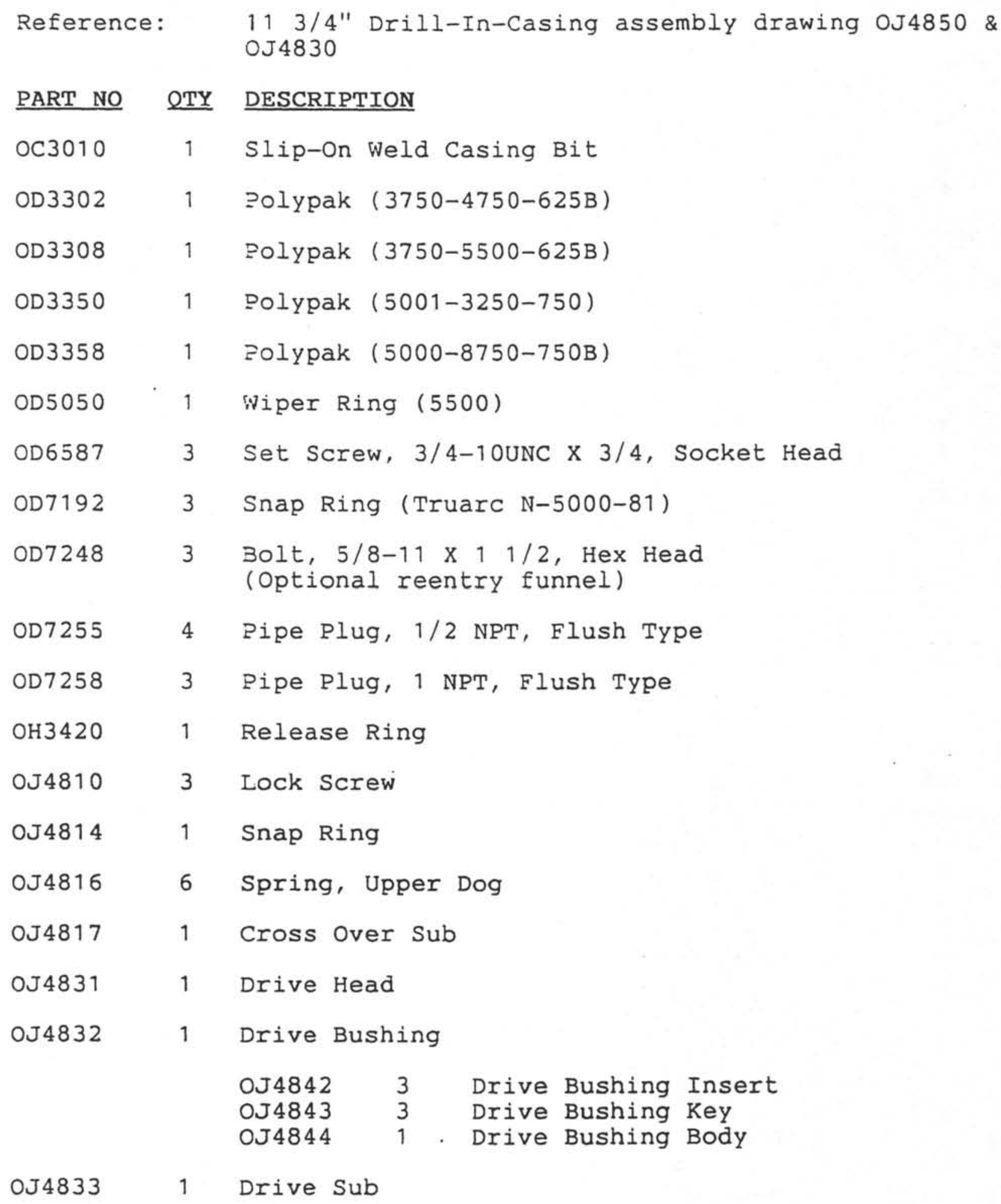

OJ4833 1 Drive Sub 


$\begin{array}{lll}\text { OJ4835 } & 3 & \text { Lower Dog } \\ \text { OJ4836 } & 1 & \text { Shifting Sleeve } \\ \text { OJ4837 } & 3 & \text { Upper Dog } \\ \text { OJ4838 } & 6 & \text { Pin, Lower Dog } \\ \text { OJ4839 } & 6 & \text { Spring, Lower Dog } \\ \text { OJ4852 } & 1 & \text { Optional Reentry Funnel } \\ \text { OJ4853 } & 3 & \text { Brace, Optional Reentry Funnel } \\ \text { OL1010 } & 1 & \text { Head Sub }\end{array}$


OCEAN DRILLING PROGRAM

\section{$113 / 4 "$ DRILL-IN CASING SYSTEM \\ SERVICE TOOLS \\ PARTS LIST \\ January 1992}

$\begin{array}{llll}\text { PART NO } & \text { OTY } & \text { DESCRIPTION } \\ \text { OJ4819 } & 4 & \text { Release Screw } \\ \text { OJ4820 } & 3 & \text { Retraction Jig } \\ \text { OJ4822 } & 1 & \text { Wiper Ring Seating ToOl } \\ \text { OJ4824 } & 1 & \text { Special } 1 / 2-13 \text { UNC Grease Fitting }\end{array}$


Appendix L

DIC Assembly Drawings 


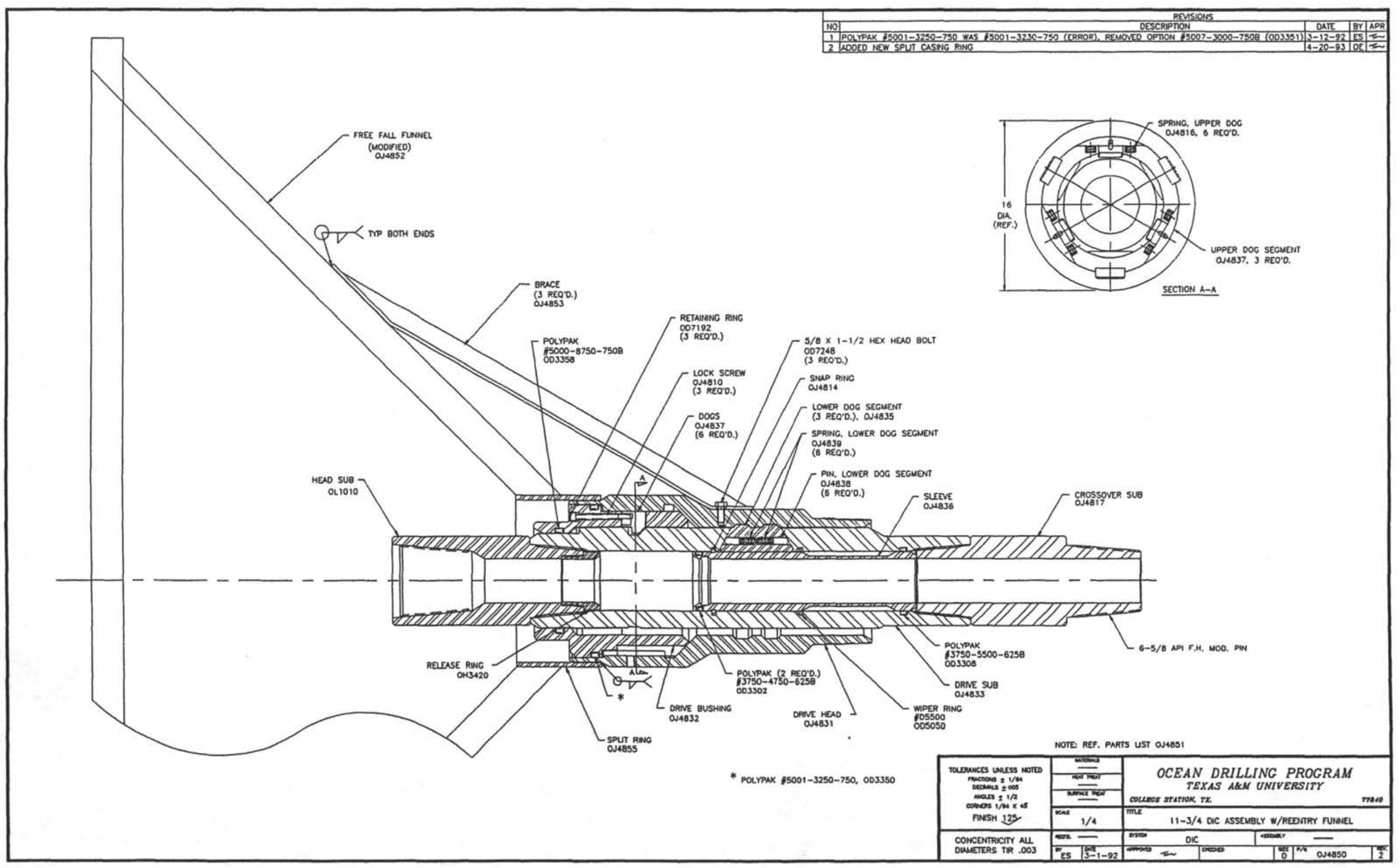


Appendix M

DIC Machine Drawings 


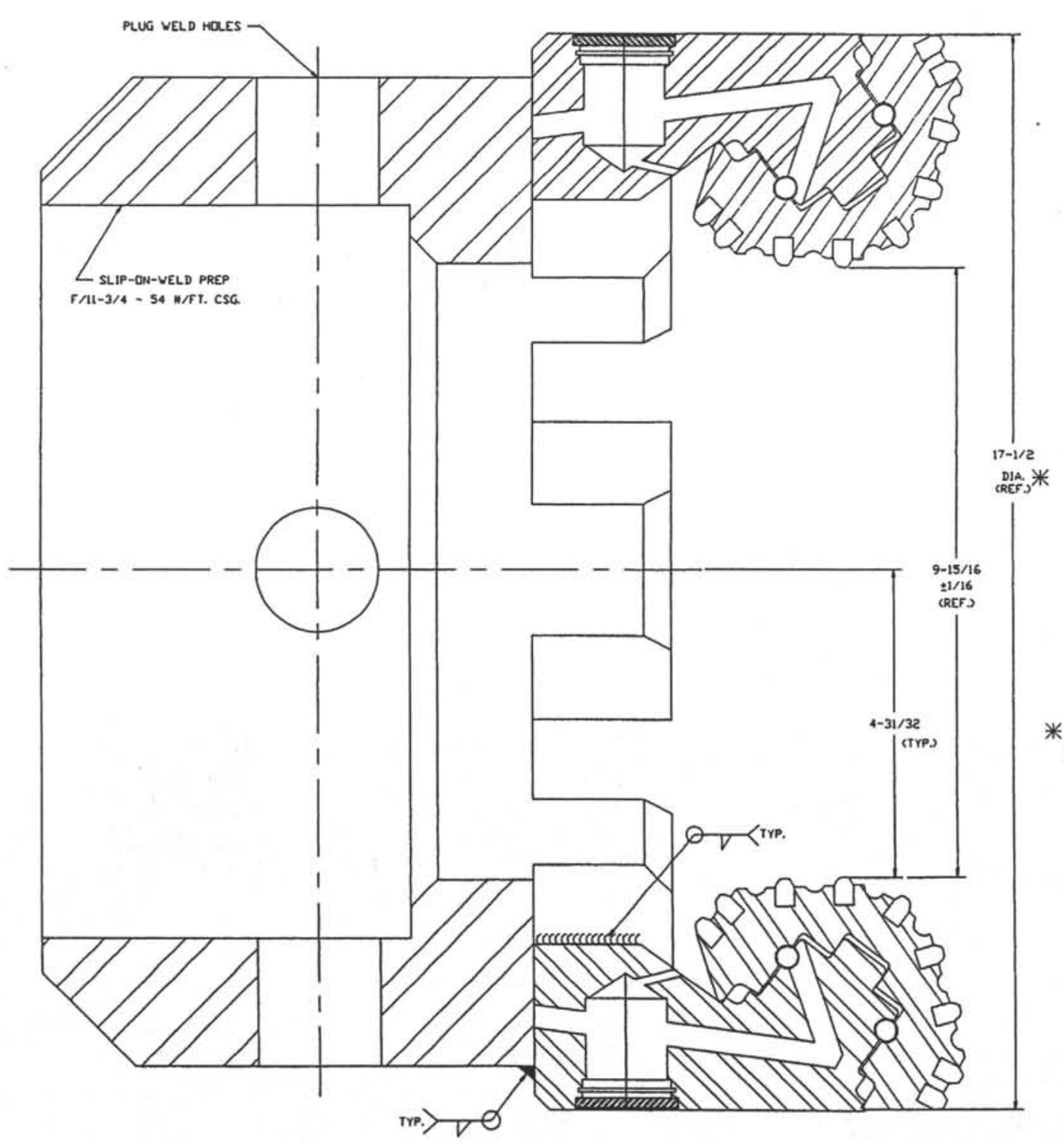

\section{PARTS LIST}

1- DC3012 BODY, DIC EXPENDABLE BIT

6- $9-7 / 8 \times 2-7 / 16$ (RCB) CUTTERS

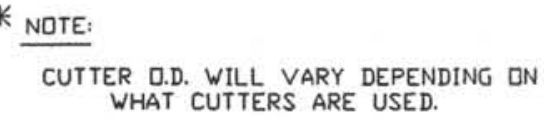

\begin{tabular}{|c|c|c|}
\hline 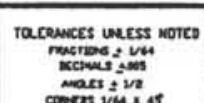 & 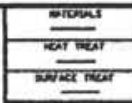 & 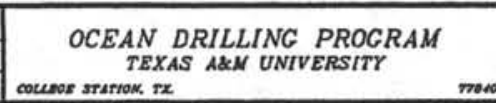 \\
\hline 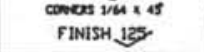 & [and Fulc & 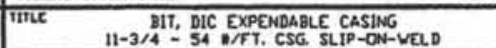 \\
\hline $\begin{array}{l}\text { CDCET } \\
\text { DAAETE }\end{array}$ & $=0$ & $\frac{11 c}{50}$ \\
\hline
\end{tabular}


THIS RELEASE RING IS DESIGNED TO BE MADE UP ONTO A HEAD SUB, PART ND. DL1010 WITH THREAD LOCKING COMPOUND (DAKERLDK DR EQUAL). WHEN ASSEMBLED, THE DISTANCE FRDM THE SHLULDER OF THE 6-5/8 API F. H. PIN TT THE LOWER EDGE OF THE RELEASE RING IS CRITICAL TO THE PRDPER DPERATH OF F

LENGTH DF THE THREADED END DF THE RELEASE RING TO ASSURE A MADE UP LENGTH DF $6.625^{\circ}$

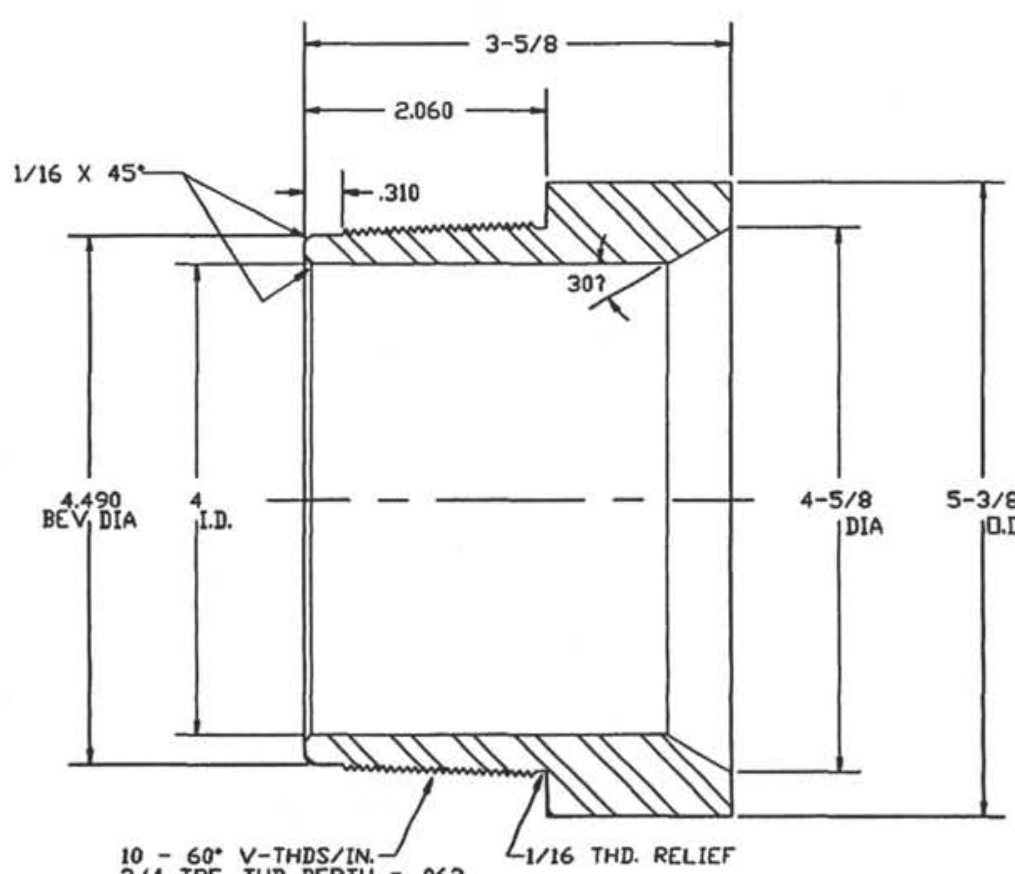

$3 / 4$ TPF, THD DEPTH $=.062$ GUAGE \#138

\begin{tabular}{|c|l|c|c|c|}
\hline 3 & REDRAWN W/ACAD & ES & $10-1-92$ & ECR478 \\
\hline 2 & DWG. NG. DL1100 WAS R-0455 & DB & $7-9-84$ & -- \\
\hline 1 & $4-3 / 4-6$ STUB ACME WAS $10-60^{\circ}$ V THDS & -- & -- & -- \\
\hline
\end{tabular}

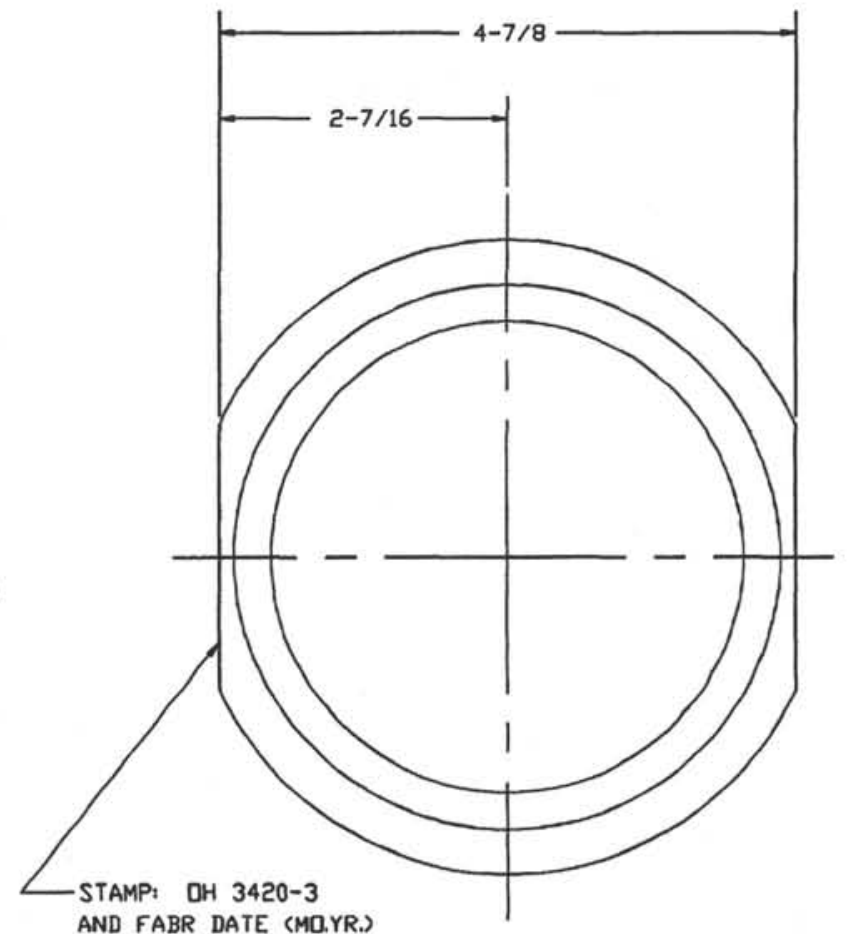

AND FABR DATE (MOYRD

MARQUENCH

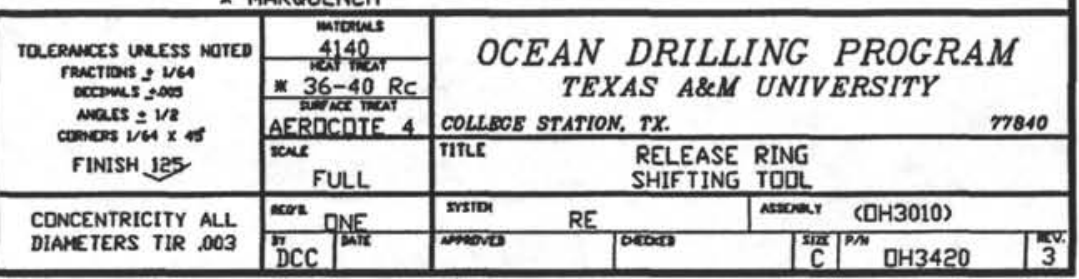




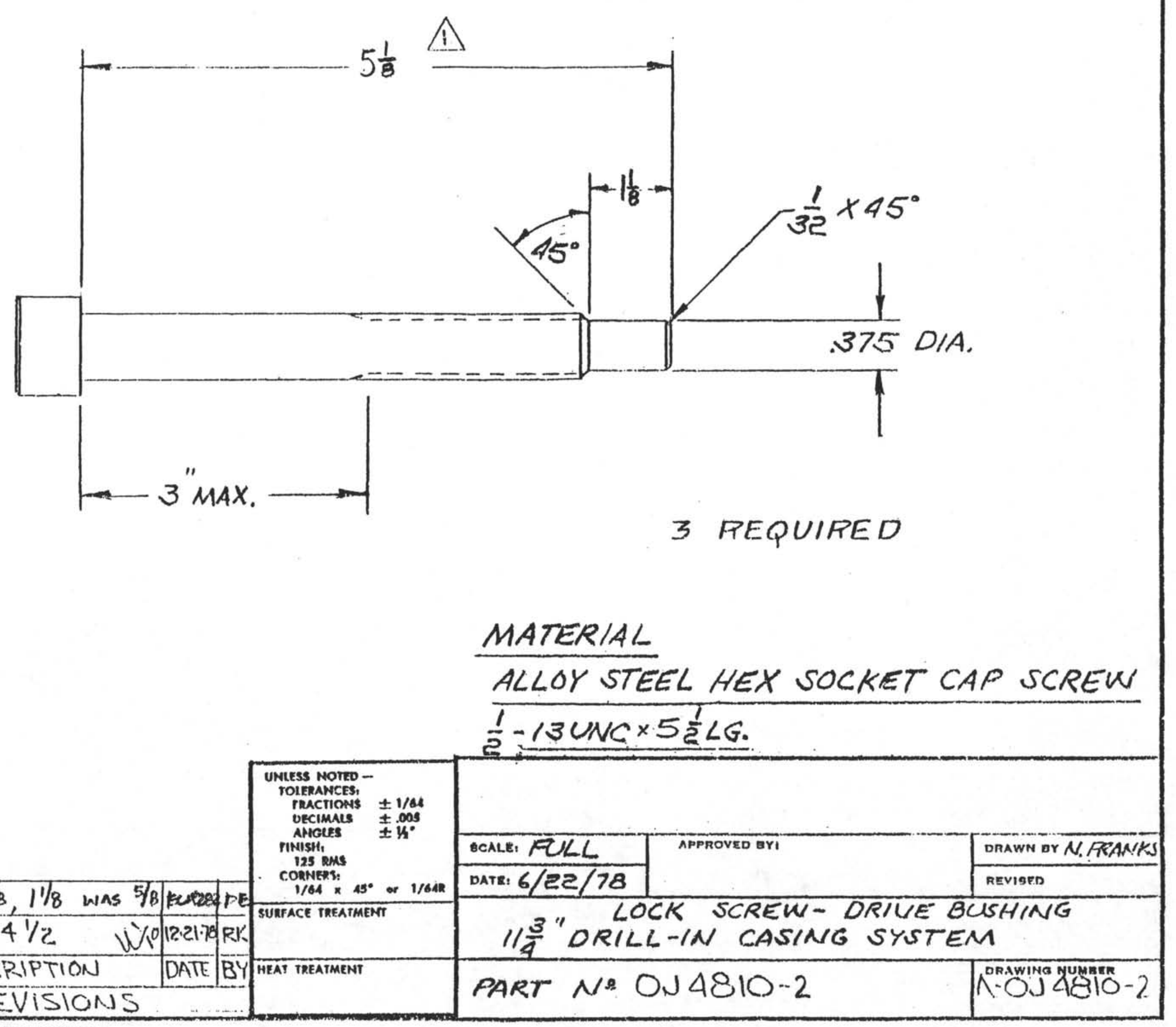




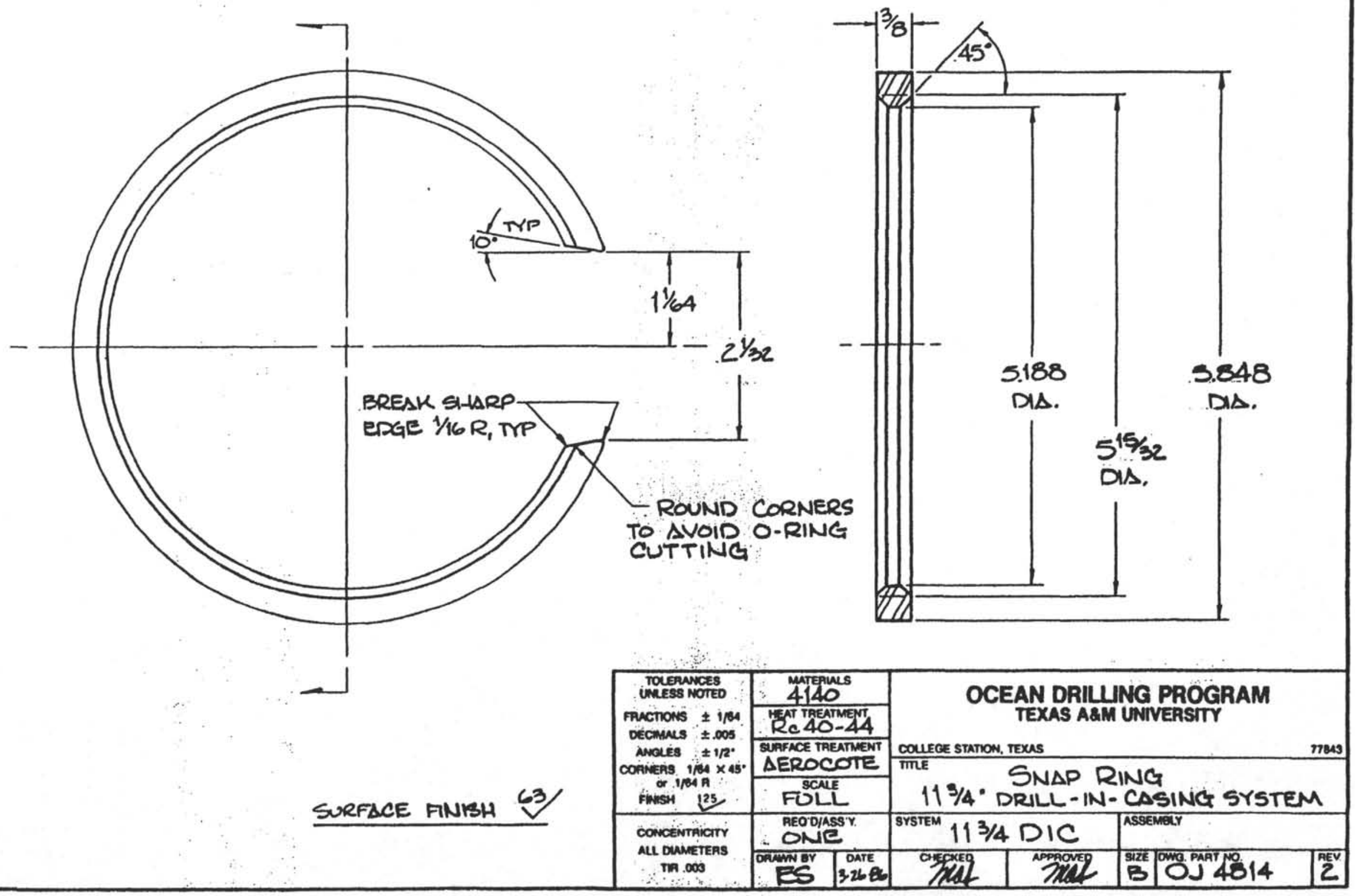




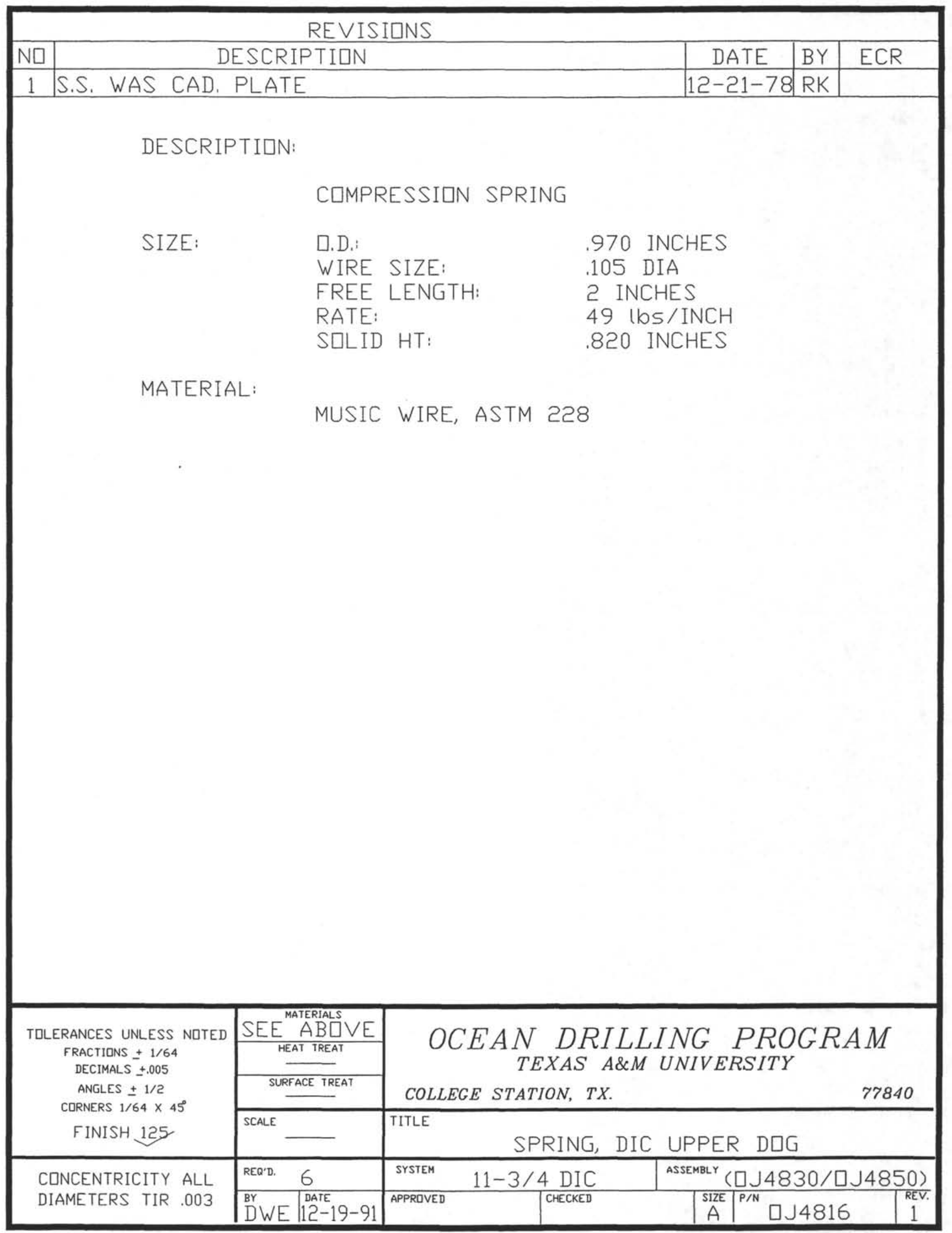




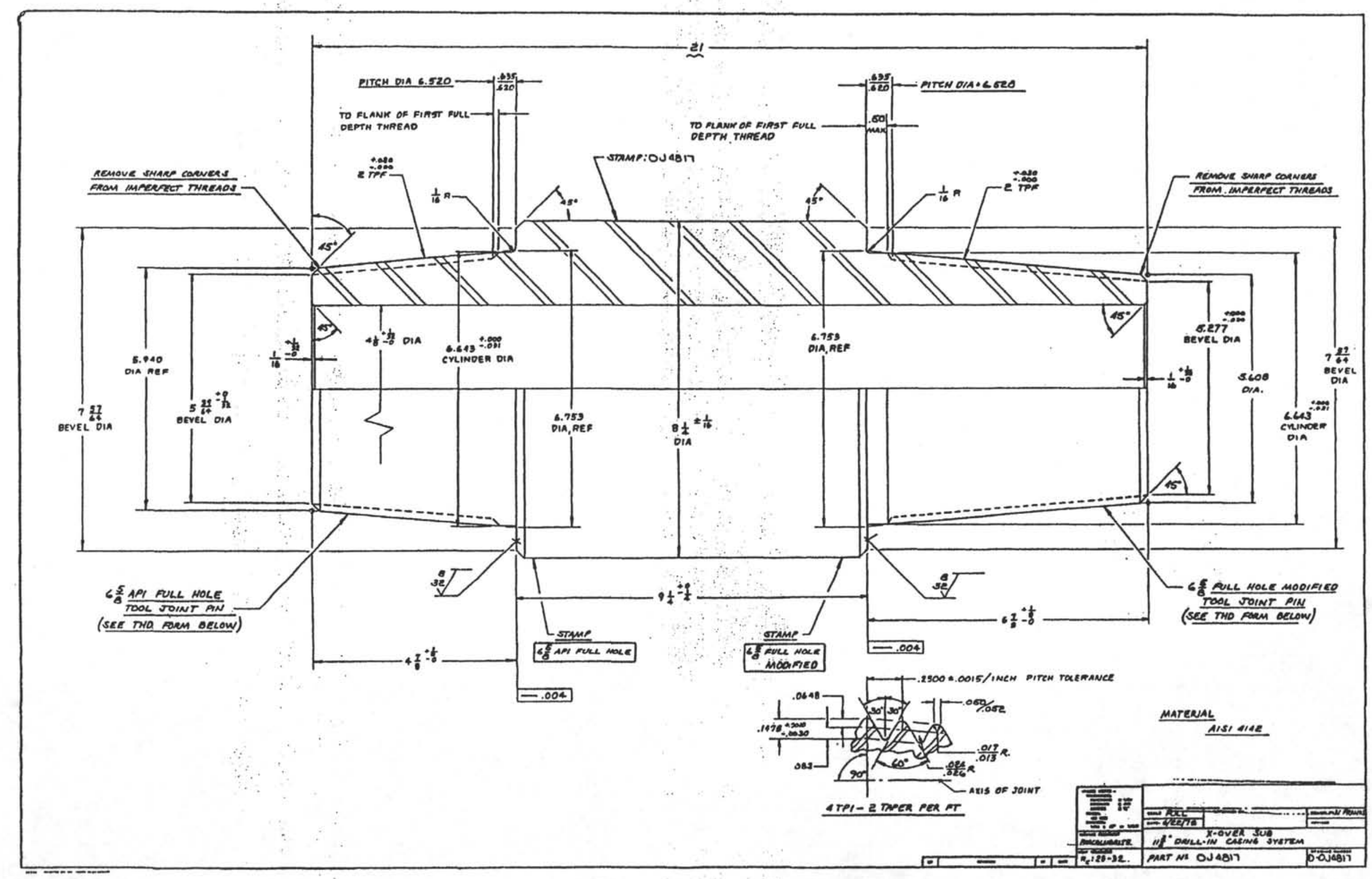




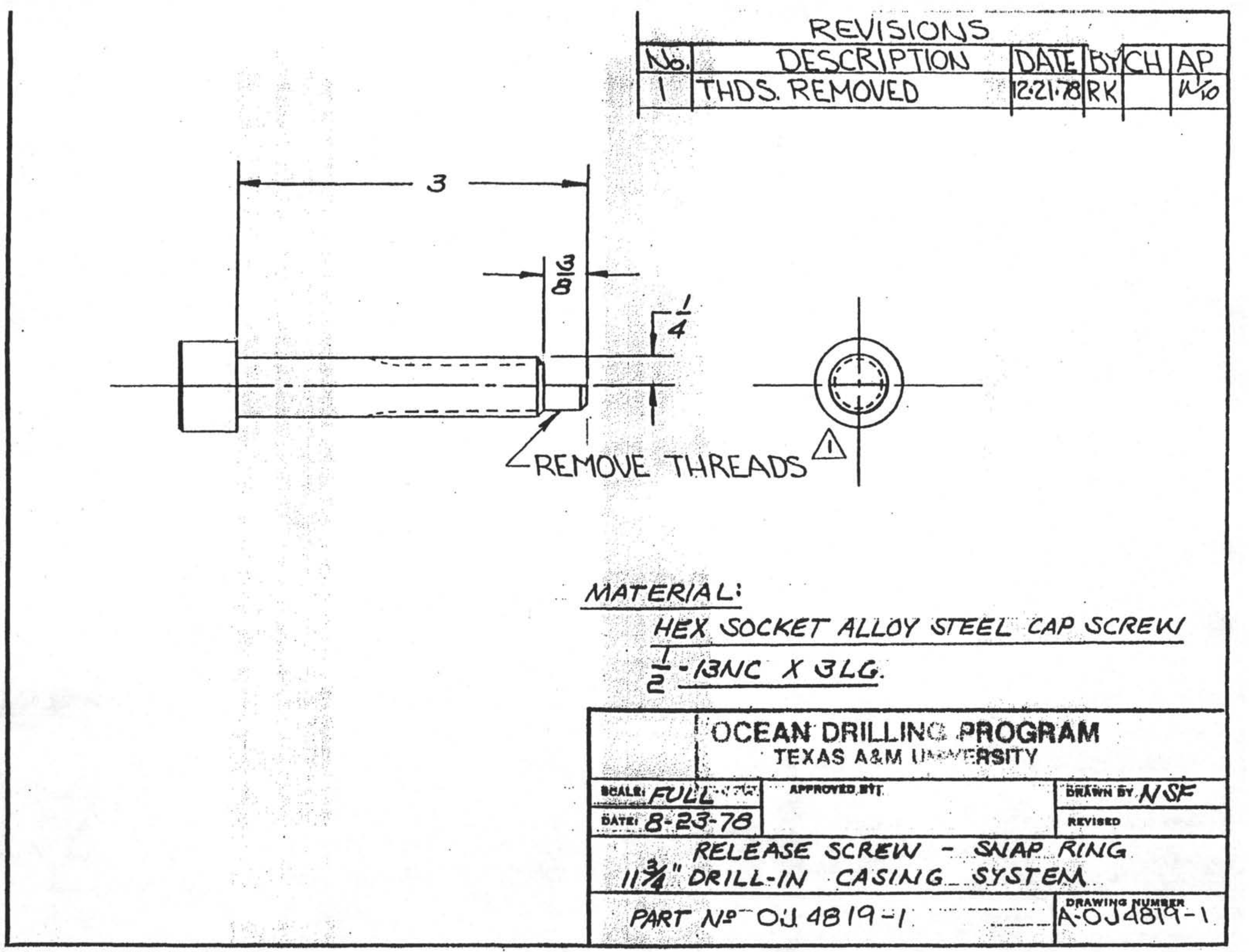




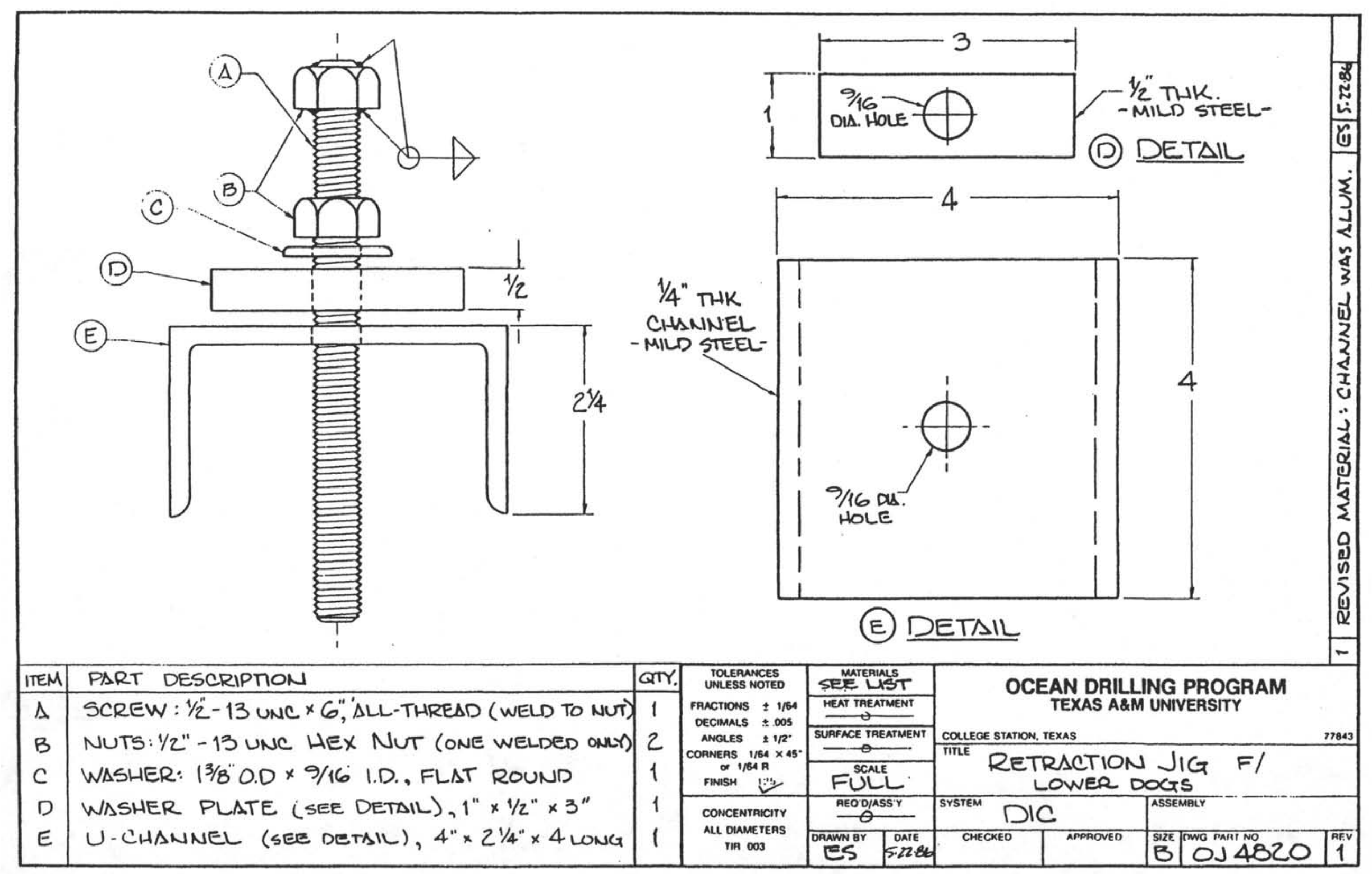




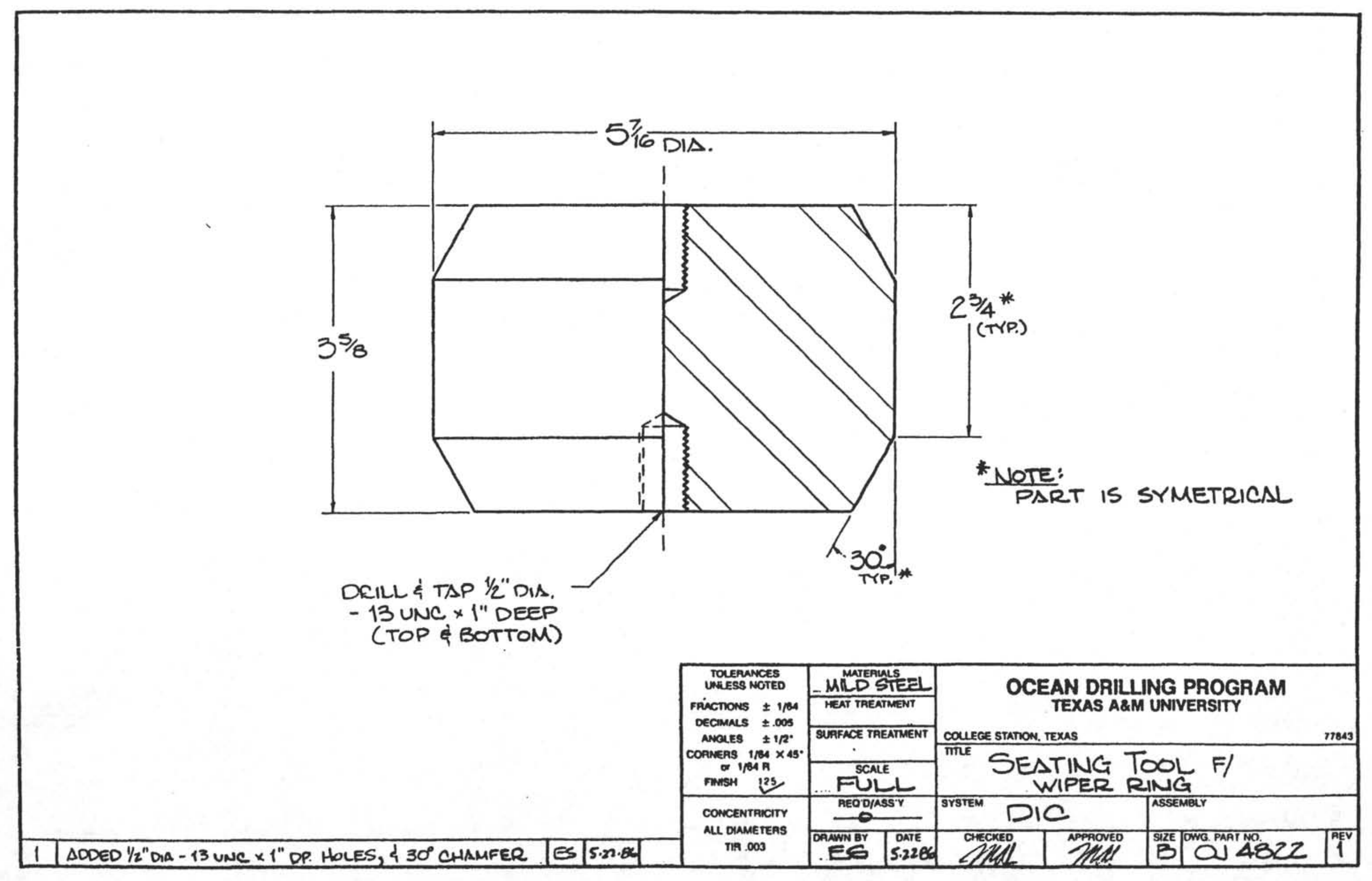




\section{REVISIONS}

\begin{tabular}{|c|c|c|c|c|}
\hline ND & DESCRIPTIQN & DATE & BY & ECR \\
\hline 1 & $1 / 2-13$ UNC $\times 2$ WAS 1/2-13 UNC $\times 2$ & $12-19-91$ & DE & ECR318 \\
\hline
\end{tabular}

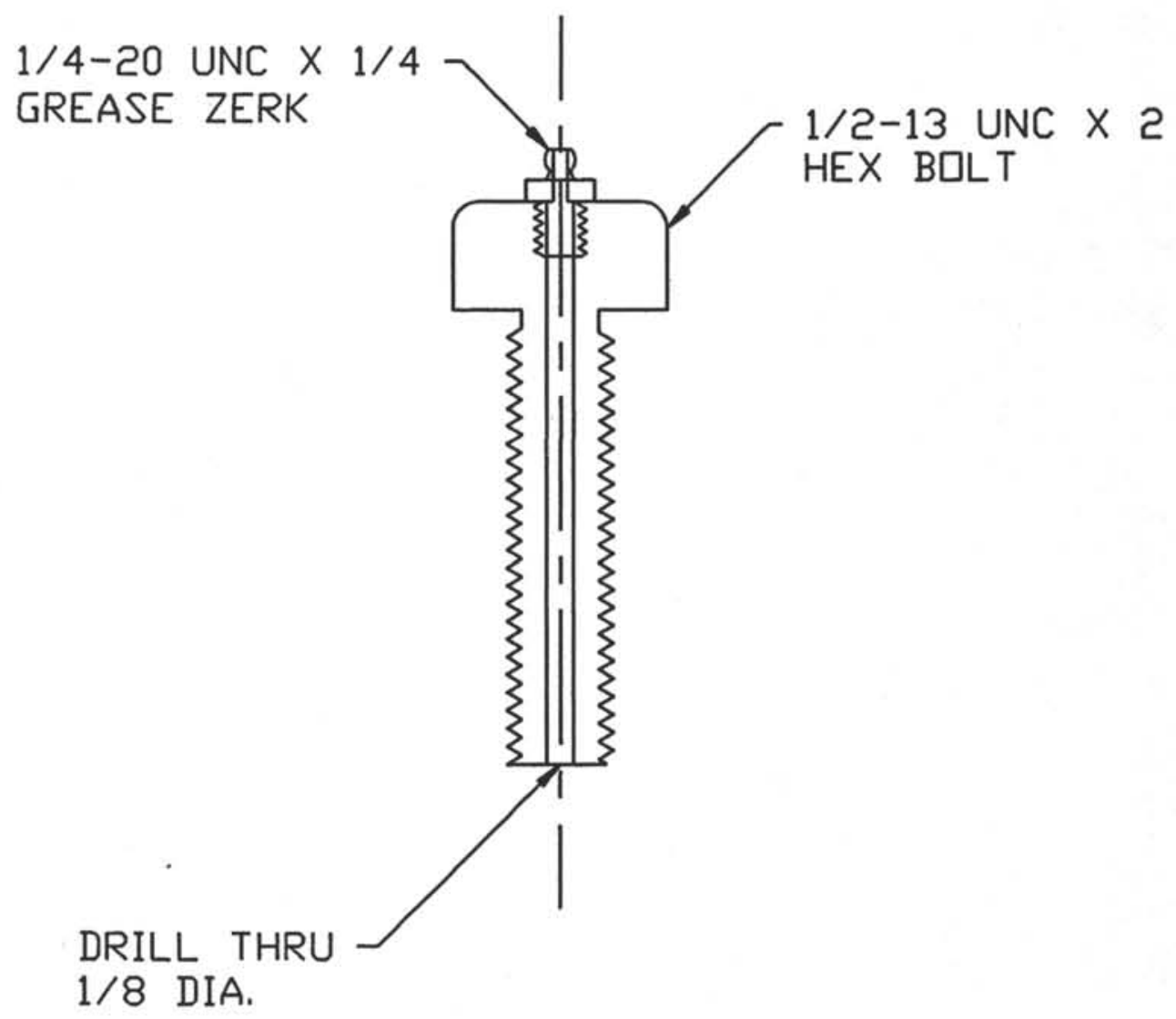

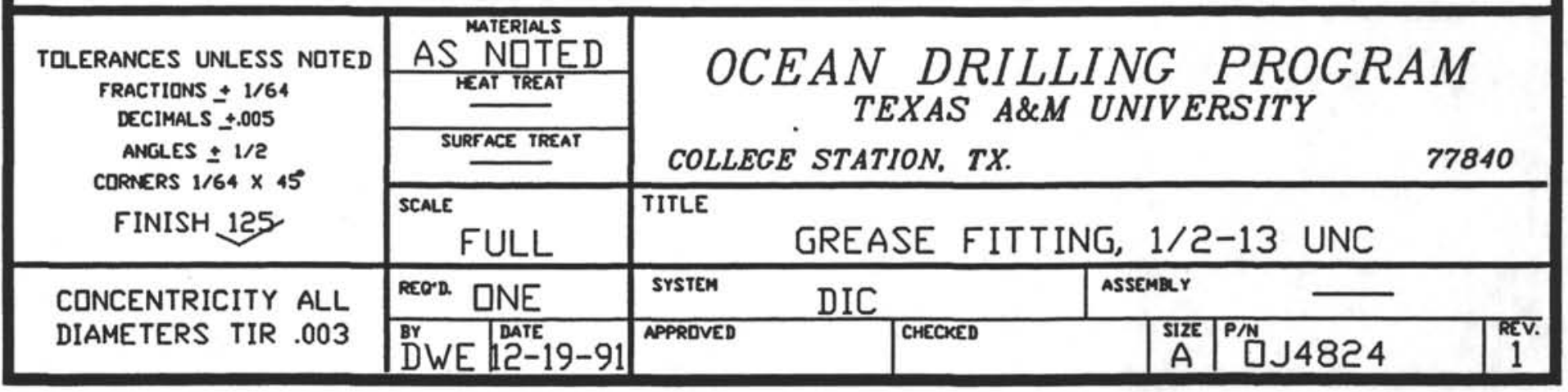



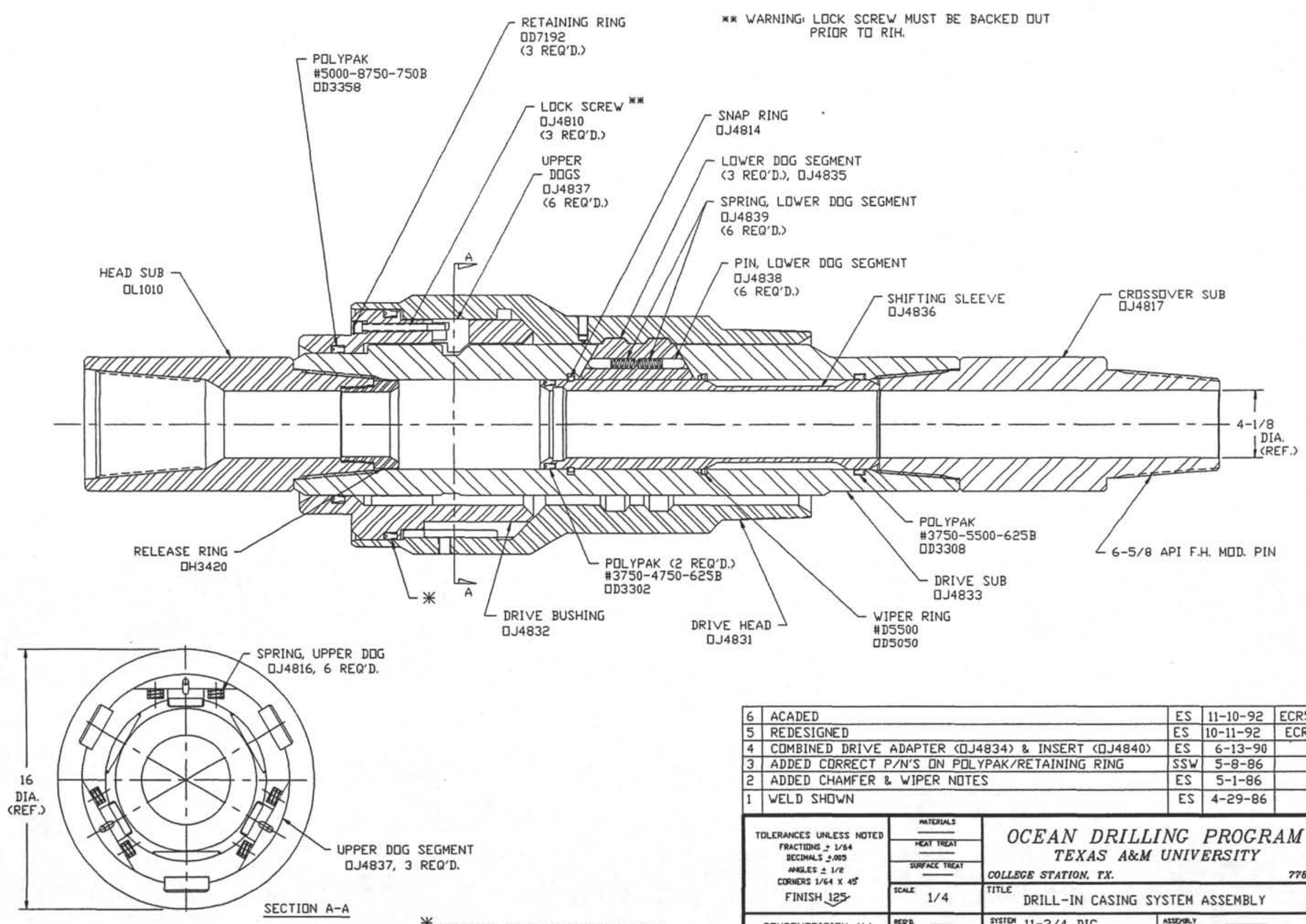

\begin{tabular}{|c|c|c|c|c|c|}
\hline \multicolumn{3}{|l|}{ ACADED } & ES & $11-10-92$ & ECR521 \\
\hline \multicolumn{3}{|l|}{ REDESIGNED } & ES & $10-11-92$ & ECR98 \\
\hline \multicolumn{3}{|c|}{ CDMBINED DRIVE ADAPTER (QJ4834) \& INSERT (DJ4840) } & ES & $6-13-90$ & \\
\hline \multicolumn{3}{|c|}{ ADDED CDRRECT P/N'S IN POLYPAK/RETAINING RING } & SSW & $5-8-86$ & \\
\hline \multicolumn{3}{|c|}{ ADDED CHAMFER \& WIPER NDTES } & ES & $5-1-86$ & \\
\hline \multicolumn{3}{|l|}{ WELD SHOWN } & ES & $4-29-86$ & \\
\hline \multirow{4}{*}{ 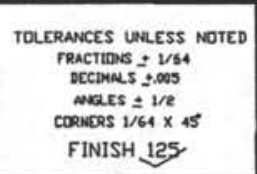 } & mascives & \multirow{3}{*}{\multicolumn{4}{|c|}{$\begin{array}{l}\text { OCEAN DRILLING PROGRAM } \\
\text { TEXAS A\&M UNIVERSITY } \\
\text { COLLEGE STATION, TX. }\end{array}$}} \\
\hline & कातिका & & & & \\
\hline & 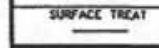 & & & & \\
\hline & $1 / 4$ & \multicolumn{4}{|c|}{ TITLE DRILL-IN CASING SYSTEM ASSEMBLY } \\
\hline \multirow{2}{*}{$\begin{array}{l}\text { CDNCENTRICITY ALL } \\
\text { DIAMETERS TIR } \\
.003\end{array}$} & econ - & srston $11-3 / 4 \mathrm{DIC}$ & \multicolumn{3}{|c|}{ assood -} \\
\hline & "ES $\left.\right|^{\circ}$ & Nemenco & & & \\
\hline
\end{tabular}

* PLLYPAK \#5001-3250-750, 口D3350 


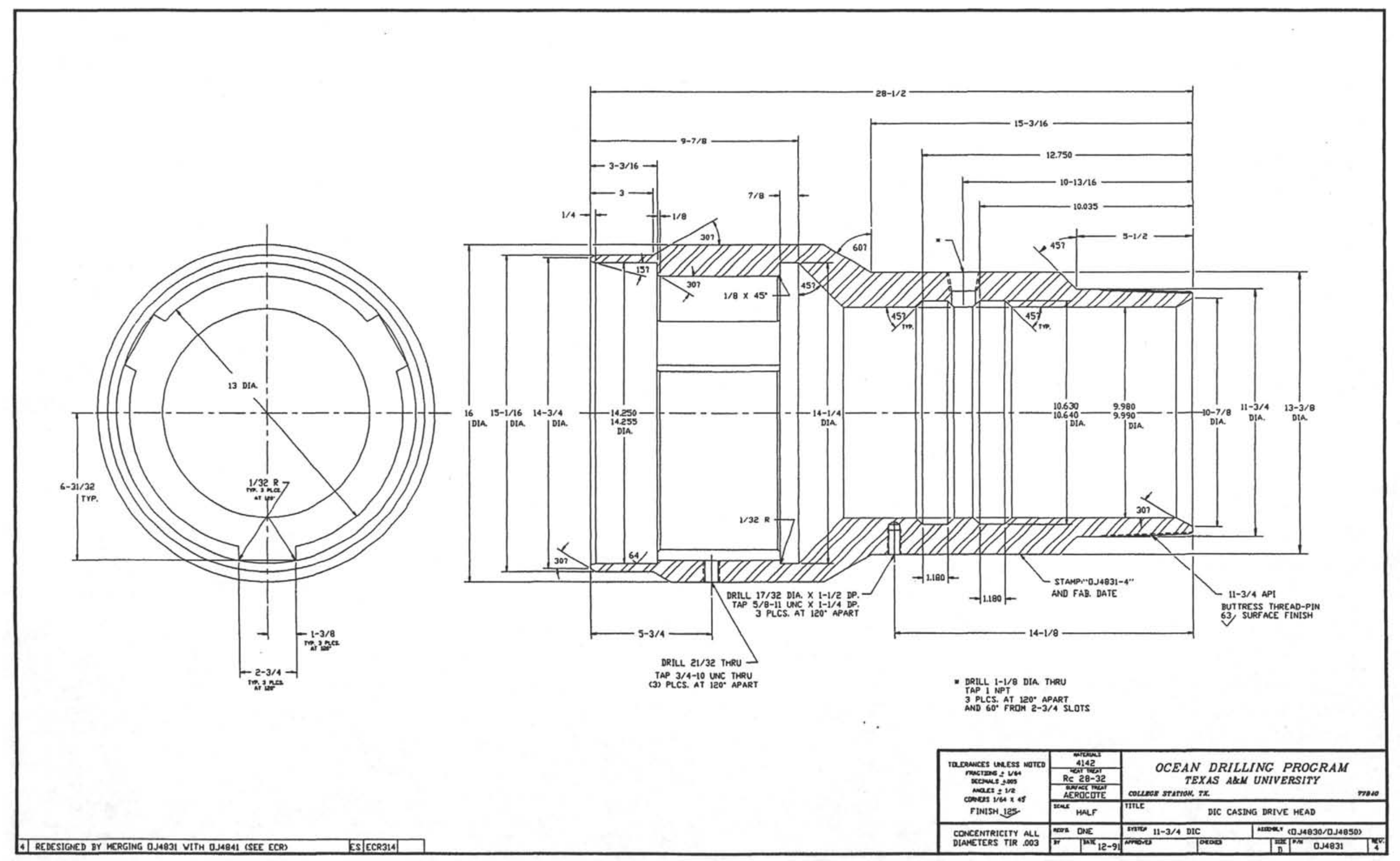




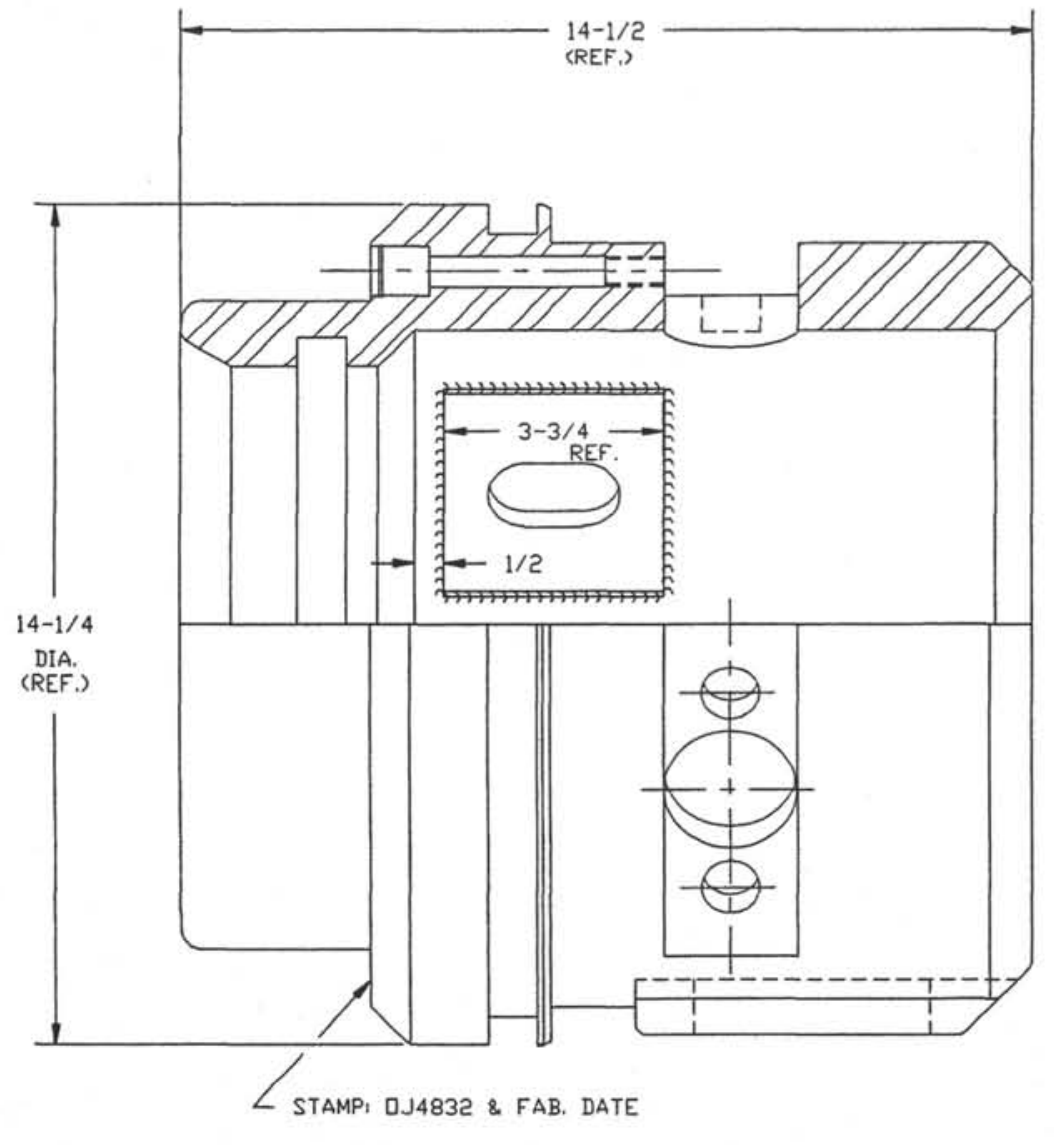

WELDING PRACEDURE

PRIDR TO WELDING, A MINIMUM DISTANCE IF 2 " EACH SIDE OF THE WELD SHALL BE PREHEATED TI A TEMPERAT 作 THE WELD AND ADJACENT AREA, 4" EACH SIDE OF THE WELD, SHALL BE STRESS

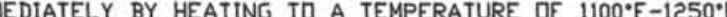
THE STRESS RELIEVING TEMPERATURE SHALL BE MAINTAINED FOR A MINIMUM DF UNE HALF HDUR. TEMPERATURE TD BE INDICATED BY "TEMPILSTIKS". IF UNUSUAL CONDITIONS MAKE IT IMPOSSIBLE TO ATTAIN THE MINIMUM TEMPERATURE LISTED, THE HIGHEST TEMPERATURE ATTAINABLE SHOULD BE HELD FOR ONE-HALF HOUR. IN ALL CASES, ALLUW TU CLOL SLOWLY IN AIR UNTIL HEAVIEST PART HAS REACHED A TEMPERATURE LESS THAN $500^{\circ} \mathrm{F}$ BEFORE PERMITTING ANY LOAD

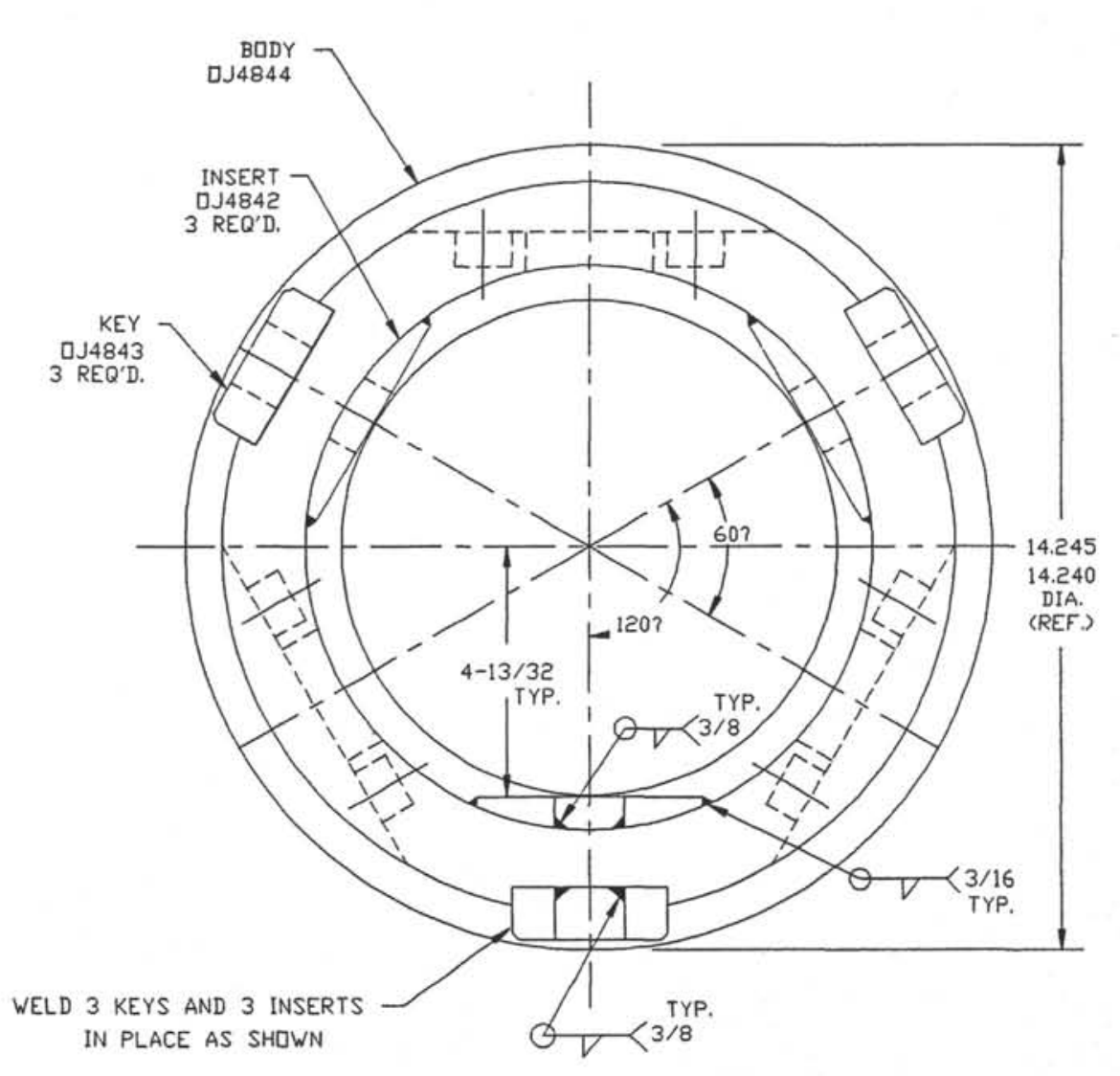

PARTS LISTI

3 - $0 J 4842$ INSERT

$3-$ DJ4843 KEY
$1-$ DJ4844 BDDY

\begin{tabular}{|c|c|c|}
\hline \multirow{3}{*}{ 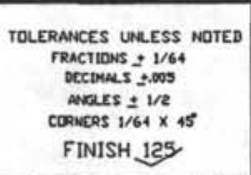 } & 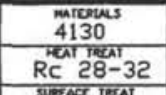 & $\begin{array}{c}\text { OCEAN DRILLING PROGRAM } \\
\text { TEXAS A\&M UNIVERSITY }\end{array}$ \\
\hline & $\begin{array}{l}\text { SEFACE IEAT } \\
\text { AERDCDTE }\end{array}$ & COLLEGE STATION, TX. \\
\hline & $\sqrt{{ }^{\text {secus }} \text { HALF }}$ & \begin{tabular}{|c|c|} 
DRILE & DRIVE BUSHING \\
& $11-3 / 4$ DRILL-IN CASING SYSTEM \\
\end{tabular} \\
\hline \multirow{2}{*}{$\begin{array}{l}\text { CONCENTRICITY ALL } \\
\text { DIAMETERS TIR } .003\end{array}$} & ECOR UNE & srstion $11-3 / 4 \mathrm{DIC}$ \\
\hline & 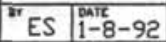 & "DJ4832 \\
\hline
\end{tabular}




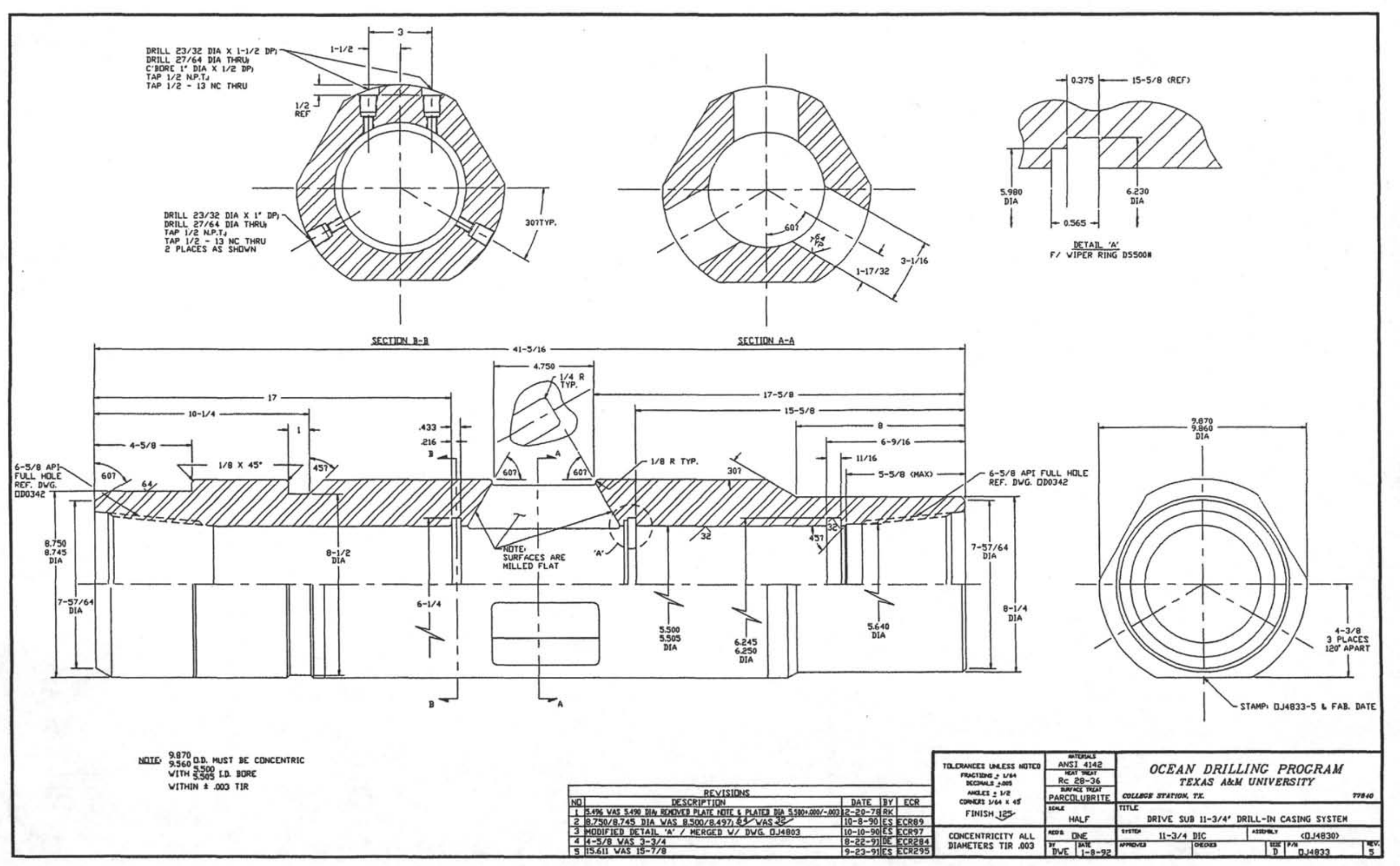




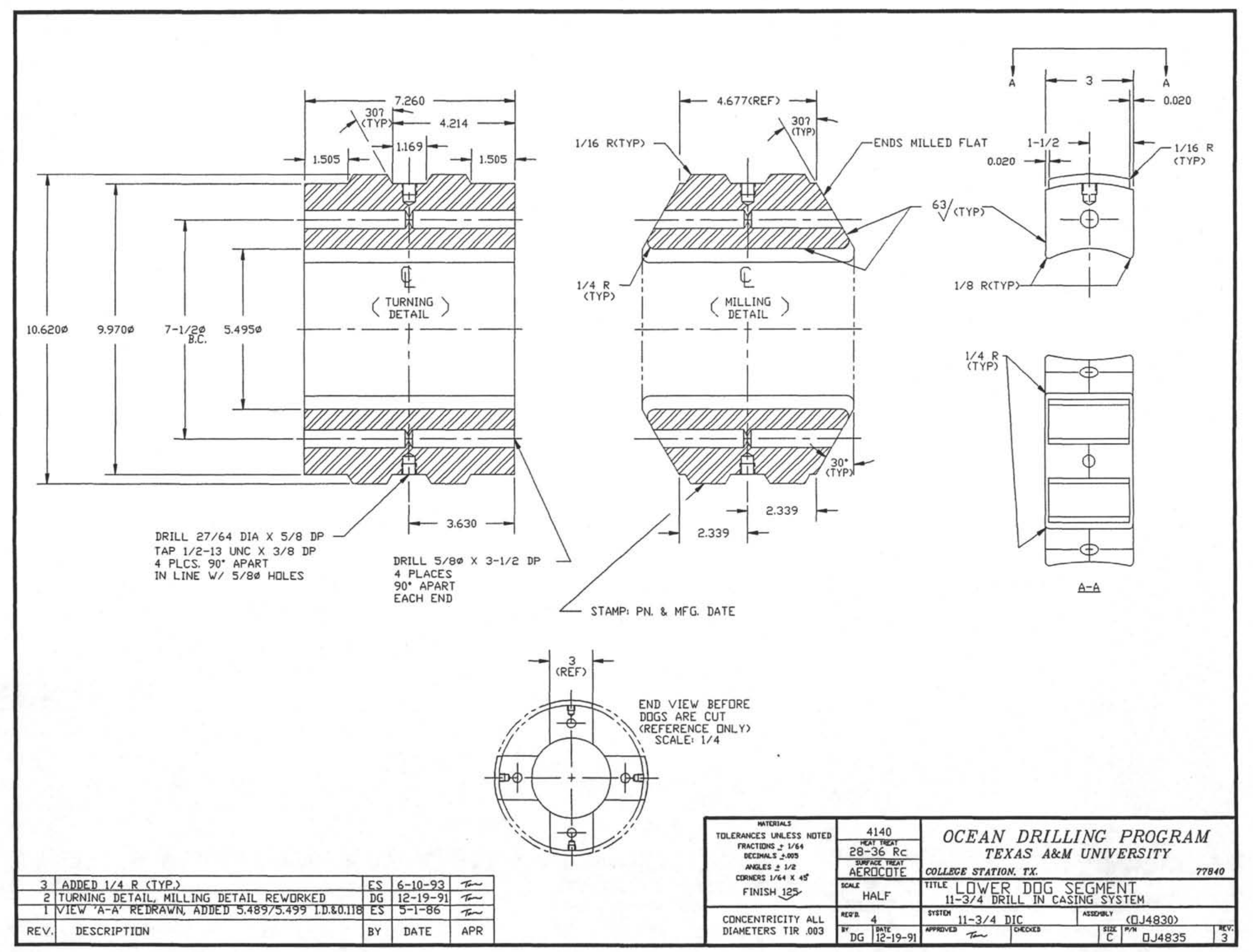




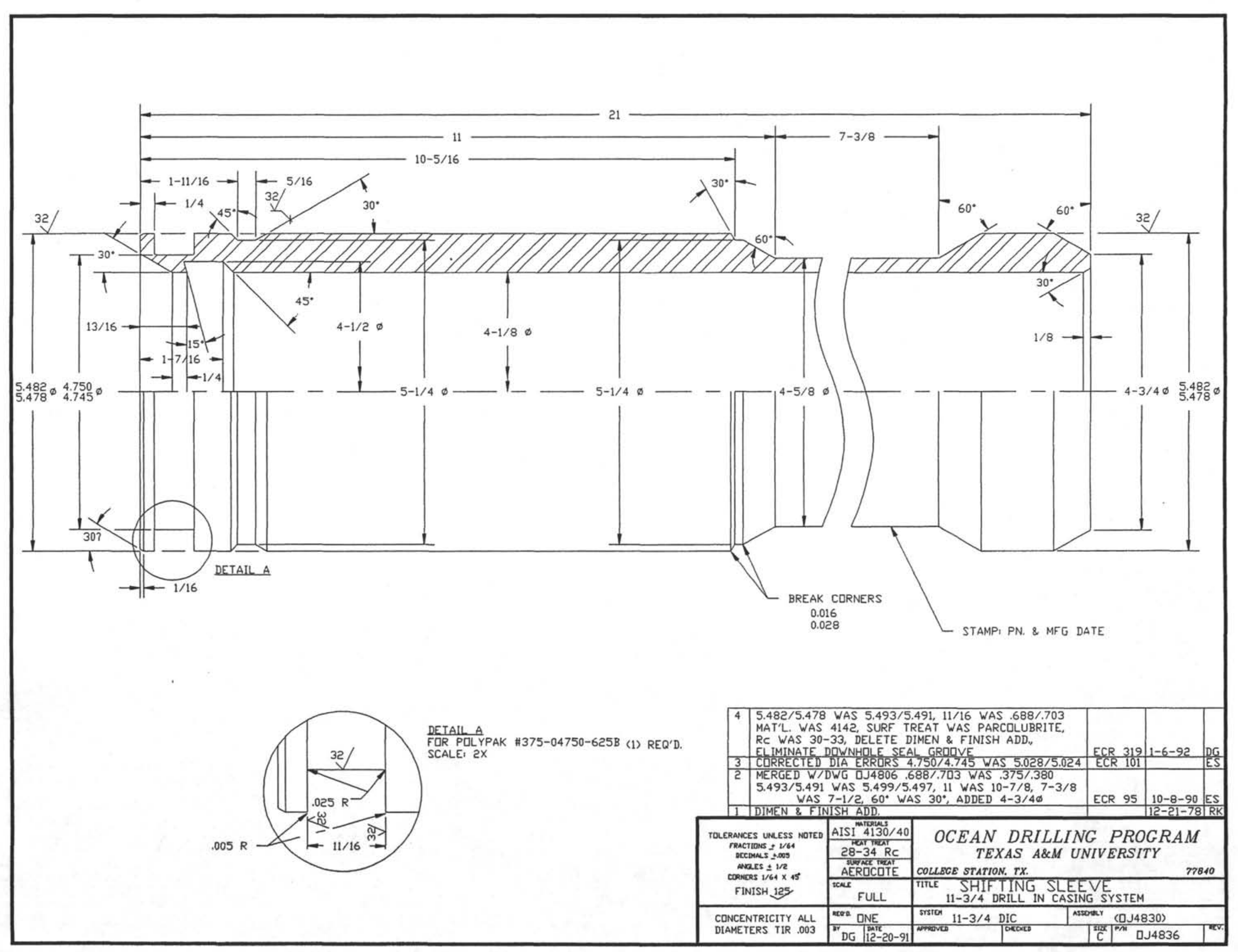




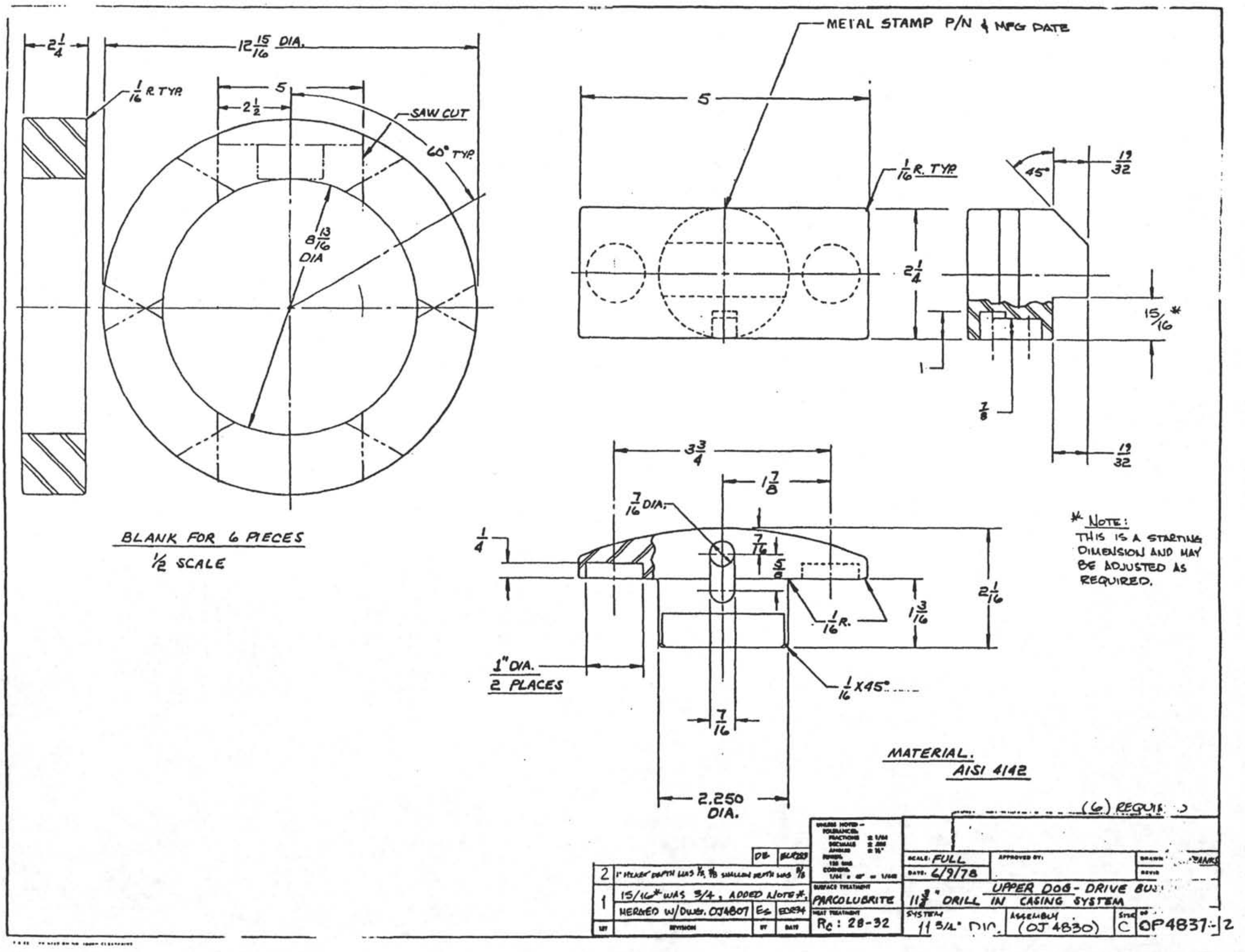




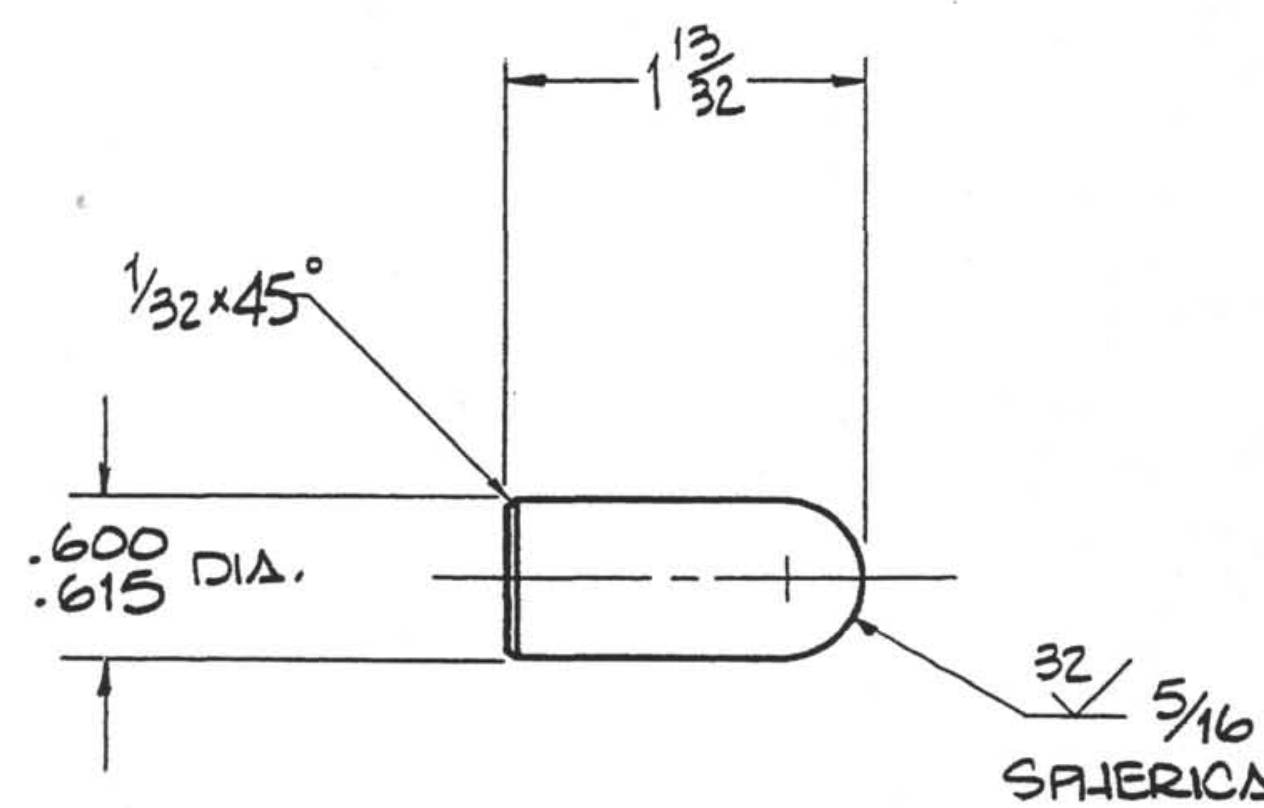

SPAERICAL RADIUS

NOTE: MAT'L.

17-4 PH SS H-900 CONDITION

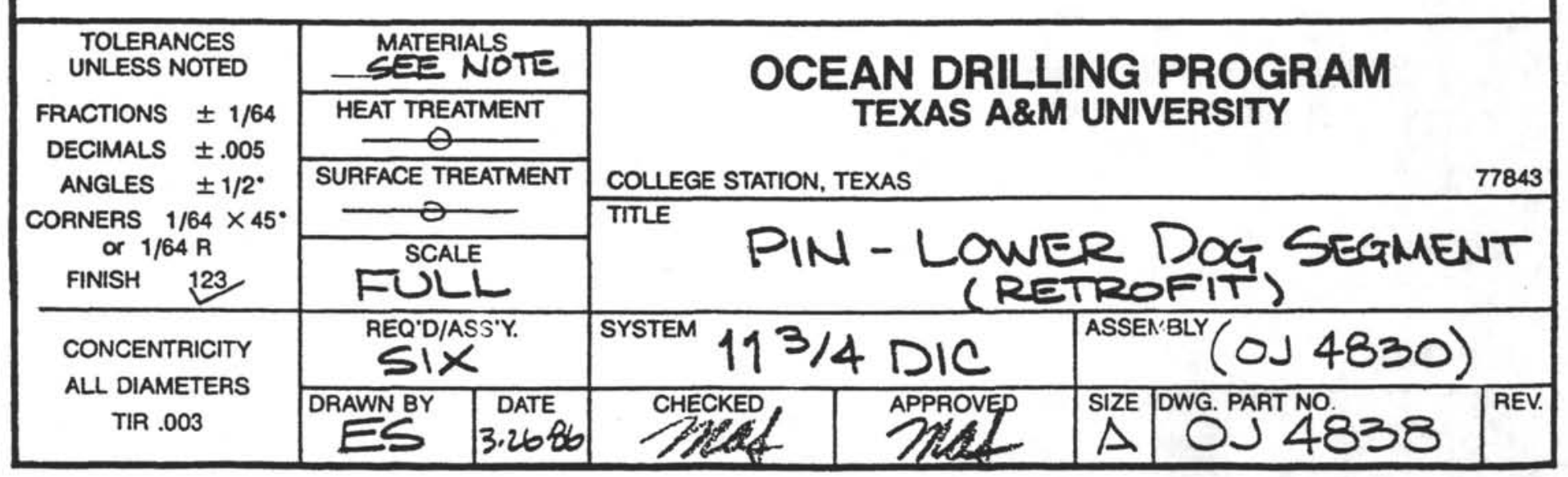


DESCRIPTION:

COMPRESSIDN SPRING

SIZE:

Q.D.:

WIRE SIZE:

$9 / 16$ INCHES

FREE LENGTH:

$.116 \times .123$ INCHES

RATE:

2 INCHES

SDLID HT:

152 lbS/INCH

1.3 INCHES

MATERIAL:

CHROME VANADIUM SPRING STEEL

PAINTED, ASTM A232

\begin{tabular}{|c|c|c|}
\hline \multirow{3}{*}{$\begin{array}{l}\text { TOLERANCES UNLESS NDTED } \\
\text { FRACTIONS } \pm 1 / 64 \\
\text { DEIMALS } \pm .005 \\
\text { ANGLES } \pm 1 / 2 \\
\text { CORNERS } 1 / 64 \times 45 \\
\text { FINISH } 125\end{array}$} & $\begin{array}{c}\text { SEE } \\
\text { REAT TREAT } \\
\end{array}$ & OCEAN $\underset{T E X A S}{D R I L L I N G} \underset{A \& M \text { UNIVERSITY }}{P R O G R A M}$ \\
\hline & SURFACE TREAT & COLLEGE STATION, TX. \\
\hline & SCALE & ${ }^{\text {TITLE }}$ SPRING, DIC LQWER DOG SEGMMENT \\
\hline CONCENTRICITY ALL & REO'D. & ASSEMBCY $^{2}(\mathrm{DJ} 4830 / \mathrm{J} \mathrm{J} 4850)$ \\
\hline DIAMETERS TIR .003 & \begin{tabular}{|l|l|} 
BY & DATE \\
$12-19-91$ \\
\end{tabular} & 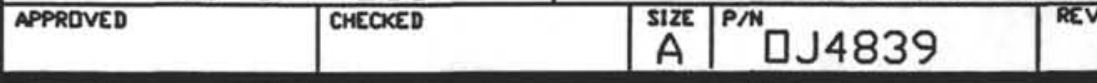 \\
\hline
\end{tabular}



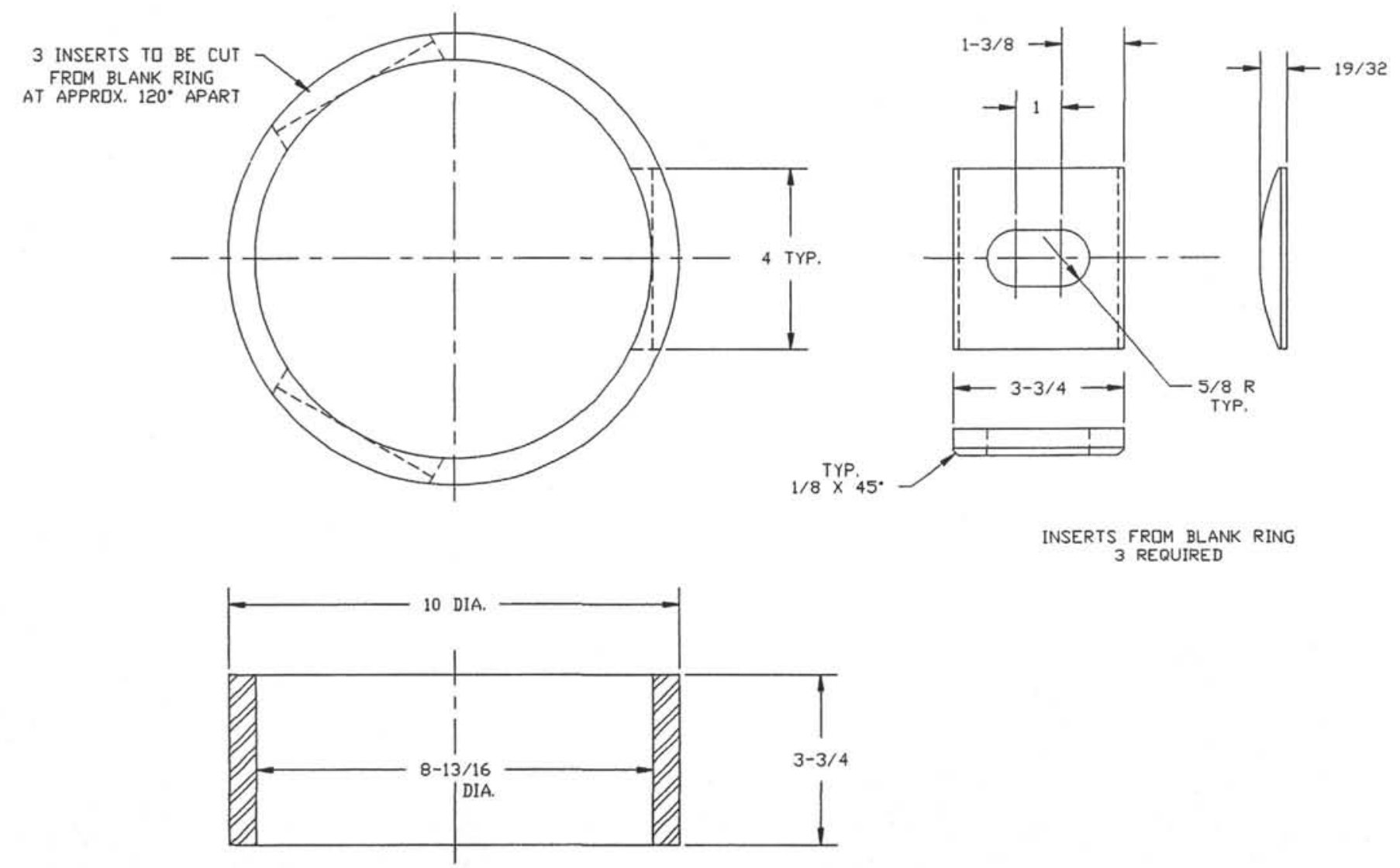

BLANK RING

\begin{tabular}{|c|c|c|}
\hline 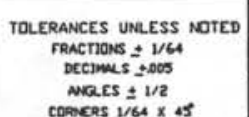 & 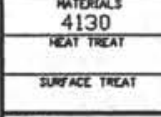 & $\begin{array}{l}\text { OCEAN DRILLING PROGRAM } \\
\text { TEXAS A\&M UNIVERSITY } \\
\text { COLLECE STATION, } T X .\end{array}$ \\
\hline FINISH 125 & seut HALF & INSERT, DIC DRIVE BUSHING \\
\hline $\begin{array}{l}\text { CDNCENTRII } \\
\text { DIAMETERS }\end{array}$ & 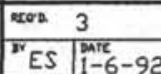 & 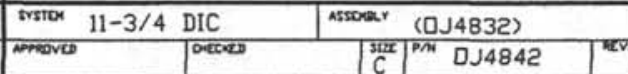 \\
\hline
\end{tabular}




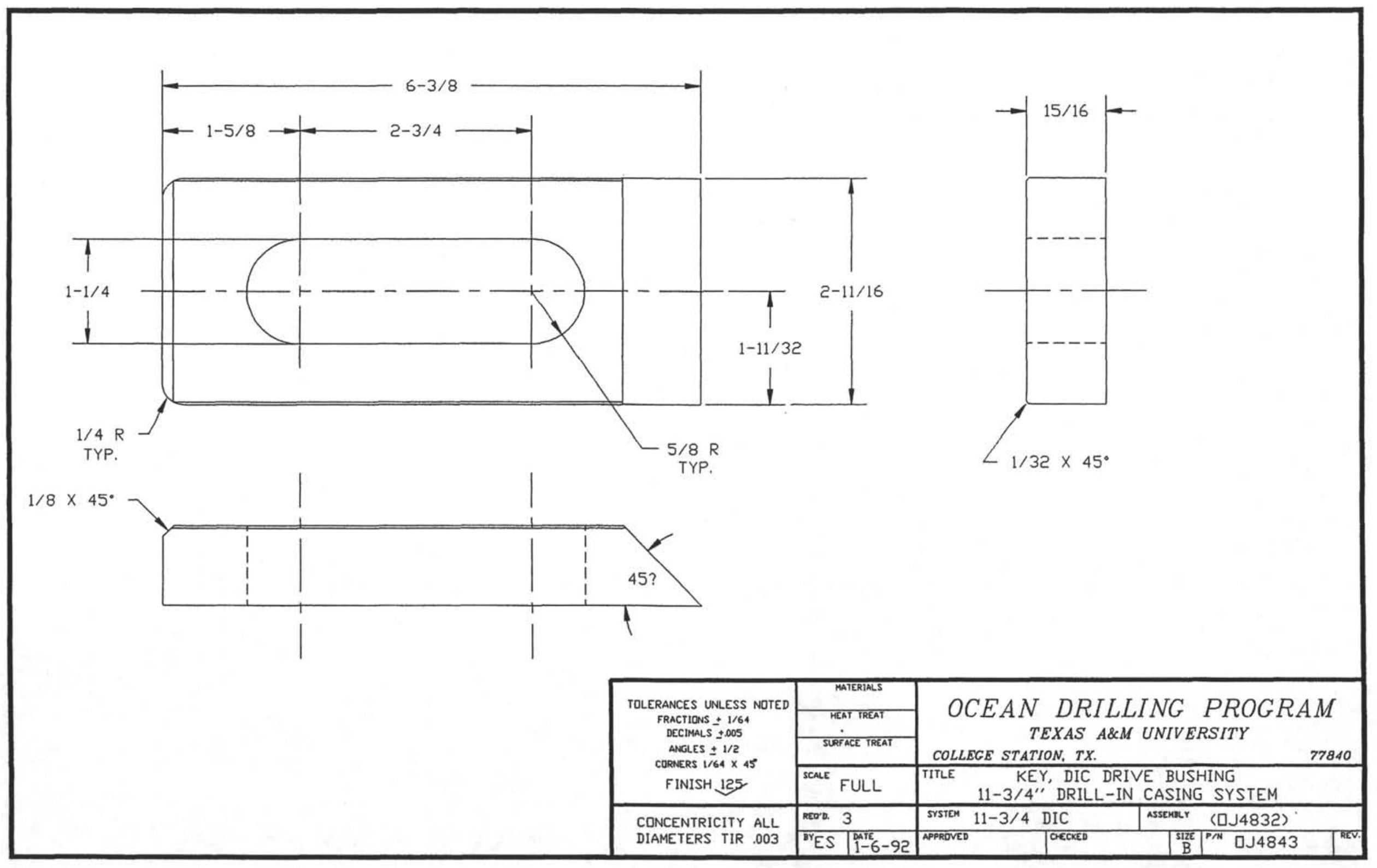




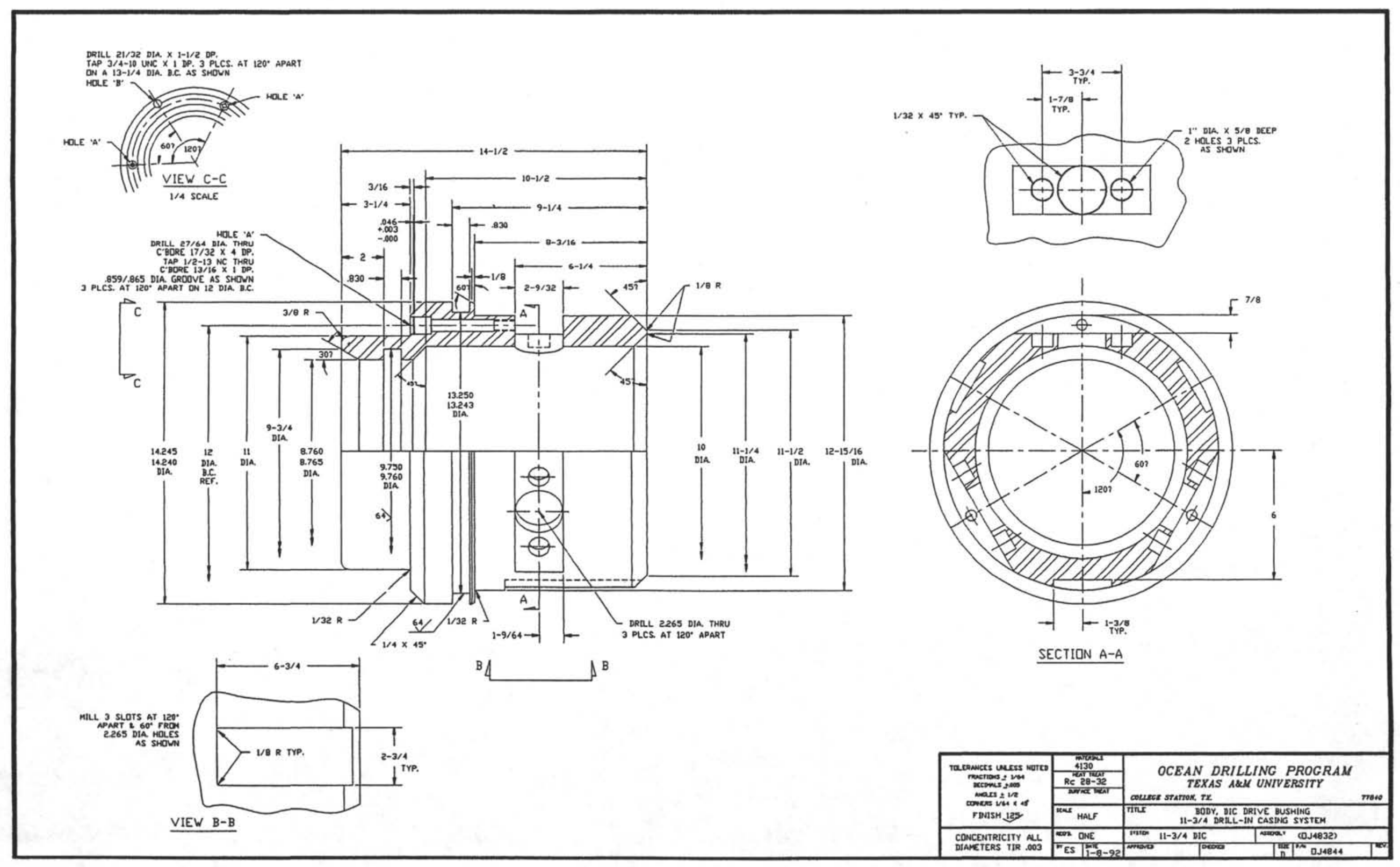




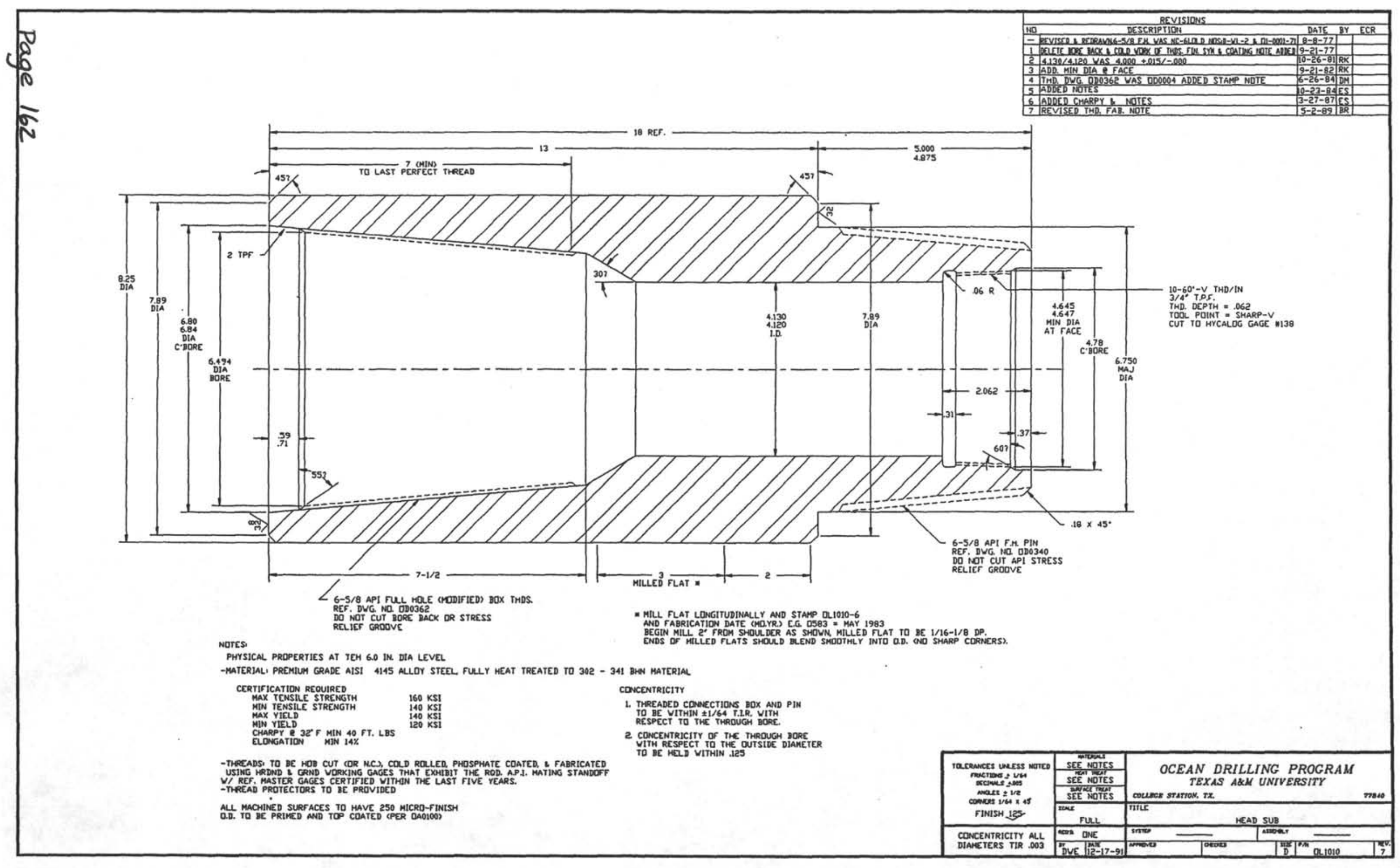

